Florida International University

FIU Digital Commons

$10-25-2018$

\title{
Unrefined Humic Substances as a Potential Low-cost Remediation Method for Groundwater Contaminated with Uranium in Acidic Conditions
}

Hansell Gonzalez Raymat

Florida International University, hgonz035@fiu.edu

Follow this and additional works at: https://digitalcommons.fiu.edu/etd

Part of the Environmental Chemistry Commons

\section{Recommended Citation}

Gonzalez Raymat, Hansell, "Unrefined Humic Substances as a Potential Low-cost Remediation Method for Groundwater Contaminated with Uranium in Acidic Conditions" (2018). FIU Electronic Theses and Dissertations. 3864.

https://digitalcommons.fiu.edu/etd/3864

This work is brought to you for free and open access by the University Graduate School at FIU Digital Commons. It has been accepted for inclusion in FIU Electronic Theses and Dissertations by an authorized administrator of FIU Digital Commons. For more information, please contact dcc@fiu.edu. 


\title{
FLORIDA INTERNATIONAL UNIVERSITY
}

Miami, Florida

\section{UNREFINED HUMIC SUBSTANCES AS A POTENTIAL LOW-COST \\ REMEDIATION METHOD FOR GROUNDWATER CONTAMINATED WITH URANIUM IN ACIDIC CONDITIONS}

\author{
A dissertation submitted in partial fulfillment of \\ the requirements for the degree of \\ DOCTOR OF PHILOSOPHY \\ in \\ CHEMISTRY \\ by \\ Hansell Gonzalez Raymat
}

2018 
To: Dean Michael R. Heithaus

College of Arts, Sciences and Education

This dissertation, written by Hansell Gonzalez Raymat, and entitled Unrefined Humic Substances as a Potential Low-cost Remediation Method for Groundwater Contaminated with Uranium in Acidic Conditions, having been approved in respect to style and intellectual content, is referred to you for judgment.

We have read this dissertation and recommend that it be approved.

Yelena Katsenovich

Miles Denham

Konstantinos Kavallieratos

Xiaotang Wang

Yong Cai, Major Professor

Date of Defense: October 25, 2018

The dissertation of Hansell Gonzalez Raymat is approved.

Dean Michael R. Heithaus College of Arts, Sciences and Education

Andrés G. Gil

Vice President for Research and Economic Development and Dean of the University Graduate School

Florida International University, 2018 
(C) Copyright 2018 by Hansell Gonzalez Raymat

All rights reserved. 


\section{DEDICATION}

I dedicate this dissertation to God, my savior and source of hope, strength, and inspiration. I also dedicate this dissertation to Flora and José, my parents, and to Handell, my brother. I never could have done the present work without their unconditional love and support. I thank them for being there for me at all times and never let me falter even in my most difficult moments.

Ad Maiorem Dei Gloriam 


\section{ACKNOWLEDGMENTS}

First of all, I would like to thank Dr. Yong Cai and Dr. Yelena Katsenovich for giving me the opportunity to be part of their research group. I thank them for their support, guidance, and patience throughout my graduate studies. It has been an honor to have worked with them, and I have no words to express my gratitude. I would also like to thank my committee members: Dr. Miles Denham, Dr. Konstantinos Kavallieratos, and Dr. Xiaotang Wang for giving me insightful suggestions regarding my research. A very special mention goes to Dr. Miles Denham. I sincerely appreciate his involvement and all the discussions we had along the way. He made my two summer internships at Savannah River Site a very pleasant experience.

I would like to thank Dr. Vasileios Anagnostopoulos, Dr. Ravi Gudavalli, and Dr. Hilary Emerson for providing invaluable suggestions and endless assistance in the lab. They challenged me to improve my research and their doors were always open to me. Special thanks to my lab/cubicle mates Alejandro Hernandez, Silvina Di Pietro, and Claudia Cardona for their friendship, support, and ideas. I would also like to thank Ms. Peggy Shoffner for reviewing my dissertation.

I would also like to thank Dr. Leonel Lagos for giving me the opportunity to become a DOE fellow and the Department of Energy (DOE) fellowship for the financial assistance and internship opportunities. 


\section{ABSTRACT OF THE DISSERTATION \\ UNREFINED HUMIC SUBSTANCES AS A POTENTIAL LOW-COST \\ REMEDIATION METHOD FOR GROUNDWATER CONTAMINATED WITH \\ URANIUM IN ACIDIC CONDITIONS}

by

Hansell Gonzalez Raymat

Florida International University, 2018

Miami, Florida

\section{Professor Yong Cai, Major Professor}

Anthropogenic activities such as uranium mining and milling, nuclear weapons production, and nuclear reprocessing have left a legacy of groundwater and soil contaminated with uranium that needs to be addressed. Therefore, developing new remediation technologies to sequester uranium in situ is crucial. The objective of the study was to determine if low-cost commercially available unrefined humic substances, such as Huma-K, can be used to facilitate uranium sorption to minerals in soil and sediment. Sediments from the saturated zone beneath the F-Area seepage basins at the Savannah River Site (SRS) in South Carolina were used for the present study. The SRS site is analogous to many contaminated locations where groundwater acidity enhances uranium and other contaminants mobility.

First, a variety of techniques were applied to characterize Huma-K and SRS sediment. Characterization studies showed that Huma-K possesses functional groups that have an acidic nature such as carboxyl and phenol groups. For SRS sediment, a mineral composition of mainly quartz $(93.2 \%)$, kaolinite $(5.1 \%)$, and goethite $(1.1 \%)$ was identified. 
Second, the interactions between Huma-K and SRS sediment were investigated through batch experiments. Sorption, homogeneous precipitation, and surfaced-induced precipitation were observed to be enhanced at $\mathrm{pH} 4$. However, Huma-K removal from solution decreased with an increase of $\mathrm{pH}$. The sorption behavior was not able to be described by any of the models employed (pseudo-first, pseudo-second, Langmuir, and Freundlich).

Third, the interactions between uranium and SRS sediment with and without Huma-K amendment were investigated. In acidic conditions ( $\mathrm{pH} 3-5)$, the sorption capacity of SRS sediment amended with Huma-K was significantly increased compared to plain sediment. At circumneutral conditions, uranium removal from solution decreased for SRS sediment amended with Huma-K, compared with plain sediments, likely as a result of the formation of aqueous uranium-humic complexes. In summary, the results from the present study suggest that Huma-K, and likely other unrefined humate products, has the characteristics and effects necessary to be suitable for subsurface injection to remediate uranium in acidic groundwater conditions. The treatment zone will persist as long as the $\mathrm{pH}$ does not increase sufficiently to cause soilbound Huma-K to be released, remobilizing uranium. 


\section{TABLE OF CONTENTS}

CHAPTER

PAGE

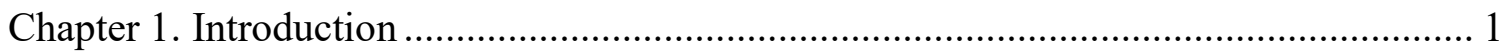

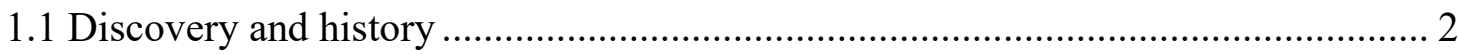

1.2 Sources of uranium in the environment .......................................................... 2

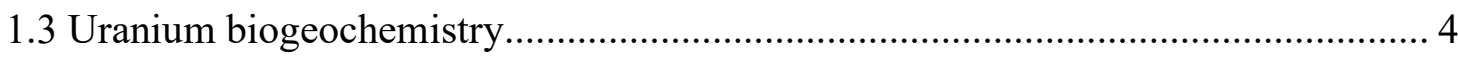

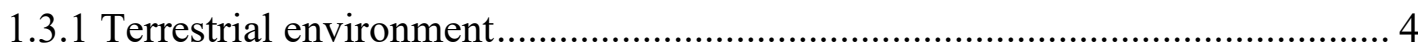

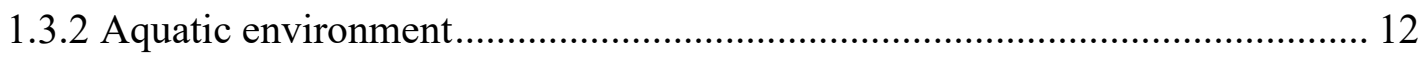

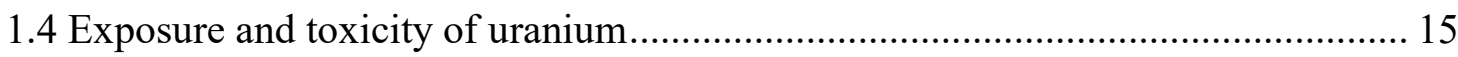

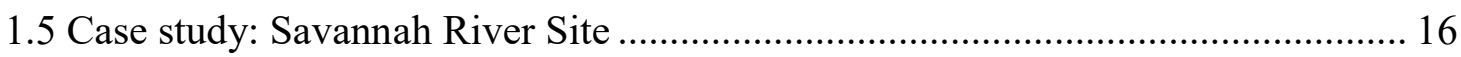

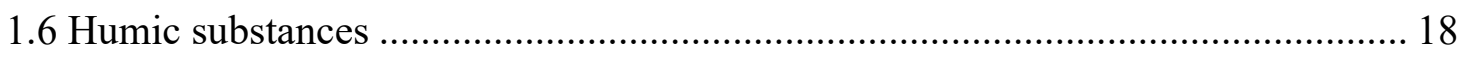

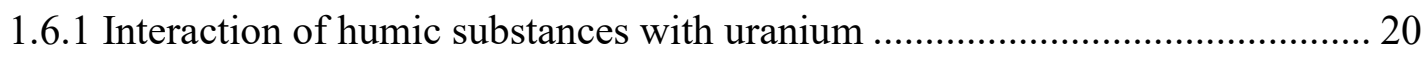

1.7 Research gaps and significance of the present study ........................................ 23

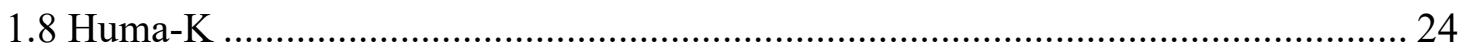

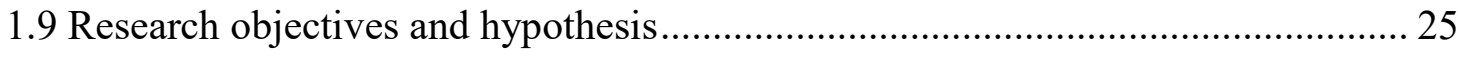

Chapter 2. Evaluating the sorption behavior of Huma-K on SRS sediment.................... 28

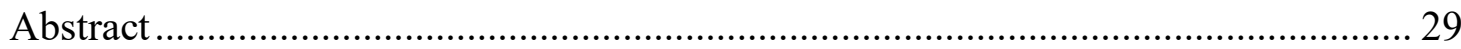

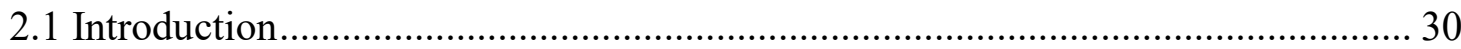

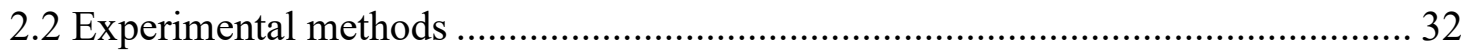

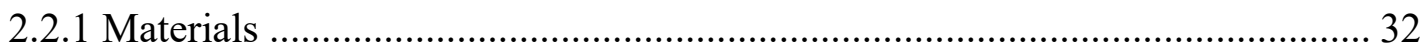

2.2.2 Characterization of SRS sediment and Huma-K ......................................... 33

2.2.3 Huma-K sorption experiments on SRS sediment .................................... 36

2.2.4 Desorption experiments of Huma-K from SRS sediment.............................. 37

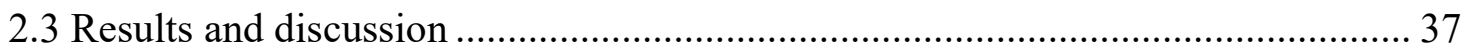

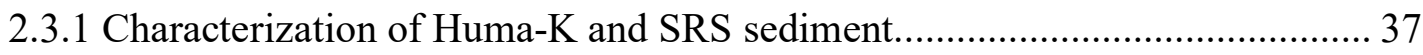

2.3.2 Effect of $\mathrm{pH}$ on Huma-K sorption on SRS sediment .................................. 45

2.3.3 Kinetic studies of Huma-K sorption on SRS sediment................................. 48

2.3.4 Equilibrium studies on Huma-K sorption ................................................ 55

2.3.5 Desorption of Huma-K from SRS sediment .............................................. 59

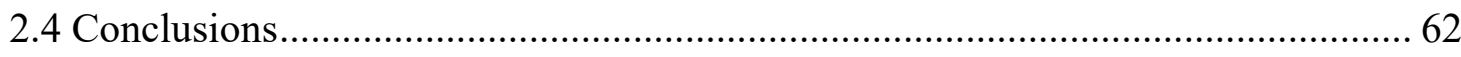

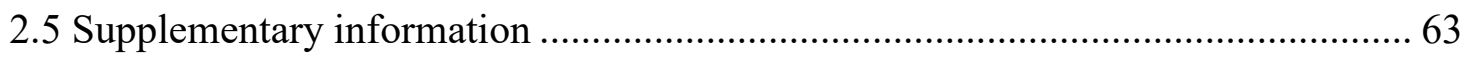


Chapter 3. Evaluation of SRS sediment amended with Huma-K to enhance

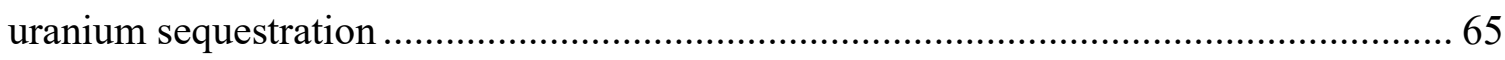

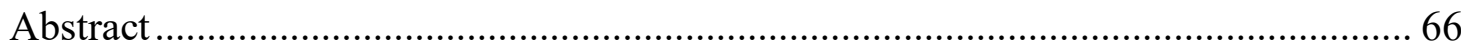

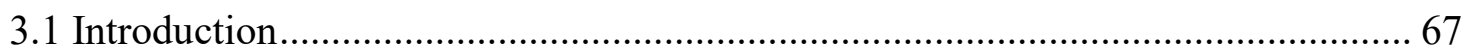

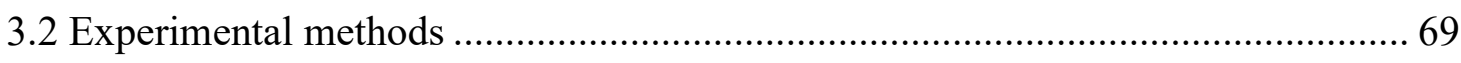

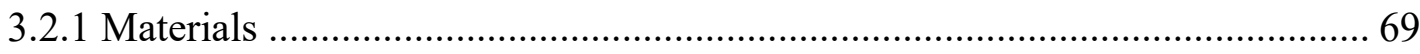

3.2.2 Sorption of U(VI) onto SRS sediment with and without Huma-K

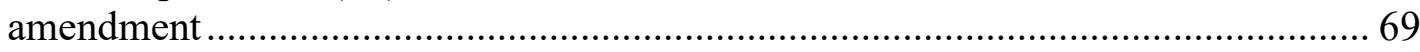

3.2.3 Desorption experiments of U(VI) from SRS sediment with and without

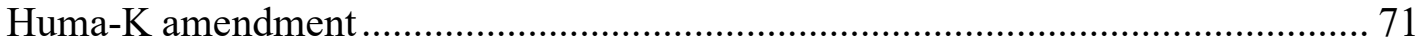

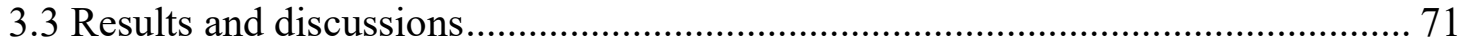

3.3.1 Kinetic studies of U(VI) sorption onto SRS sediment with and without

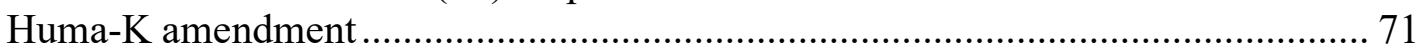

3.3.2 Equilibrium studies of U(VI) sorption onto SRS sediment with and

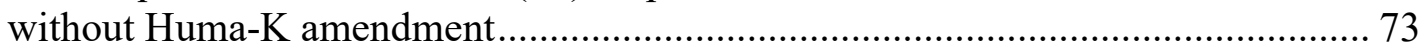

3.3.3 Effect of $\mathrm{pH}$ on $\mathrm{U}(\mathrm{VI})$ sorption on SRS sediment with and without

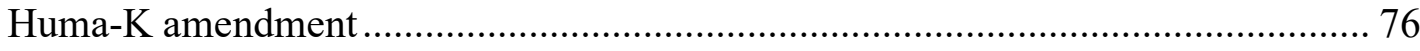

3.3.4 Comparison of U(VI) sorption onto quartz, kaolinite, goethite, and SRS

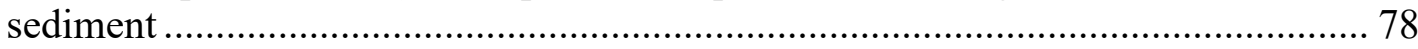

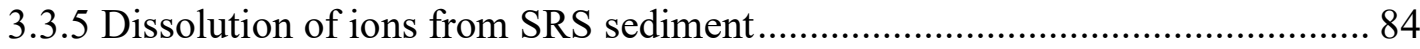

3.3.6 Desorption of U(VI) from SRS sediment with and without Huma-K

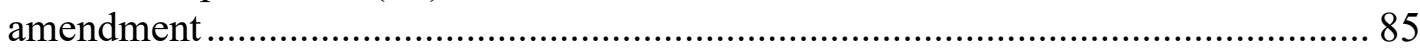

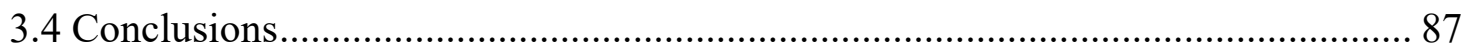

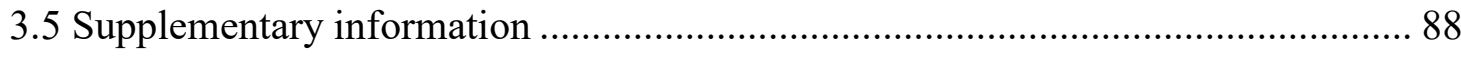

Chapter 4. Summary and future work ..................................................................... 90

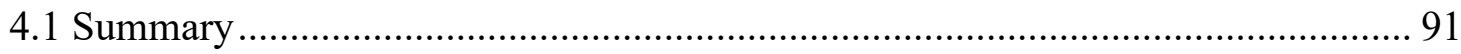

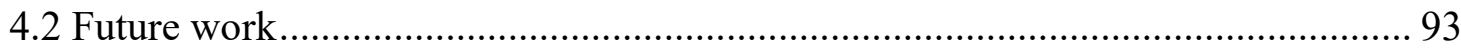

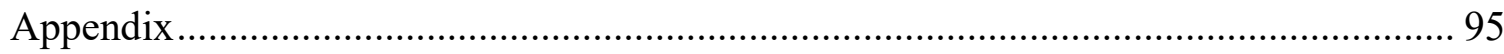

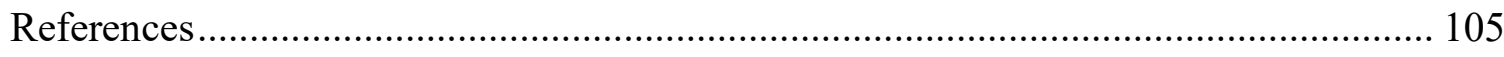

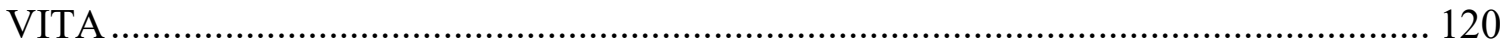




\section{LIST OF FIGURES}

FIGURE

PAGE

Figure 1.1 Surface complexation of uranium on quartz: (a) outer sphere, (b) monodentate, and (c) bidentate.

Figure 1.2 Surface complexation of uranium on kaolinite. ............................................ 8

Figure 1.3 Surface complexation of uranium on goethite......................................... 10

Figure 1.4 (a) Speciation of $U(V I)\left(C_{i}=0.5 \mathrm{mg} \mathrm{L}^{-1}\right)$ as a function of $\mathrm{pH}$ was created by using Geochemist's Workbench $\left(\mathrm{P}_{\mathrm{CO} 2}=10^{-3.5}\right.$ atm and $\left.\mathrm{T}=25^{\circ} \mathrm{C}\right)$. 14

Figure 1.5 Proposed structure of humic substances from Schulten and Schnitzer (1993).

Figure 1.6 Aqueous speciation of U(VI) in the presence of humic acid (HA) was created by using Geochemist's Workbench using the following conditions: U(VI) $=0.5 \mathrm{mg} \mathrm{L}^{-1} ; \mathrm{HA}=10 \mathrm{mg} \mathrm{L}^{-1} ; \mathrm{P}_{\mathrm{CO} 2}=10^{-3.5} \mathrm{~atm}$. 22

Figure 1.7 Huma-K dried (left) and dissolved in deionized water (right). ..................... 25

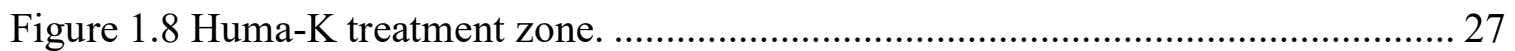

Figure 2.1 X-ray diffraction of SRS sediment..................................................... 38

Figure 2.2 SEM-EDS of Huma-K (left column) and SRS sediment (right column). Red square indicates the location where spot analysis was performed.

Figure 2.3 Fourier-transform infrared spectra of: (a) Huma-K, and (b) kaolinite (red line) and SRS sediment fine fraction (mean particle diameter $\leq 63 \mu \mathrm{m}$ ) (black line).

Figure 2.4 Differential potentiometric titration of: (a) SRS sediment (mean particle diameter $\leq 2 \mathrm{~mm}$ ), (b) quartz mineral, (c) SRS sediment (mean particle diameter $\leq 63 \mu \mathrm{m}$ ), and (d) Huma-K.

Figure $2.5 \%$ Removal of Huma-K $\left(\mathrm{C}_{\mathrm{i}}=50 \mathrm{mg} \mathrm{L}^{-1}\right)$ from the aqueous phase as a function of $\mathrm{pH}\left(49 \mathrm{~g} \mathrm{~L}^{-1}\right.$ of sediment, $\mathrm{T}=25^{\circ} \mathrm{C}$, and 5 days $)$.

Figure 2.6 (a) Kinetics of Huma-K $\left(\mathrm{C}_{\mathrm{i}}=50 \mathrm{mg} \mathrm{L}^{-1}\right)$ sorption on SRS sediment (49

$\mathrm{g} \mathrm{L}^{-1}$ of sediment, $\mathrm{pH} 4$, and $\left.\mathrm{T}=25^{\circ} \mathrm{C}\right)$. (b) Non-linear fit of fractional uptake $(\mathrm{F}$

$=\mathrm{q}_{\mathrm{t}} / \mathrm{q}_{\mathrm{e}}$ ) data for $\mathrm{t}<100 \mathrm{~h}$. 50

Figure 2.7 (a) Weber and Morris plot of Huma-K. (b) Boyd plot of Huma-K. Bt = $-0.4977-\ln (1-F)$ where $F$ represents the fractional uptake $\left(F=q_{t} / q_{e}\right)$. 
Figure 2.8 (a) Sorption isotherm of Huma-K $\left(\mathrm{C}_{\mathrm{i}}=10-500 \mathrm{mg} \mathrm{L}^{-1}\right)$ on SRS sediment (49 $\mathrm{g} \mathrm{L}^{-1}$ of sediment). (b) Precipitation of Huma-K without SRS sediment ( $\mathrm{pH} 4, \mathrm{~T}=25^{\circ} \mathrm{C}$, and 5 days)

Figure 2.9 Non-linear fit of sorption isotherm of Huma-K on SRS sediment. 58

Figure 2.10 (a) Desorption of Huma-K from SRS sediment $\left(49 \mathrm{~g} \mathrm{~L}^{-1}\right)$ was conducted by first sorbing Huma-K $\left(\mathrm{C}_{\mathrm{i}}=50 \mathrm{mg} \mathrm{L}^{-1}\right)$ at $\mathrm{pH} 4$ and then desorbing Huma-K with DI water adjusted to $\mathrm{pH}$ ranging from $4-8\left(\mathrm{~T}=25^{\circ} \mathrm{C}, 5\right.$ days). (b) Huma-K desorption from SRS sediment using DI water at $\mathrm{pH} 4$ in four desorption cycles

Figure 3.1 Kinetic study of U(VI) $\left(C_{i}=0.5 \mathrm{mg} \mathrm{L}^{-1}\right)$ sorption on (a) SRS sediment and (b) SRS sediment amended with Huma-K $\left(10 \mathrm{~g} \mathrm{~L}^{-1}\right.$ of sediment, $\mathrm{pH} 4, \mathrm{I}=$ $0.01 \mathrm{M} \mathrm{NaClO}_{4}$, and $\mathrm{T}=25^{\circ} \mathrm{C}$ ).

Figure 3.2 Non-linear fit of $F$ data for (a) SRS sediment ( $t \leq 0.125$ days) and (b) SRS sediment amended with Huma-K ( $\mathrm{t} \leq 3$ days). 73

Figure 3.3 Sorption isotherm of U(VI) $\left(C_{i}=0.025-1 \mathrm{mg} \mathrm{L}^{-1}\right)$ on SRS sediment with and without Huma-K amendment for 7 days $\left(10 \mathrm{~g} \mathrm{~L}^{-1}\right.$ of sediment, $\mathrm{pH} 4, \mathrm{I}=$ $0.01 \mathrm{M} \mathrm{NaClO}_{4}$, and $\mathrm{T}=25^{\circ} \mathrm{C}$ ).

Figure 3.4 Coordination modes of carboxyl and phenolic $\mathrm{OH}$ groups of humic acid (HA) with the uranyl ion: (a) monodentate, (b) bidentate, and (c) chelate form.

Figure 3.5 Non-linear fit adsorption isotherm for (a) SRS sediment and (b) SRS sediment amended with Huma-K 76

Figure $3.6 \%$ Removal of $\mathrm{U}(\mathrm{VI})\left(\mathrm{C}_{\mathrm{i}}=0.5 \mathrm{mg} \mathrm{L}^{-1}\right)$ from the aqueous phase as a function of $\mathrm{pH}\left(10 \mathrm{~g} \mathrm{~L}^{-1}\right.$ of sediment, 7 days, $\mathrm{I}=0.01 \mathrm{M} \mathrm{NaClO}_{4}$, and $\left.\mathrm{T}=25^{\circ} \mathrm{C}\right)$. 78

Figure 3.7 (a) Comparison of $\mathrm{U}(\mathrm{VI})\left(\mathrm{C}_{\mathrm{i}}=0.5 \mathrm{mg} \mathrm{L}^{-1}\right)$ removal for SRS sediment, quartz (100\%), quartz/kaolinite (95\%:5\%), quartz/kaolinite/goethite (93\%:5\%:2\%). (b) Control samples with no sediment (circles) and $\mathrm{E}_{\mathrm{h}}$ (squares). (7 days, $\mathrm{I}=0.01 \mathrm{M} \mathrm{NaClO}_{4}$, and $\mathrm{T}=25^{\circ} \mathrm{C}$ ).

Figure 3.8 Dissolution of aluminum and silicon from SRS sediment. 85

Figure 3.9 (a) Desorption of U(VI) from SRS sediment with and without Huma-K amendment removal $\left(10 \mathrm{~g} \mathrm{~L}^{-1}\right.$ of sediment, 14 days, $\mathrm{I}=0.01 \mathrm{M} \mathrm{NaClO}_{4}$, and $\mathrm{T}=$ $25^{\circ} \mathrm{C}$ ). (b) Uranium remaining sorbed in SRS sediment after desorption. 


\section{ABBREVIATIONS AND ACRONYMS}

\begin{tabular}{|c|c|}
\hline ATR FT-IR & Attenuated total reflection Fourier-transform infrared spectroscopy \\
\hline DOE & Department of Energy \\
\hline DPT & Differential potentiometric titrations \\
\hline DOM & Dissolved organic matter \\
\hline FA & Fulvic acid \\
\hline HA & Humic acid \\
\hline KPA & Kinetic phosphorescence analyzer \\
\hline $\mathrm{PZC}$ & Point of zero charge \\
\hline $\mathrm{E}_{\mathrm{h}}$ & Redox potential \\
\hline SRS & Savannah River Site \\
\hline SEM-EDS & Scanning electron microscopy with energy dispersive spectroscopy \\
\hline $\mathrm{U}$ & Uranium \\
\hline $\mathrm{U}(\mathrm{IV})$ & Uranium (IV) \\
\hline $\mathrm{U}(\mathrm{VI})$ & Uranium (VI) \\
\hline $\mathrm{UO}_{2}^{2+}$ & Uranyl ion \\
\hline XRD & X-ray diffraction \\
\hline XRF & $\mathrm{X}$-ray fluorescence \\
\hline
\end{tabular}


Chapter 1. Introduction 


\subsection{Discovery and history}

Uranium (U) was discovered in 1789 by the German chemist Martin Heinrich Klaproth. He was studying a mysterious waste product (pitchblende) from a silver mine in St. Joachimsthal, Bohemia. After heating the pitchblende in solution and adding wax and oil, he obtained a heavy grey residue. He concluded that a new element was present, so he named this new element "uranium" after the recently discovered planet Uranus (the Greek god of the sky). In 1841, the French chemist Eugène-Melchior Péligot demonstrated that Klaproth had isolated uranium dioxide and not the pure element. After further testing, Péligot was able to isolate elemental uranium. However, the radioactive properties of uranium were not recognized until 1896 when French physicist Antoine Henri Becquerel noticed that uranium produced fogging on a photographic plate without exposure to sunlight (Karpas, 2015). The discovery attracted two scientists, Marie and Pierre Curie, who suggested that the emissions from uranium appeared to be an atomic property and not a product of the arrangement of atoms. Uranium became the subject of intense study and broad interest. In 1938, Otto Hahn and Fritz Strassmann discovered nuclear fission through the bombardment of uranium with neutrons. Subsequent studies led to the first self-sustaining nuclear chain reaction (1942) and the first atomic bomb (1945).

\subsection{Sources of uranium in the environment}

Uranium is a radionuclide found in the environment with a natural occurrence of $2.7 \mathrm{mg} \mathrm{kg}^{-1}$ in the Earth's crust (Langmuir, 1997). Twenty five uranium isotopes have been identified, but the most prevalent uranium isotopes found in the environment are 
${ }^{238} \mathrm{U}(99.274 \%)$ with a half-life of $4.468 \times 10^{9}$ years, ${ }^{235} \mathrm{U}(0.7204 \%)$ with a half-life of $7.04 \times 10^{8}$ years, and ${ }^{234} \mathrm{U}(0.00548 \%)$ with a half-life of $2.455 \times 10^{5}$ years (Karpas, 2015). Uranium is present in numerous ores such as uraninite $\left(\mathrm{UO}_{2}\right)$, pitchblende (a mixture of $\mathrm{UO}_{2}$ and $\mathrm{UO}_{3}$ ), and secondary minerals (oxides, carbonates, silicates, and phosphates) (Bleise et al., 2003). Natural processes such as wind and water erosion lead to the redistribution of uranium in soils $\left(1.2-11 \mathrm{mg} \mathrm{kg}^{-1}\right)$, air $\left(0.5 \mathrm{ng} \mathrm{m}^{-3}\right)$, groundwater (2-12 $\left.\mu \mathrm{g} \mathrm{L}^{-1}\right)$, and seawater $\left(3 \mu \mathrm{g} \mathrm{L}^{-1}\right)$ (Kabata-Pendias and Mukherjee, 2007; Seko et al., 2003).

In addition to natural sources, anthropogenic activities have generated additional sources and contributed to the release of uranium into the environment. For instance, uranium mining and milling have generated large volumes of waste (mill tailings) because uranium abundance in ores is generally less than $1 \%$. Also, improper waste disposal have led to the contamination of soil, surface water, and groundwater (Abdelouas, 2006). On the other hand, nuclear weapons testing, near-surface storage of high- and low-level radioactive waste, nuclear fuel reprocessing, and nuclear accidents have contributed to the release of radionuclides into the environment (Hu et al., 2010). For instance, during World War II and the Cold War, the Hanford Site in Washington State and the Savannah River Site in South Carolina (U.S.) reprocessed nuclear fuel for the nuclear weapons production. The reprocessing of nuclear fuel created high- and low-level nuclear waste. High-level waste was stored in tanks, whereas low-level waste was generally released to cribs (Hanford Site) and unlined basins (Savannah River Site), from which the waste seeped into the subsurface (Ahearne, 1997; Wan et al., 2009). 


\subsection{Uranium biogeochemistry}

\subsubsection{Terrestrial environment}

Uranium has a complex behavior in soils. Several factors such as redox potential

$\left(\mathrm{E}_{\mathrm{h}}\right), \mathrm{pH}$, minerals, and microbial activity can affect the speciation and behavior of uranium in the environment. The most important factors that control uranium speciation are $\mathrm{E}_{\mathrm{h}}$ and $\mathrm{pH}$. Uranium has four potential oxidation states: U(III), U(IV), U(V), and U(VI). However, the oxidation states U(IV) and U(VI) are the most stable and common in environmentally relevant conditions. Under reducing conditions such as waterlogged and wet soils that have a $\mathrm{E}_{\mathrm{h}}<200 \mathrm{mV}, \mathrm{U}(\mathrm{IV})$ is the main oxidation state (Newsome et al., 2014). In these conditions, U(IV) is sparingly soluble and tends to precipitate as uraninite and coffinite $\left(\mathrm{USiO}_{4}\right)$. Under oxidizing conditions, $\mathrm{U}(\mathrm{IV})$ is oxidized to $\mathrm{U}(\mathrm{VI})$ (Eq. 1.1). Uranium (VI) has a much greater environmental mobility compared to U(IV), and it is usually found as the uranyl ion $\left(\mathrm{UO}_{2}^{2+}\right)$.

$$
2 \mathrm{UO}_{2(\mathrm{~s})}+4 \mathrm{H}^{+}+\mathrm{O}_{2} \rightarrow 2 \mathrm{UO}_{2}^{2+}(\mathrm{aq})+2 \mathrm{H}_{2} \mathrm{O}
$$

There are a number of U(VI) minerals that can form under oxidizing conditions in the presence of hydroxyl, carbonate, silicate, phosphate, and vanadate ligands. For instance, uranyl (hydr)oxides such as schoepite $\left(\mathrm{UO}_{3} \cdot 2.25 \mathrm{H}_{2} \mathrm{O}\right)$ and metaschoepite $\left(\mathrm{UO}_{3} \cdot 2 \mathrm{H}_{2} \mathrm{O}\right)$ are minerals that form when uraninite is oxidized in uranium deposits (Finch and Ewing, 1992). Uranyl (hydr)oxides are characterized for having electroneutral sheets of uranyl pentagonal bipyramids polyhedra. The sheets are bound together by hydrogen bonding, involving water molecules located in the interlayer spaces. Carbonates readily form complexes with $\mathrm{UO}_{2}^{2+}$ at basic conditions, increasing 
U(VI) mobility and solubility. However, in cases where aqueous solutions become oversaturated with uranyl carbonate species, uranyl carbonate minerals such as rutherfordine $\left(\mathrm{UO}_{2} \mathrm{CO}_{3}\right)$ can form (Clark et al., 1995). In the presence of dissolved silica, U(VI) may precipitate by forming uranyl silicates such as soddyte $\left(\left(\mathrm{UO}_{2}\right)_{2}\left(\mathrm{SiO}_{4}\right)\left(\mathrm{H}_{2} \mathrm{O}\right)_{2}\right)$, boltwoodite $\left((\mathrm{Na}, \mathrm{K})\left(\mathrm{UO}_{2}\right)\left(\mathrm{HSiO}_{4}\right) \cdot \mathrm{H}_{2} \mathrm{O}\right)$, and uranophane $\left(\mathrm{Ca}\left(\mathrm{UO}_{2}\right)_{2}\left(\mathrm{HSiO}_{4}\right)_{2} \cdot 5 \mathrm{H}_{2} \mathrm{O}\right)$. These minerals are less soluble than uranyl carbonates or uranyl (hydr)oxides under circumneutral conditions. Phosphates have a high affinity for $\mathrm{U}(\mathrm{VI})$, and their complexation can induce the formation of uranyl phosphate minerals, which are stable and highly insoluble under circumneutral conditions. However, the presence of carbonates prevents the formation of uranyl phosphate minerals because carbonates compete with phosphates for uranium complexation. Uranium solubility is also reduced in the presence of dissolved vanadates by forming low solubility minerals such as carnotite $\left(\mathrm{K}_{2}\left(\mathrm{UO}_{2}\right) 2 \mathrm{~V}_{2} \mathrm{O}_{8} \cdot 3 \mathrm{H}_{2} \mathrm{O}\right)$ and tyuyamunite $\left(\mathrm{Ca}\left(\mathrm{UO}_{2}\right) 2 \mathrm{~V}_{2} \mathrm{O}_{8} \cdot 8 \mathrm{H}_{2} \mathrm{O}\right)$, which are known to be insoluble except at pH 7-8 (Cumberland et al., 2016; GormanLewis et al., 2008).

\subsubsection{Sorption/Surface interactions}

Minerals contribute to the retention of uranium in soils. Mineral surfaces have the ability to carry either positive or negative charges, depending on the degree of protonation/deprotonation of reactive surface functional groups associated with $\mathrm{Si}, \mathrm{Al}$, and Fe. The charge developed at the mineral surface has an effect in the electrostatic attraction or repulsion of the different U(VI) species for the sorption to take place. The mechanism of uranium sorption involves a variety of processes, which include outer- 
sphere complexation through electrostatic attraction, inner-sphere complexation through covalent bonding to the mineral phase, and ion exchange. For instance, several studies have shown that uranium sorption onto montmorillonite occurs via an outer-sphere complexation at low $\mathrm{pH}$ and an inner-sphere complexation at high $\mathrm{pH}$ (ChisholmBrause et al., 2001; Sylwester et al., 2000).

Different studies have focused on uranium sorption on minerals such as quartz (Greathouse et al., 2002), kaolinite (Křepelová et al., 2007), and iron (hydr)oxide (Ching-kuo Daniel and Langmuir, 1985). Quartz $\left(\mathrm{SiO}_{2}\right)$ is one of the most abundant minerals in the Earth's crust. Quartz is a silicate mineral whose structure consists of corner-sharing $\mathrm{SiO}_{4}$ tetrahedra, in which each $\mathrm{Si}$ is bonded to four oxygens, and each oxygen is bonded to two silicon atoms. Greathouse et al. (2002) used molecular dynamics simulations to study the interactions between uranium and quartz. The simulations revealed the formation of an outer-sphere surface complexation characterized by hydrogen bonding between a coordinated water molecule from $\mathrm{UO}_{2}^{2+}$ and the protonated quartz surface. For a partially deprotonated quartz surface, the simulations revealed an inner-sphere complex between $\mathrm{UO}_{2}^{2+}$ and one or two surface oxygen atoms (Figure 1.1). In the presence of carbonate ions, an inner-sphere surface complex is formed only when one carbonate ion is coordinated to $\mathrm{UO}_{2}^{2+}$. On the other hand, when two carbonate ions are in the coordination shell, $\mathrm{UO}_{2}^{2+}$ forms only an outersphere complex with the quartz surface (Greathouse et al., 2002). In addition, Gabriel et al. (2001) investigated the sorption of U(VI) onto amorphous silica by laser-induced time-resolved fluorescence spectroscopy, and the study distinguished three surface complexes: $\equiv \mathrm{SiO}_{2} \mathrm{UO}_{2}, \equiv \mathrm{SiO}_{2} \mathrm{UO}_{2} \mathrm{OH}^{-}$, and $\equiv \mathrm{SiO}_{2} \mathrm{UO}_{2} \mathrm{OHCO}_{3}^{3-}$ dominating at $\mathrm{pH}$, 
7.7, and 8.6, respectively (Eq. 1.2-1.4). Similar surface complexes might form at the quartz surface.
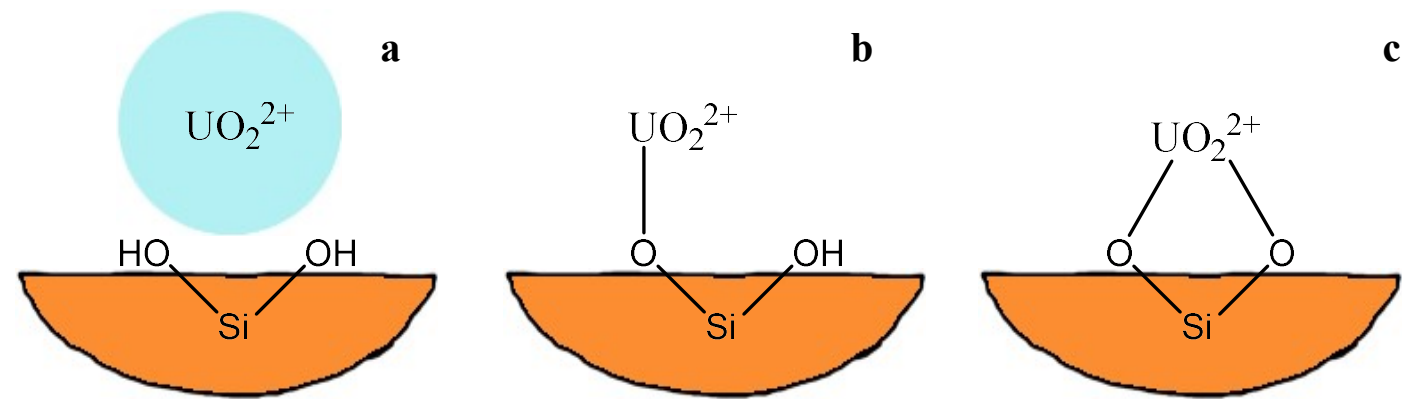

Figure 1.1 Surface complexation of uranium on quartz: (a) outer sphere, (b) monodentate, and (c) bidentate.

$$
\begin{aligned}
& \equiv \mathrm{Si}(\mathrm{OH})_{2}+\mathrm{UO}_{2}^{2+} \rightleftarrows \equiv \mathrm{SiO}_{2} \mathrm{UO}_{2}+2 \mathrm{H}^{+} \\
& \equiv \mathrm{Si}(\mathrm{OH})_{2}+\mathrm{UO}_{2}^{2+}+\mathrm{H}_{2} \mathrm{O} \rightleftarrows \equiv \mathrm{SiO}_{2} \mathrm{UO}_{2} \mathrm{OH}^{-}+3 \mathrm{H}^{+} \\
& \equiv \mathrm{Si}(\mathrm{OH})_{2}+\mathrm{UO}_{2}^{2+}+\mathrm{H}_{2} \mathrm{CO}_{3}+\mathrm{H}_{2} \mathrm{O} \rightleftarrows \equiv \mathrm{SiO}_{2} \mathrm{UO}_{2} \mathrm{OHCO}_{3}^{3-}+5 \mathrm{H}^{+}
\end{aligned}
$$

Kaolinite $\left(\mathrm{Al}_{2} \mathrm{Si}_{2} \mathrm{O}_{5}(\mathrm{OH})_{4}\right)$ is a clay mineral characterized by 1:1 stacking structural layer whose structure consists of one $\mathrm{Al}$ octahedral sheet connected to one $\mathrm{Si}$ tetrahedral sheet by bridging oxygens. The $\mathrm{Al}$ octahedral surface is considered to be more reactive than the Si tetrahedral surface because the Al octahedral surface contains hydroxyl groups while the Si tetrahedral surface contains only coordinatively saturated oxygen centers (Kremleva et al., 2008). Also, kaolinite possesses edge surfaces, which contain reactive groups such as $\mathrm{AlOH}, \mathrm{AlOH}_{2}$, and $\mathrm{SiOH}$ (Liu et al., 2013).

Kremleva et al. (2008) studied U(VI) sorption on kaolinite surfaces by using density functional calculations. The study found that $\mathrm{UO}_{2}^{2+}$ sorption is thermodynamically favored at the $\mathrm{Al}$ octahedral surface and unfavorable at the $\mathrm{Si}$ tetrahedral surface. The $\mathrm{Si}$ tetrahedral surface exhibits a low reactivity towards $\mathrm{UO}_{2}^{2+}$ 
because of the absence of surface hydroxyl groups. On the other hand, the Al octahedral surface is considered to be more reactive because of the presence of surface hydroxyl groups. Also, the study found that inner-sphere adsorption and outer sphere complexation of $\mathrm{U}(\mathrm{VI})$ was favored at the neutral $\mathrm{AlOHOH}$ and $\mathrm{AlOH}$ sites of the $\mathrm{Al}$ octahedral surface. Martorell et al. (2010) continued the density functional model study of Kremleva et al. (2008) and explored two possible binding sites where $\mathrm{UO}_{2}^{2+}$ can form surface complexes on kaolinite. The first binding site is composed of two surface oxygen atoms connected to one $\mathrm{Al}$ atom (AlOO) designated short-bridge site. The second binding site consists of two surface oxygen atoms attached to two neighboring Al atoms (AlO-AlO) designated long-bridge site (Figure 1.2). The results from the study concluded that sorption to a short-bridge site required less energy than a longbridge site, so the short-bridge would be preferred for $\mathrm{UO}_{2}^{2+}$ sorption.
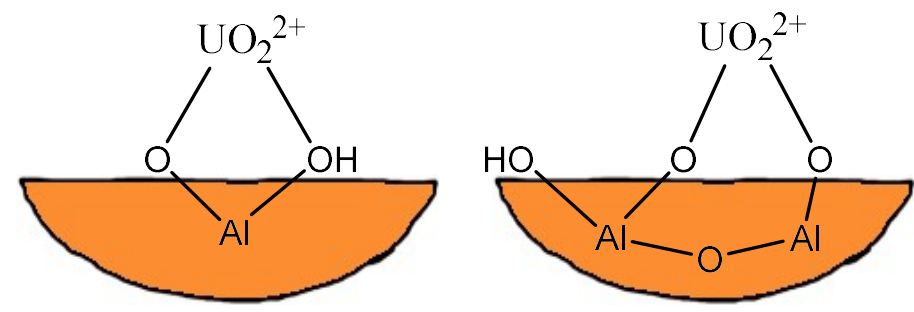

Figure 1.2 Surface complexation of uranium on kaolinite.

Other studies have used molecular dynamics simulations to investigate the effect of carbonates on U(VI) sorption onto kaolinite. Kerisit and Liu (2014) found that sorption of uranyl complexes coordinated by two or more carbonate ions is unfavorable at the kaolinite surface because of the steric hindrance caused by the carbonate ions (Kerisit and Liu, 2014). On the other hand, the simulations performed by Li et al. (2015) showed that non-carbonato and monocarbonato uranyl species form outer-sphere 
complexes at the Si tetrahedral surface through electrostatic attraction while dicarbonato and tricarbonato uranyl species do not sorb because of electrostatic repulsion from the negatively charged $\mathrm{Si}$ tetrahedral surface. In the case of the Al octahedral sheet, sorption of uranyl carbonate complexes is favored because carbonates can form hydrogen bonds with the surface hydroxyl groups.

Iron (hydr)oxide minerals have shown to have a strong sorption capacity for U(VI) (Ching-kuo Daniel and Langmuir, 1985). Goethite $(\alpha-\mathrm{FeOOH})$ is one the most common and reactive iron oxide phases found in soils and sediments, and its structure is characterized for having a needle or lath shape. The goethite surface contains singly coordinated $(\mathrm{FeOH})$, doubly coordinated $\left(\mathrm{Fe}_{2} \mathrm{OH}\right)$, and triply coordinated $\left(\mathrm{Fe}_{3} \mathrm{OH}\right)$ hydroxyl groups (Cornell and Schwertmann, 2003). Hiemstra and Van Riemsdijk (1996) suggested that singly and triply coordinated hydroxyl groups contribute to the charging behavior of the goethite surface, but only the singly hydroxyl groups are active in oxyanion binding. On the other hand, doubly coordinated hydroxyl groups are considered to be inert and zero charged over a wide $\mathrm{pH}$ range.

Sherman et al. (2008) investigated the interactions between U(VI) and goethite using extended X-ray absorption fine structure spectroscopy. The study postulated that in the absence of $\mathrm{CO}_{2}$, the dominant surface complex is $(\equiv \mathrm{FeOH})_{2} \mathrm{UO}_{2}\left(\mathrm{H}_{2} \mathrm{O}\right)_{3}$. In the presence of $\mathrm{CO}_{2}, \mathrm{U}(\mathrm{VI})$ sorption might be enhanced either through the sorption of $\mathrm{CO}_{3}^{2-}$ on the goethite surface or the formation of ternary complexes $\equiv \mathrm{FeOCO}_{2} \mathrm{UO}_{2}$ and $(\equiv \mathrm{FeOH})_{2} \mathrm{UO}_{2} \mathrm{CO}_{3}$ (Figure 1.3) 

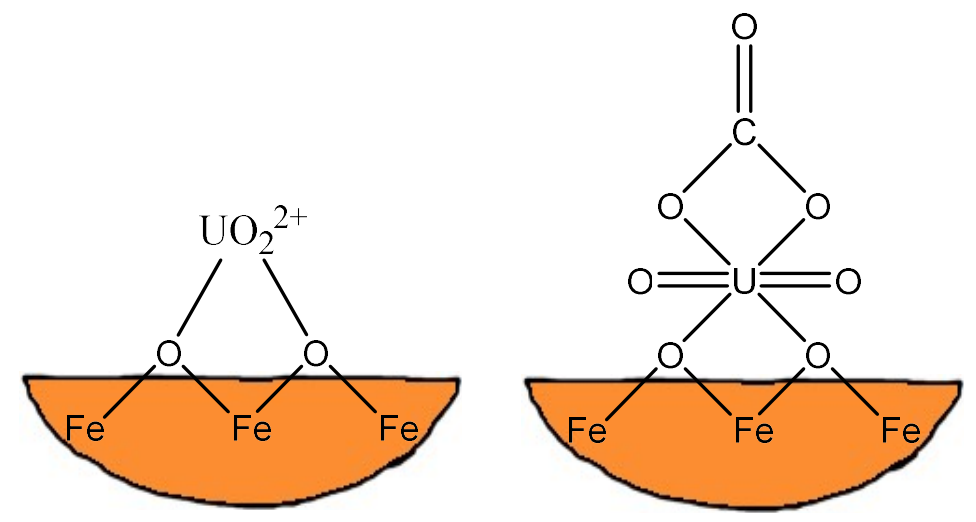

Figure 1.3 Surface complexation of uranium on goethite.

\subsubsection{Microbe-uranium interactions}

Microorganisms are ubiquitous in nature. They can influence in the environmental behavior of many elements including uranium through various processes such as reduction-oxidation reactions, biosorption, bioaccumulation, and biomineralization. In particular, reduction-oxidation reactions affect the solubility and mobility of uranium. For instance, microorganisms such as Thiobacillus ferrooxidans can enzymatically catalyze the oxidation of $\mathrm{U}(\mathrm{IV})$ to $\mathrm{U}(\mathrm{VI})$ in aerobic environments in order to obtain energy for the fixation of $\mathrm{CO}_{2}$ (Eq. 1.5 and 1.6) (DiSpirito and Tuovinen, 1982). Other microorganisms such as Thiobacillus denitrificans and Geobacter metallireducens couple the oxidation of $\mathrm{U}(\mathrm{IV})$ to the reduction of nitrate under anaerobic conditions (Beller, 2005; Finneran et al., 2002). However, the accumulation of dissimilatory nitrate reduction intermediates creates a highly oxidizing environment that leads to the reoxidation and mobilization of previously reduced U(IV) (Senko et al., 2002).

$$
\begin{aligned}
& 4 \mathrm{Fe}^{2+}+\mathrm{O}_{2}+4 \mathrm{H}^{+} \stackrel{\text { T. ferrooxidans }}{\longrightarrow} 4 \mathrm{Fe}^{3+}+2 \mathrm{H}_{2} \mathrm{O} \\
& \mathrm{UO}_{2(\mathrm{~s})}+2 \mathrm{Fe}^{3+} \rightarrow 2 \mathrm{Fe}^{2+}+\mathrm{UO}_{2}^{2+}{ }_{(\mathrm{aq})}
\end{aligned}
$$


Dissimilatory Fe(III)-reducing bacteria (Geobacter spp. and Shewanella spp.) and sulfate-reducing bacteria (Desulfovibrio spp.) (Lovley and Phillips, 1992; Lovley et al., 1991), acid-resistant bacteria (Salmonella subterranean sp. nov.) (Shelobolina et al., 2004), and fermentative bacteria (Clostridium spp.) (Francis et al., 1994) can enzymatically reduce U(VI) to U(IV) under anaerobic conditions. Several studies have found that the enzyme responsible for $\mathrm{U}(\mathrm{VI})$ reduction is cytochrome $\mathrm{c}_{3}$. The reduction process requires the presence of hydrogen or organic compounds as electron donors to convert the soluble U(VI) to the relative insoluble U(IV) state (Eq. 1.7 an 1.8) (Lovley et al., 1993; Payne et al., 2002). In addition, Lloyd et al. (2002) showed that U(VI) reduction is not mediated by proteins located on the cell surface but, rather, occurs via an intracellular electron transfer chain that terminates in the cytoplasmic membrane. Nonetheless, when biologically reduced U(IV) is exposed to $\mathrm{O}_{2}, \mathrm{Fe}(\mathrm{III})$, and $\mathrm{NO}_{3}^{-}$, it is susceptible to reoxidation to U(VI) (Ginder-Vogel et al., 2006; Komlos et al., 2008; Senko et al., 2002).

$$
\begin{aligned}
& \mathrm{UO}_{2}^{2+}{ }_{(\mathrm{aq})}+\mathrm{H}_{2} \rightarrow \mathrm{UO}_{2(\mathrm{~s})}+2 \mathrm{H}^{+} \\
& 2 \mathrm{UO}_{2}^{2+}{ }_{(\mathrm{aq})}+\mathrm{CH}_{2} \mathrm{O}+\mathrm{H}_{2} \mathrm{O} \rightarrow 2 \mathrm{UO}_{2(\mathrm{~s})}+\mathrm{CO}_{2}+4 \mathrm{H}^{+}
\end{aligned}
$$

Biosorption is another form of interaction between uranium and microorganisms. The cell surface of microorganisms contains a diversity of functional groups that include carboxyl, amine, hydroxyl, and phosphate. These functional groups are in contact with the aqueous phase and can electrostatically attract and bind uranium to the cell surface. Several studies have found that phosphates and carboxyl groups are the main functional groups involved in the binding of U(VI) (Francis et al., 2004; Haas et al., 2001; Strandberg et al., 1981). Also, intracellular accumulation of uranium caused 
by membrane permeability has been observed in microorganisms even though uranium does not play an essential biological function (Merroun and Selenska-Pobell, 2008).

Other studies have found that microorganisms can catalyze the precipitation of U(VI) in aerobic conditions. During the growth stage, bacteria such as Citrobacter sp. (Macaskie et al., 1994), Sphingomonas sp. BSAR-1 (Nilgiriwala et al., 2008), Rahnella sp., and Bacillus sp. (Martinez et al., 2007) release inorganic phosphate to the surrounding media. The release of inorganic phosphate can promote the precipitation of $\mathrm{U}(\mathrm{VI})$ via the formation of uranyl phosphate solid phases.

Humic substances can enhance the bioreduction of U(VI). Humic substances, which are organic compounds originating from the decomposition of plants and animal residues, have the ability to accept electrons from microorganisms such as Shewanella putrefaciens $\mathrm{CN} 32$ and serve as electron mediators or shuttles by donating electrons to U(VI) (Gu and Chen, 2003). However, it has also been found that U(IV) complexed with humic substances can be reoxidized when exposed to $\mathrm{O}_{2}$ (Gu et al., 2005).

\subsubsection{Aquatic environment}

Uranium is introduced in waters by leaching from rocks and soils. In water, the most stable form of $\mathrm{U}(\mathrm{VI})$ is the $\mathrm{UO}_{2}^{2+}$, which has a linear structure and is surrounded by five equatorial water molecules. Since U(VI) is considered to be a Lewis acid and a hard electron acceptor, it tends to form complexes with hard bases in the order of $\mathrm{CO}_{3}^{2-}$ $>\mathrm{OH}^{-}>\mathrm{F}^{-}, \mathrm{HPO}_{4}^{2-}>\mathrm{SO}_{4}^{2-}>\mathrm{Cl}^{-}, \mathrm{NO}_{3}^{-}$(Langmuir, 1997). In general, only the carbonates and hydroxides form strong complexes with $\mathrm{U}(\mathrm{VI})$, resulting in an enhancement of U(VI) solubility and mobility (Ginder-Vogel and Fendorf, 2007). Also, 
humic substances and other organic molecules form complexes with U(VI). For instance, water soluble compounds with low molecular weight such as fulvic acids and polysaccharides have the ability to complex with $\mathrm{U}(\mathrm{VI})$, increasing its mobility. On the other hand, high molecular weight compounds such as humic acids that complex with U(VI) either settle out from the aqueous phase or are unable to pass through the porous solid matrix, limiting its mobility (Koch-Steindl and Pröhl, 2001).

Coordination with $\mathrm{U}(\mathrm{VI})$ occurs exclusively in the equatorial plane by four, five, and six coordinating ligands. The equatorial coordination is favored because the axial oxygen atoms of $\mathrm{UO}_{2}^{2+}$ repel coordination ligand atoms, forcing the ligands to be in a plane perpendicular to the axis of the ion. X-ray absorption fine structure spectroscopy studies have shown that coordination by five ligands is found in the presence of water molecules (Allen et al., 1997). Coordination by four ligands is seen for hydroxide in strongly alkaline conditions, and in the presence of sterically demanding ligands (Wahlgren et al., 1999). The axial oxygen atoms of $\mathrm{UO}_{2}^{2+}$ do not coordinate to another cation as a ligand, but they might form hydrogen bonds with water. On the other hand, equatorial ligand atoms serve as terminal and bridging ligands to form polymeric species.

In water, $\mathrm{U}(\mathrm{VI})$ undergoes strong hydrolysis. At $\mathrm{pH} \leq 5, \mathrm{UO}_{2}^{2+}$ is the most prevalent species. An increase in $\mathrm{pH}$ leads to the hydrolysis of $\mathrm{UO}_{2}^{2+}$ and the formation of mono- and poly-nuclear species (Figure 1.4). Different spectroscopy techniques have confirmed the formation of $\left(\mathrm{UO}_{2}\right) \mathrm{OH}^{+},\left(\mathrm{UO}_{2}\right)_{2}(\mathrm{OH})_{2}^{2+},\left(\mathrm{UO}_{2}\right)_{3}(\mathrm{OH})_{5}^{+}$(Quilès and Burneau, 2000). At basic conditions, thermodynamic calculations predict the dominance 
of the uranyl tricarbonato complex $\mathrm{UO}_{2}\left(\mathrm{CO}_{3}\right)_{3}^{4-}$ with the additional formation of $\mathrm{UO}_{2}\left(\mathrm{CO}_{3}\right)_{3}^{2-}$.

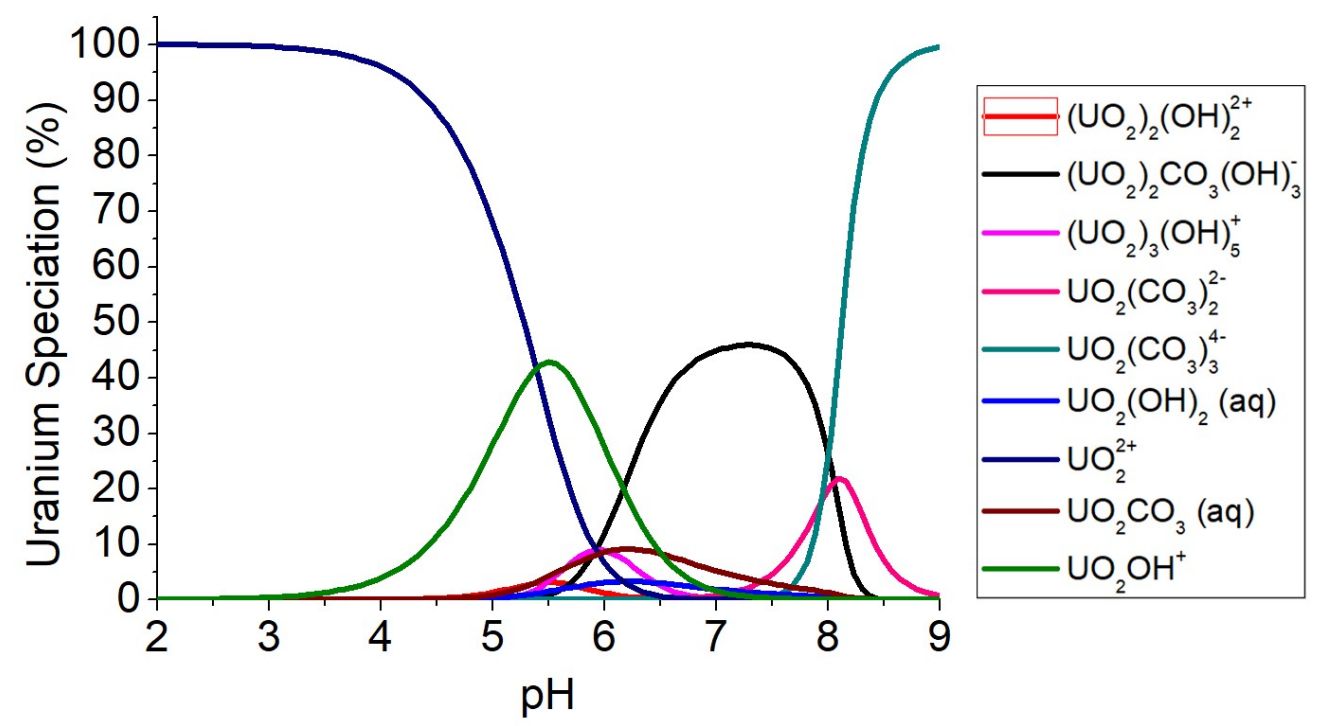

Figure 1.4 (a) Speciation of $U(V I)\left(C_{i}=0.5 \mathrm{mg} \mathrm{L}^{-1}\right)$ as a function of $\mathrm{pH}$ was created by using Geochemist's Workbench $\left(\mathrm{P}_{\mathrm{CO} 2}=10^{-3.5}\right.$ atm and $\left.\mathrm{T}=25^{\circ} \mathrm{C}\right)$.

Müller et al. (2008) investigated U(VI) speciation at the micromolar range under ambient atmospheric conditions using attenuated total reflection Fourier-transform infrared spectroscopy. The study revealed the presence of monomeric U(VI) hydroxo species at $\mathrm{pH} \geq 2.5$, which indicates discrepancies with the predicted speciation obtained by thermodynamic calculations where $\mathrm{UO}_{2}^{2+}$ is expected to dominate. Also, the predicted dominance of $\mathrm{UO}_{2}\left(\mathrm{CO}_{3}\right)_{3}^{4-}$ at $\mathrm{pH} \geq 8$ was not able to be confirmed by the study.

Generally, thermodynamic constants of U(VI) species in aqueous solution are obtained from non-structural techniques such as potentiometric titrations and solubility measurements (Guillaumont et al., 2003). Also, infrared and Raman spectroscopy studies have been used to confirm the presence of U(VI) species, but these studies have 
been done in the millimolar range (Nguyen-Trung et al., 2000; Quilès and Burneau, 2000). On the other hand, Müller et al. (2008) found that U(VI) speciation changes from the millimolar range obtained by thermodynamic calculations to the micromolar range obtained by infrared spectroscopy. There are discrepancies between the calculated predictions by using the thermodynamic database and the spectroscopic findings of Müller et al. (2008). Therefore, further investigations should verify that a change in $\mathrm{U}(\mathrm{VI})$ speciation occurs from millimolar to the micromolar range.

\subsection{Exposure and toxicity of uranium}

The toxicity of uranium comes from its chemical and, to a lesser extent, its radiological properties. Uranium is a weakly radioactive element that decays slowly by emitting alpha particles. Alpha particles have very limited penetrating power because their large masses cause them to move slowly and interact strongly with any material they pass through. As a result, alpha particles lose energy very quickly. In the case uranium enters the human body, the main concern is the long term dose of radiation to organs and its decay products (Bleise et al., 2003). However, no human cancer has been reported as a direct result of uranium exposure (Keith et al., 2013). With respect to its chemical toxicity, uranium has a detrimental effect in organs such as the kidneys (Vicente-Vicente et al., 2010). Approximately, 1-2\% of uranium ingested is adsorbed in the gastrointestinal tract. Once adsorbed, uranium is redistributed by entering the bloodstream and forming complexes with citrate, bicarbonate, and protein plasma. Some uranium in blood is filtered through the kidneys and leaves the body in urine within 24 hours, but the rest is distributed to the bones, kidneys, and liver (Weir, 2004). 
Kidneys are the most susceptible organs to uranium toxicity. Kidney damage has been observed in humans and animals after inhaling or ingesting uranium. According to Kathren and Burklin (2008), humans are the least sensitive to acute and chronic toxic effects of uranium as compared to other mammalian species. Experimental work and clinical studies with rats have shown that uranium can cause damage to proximal tubular membrane (Banday et al., 2008). In humans, few cases of acute uranium overexposure have been documented, but there is evidence of altered glomerular filtration rates. Nonetheless, further studies should be performed because there are still uncertainties about the nephrotoxic effects from chronic exposure of uranium in humans, and kidney damage may reverse with time (Vicente-Vicente et al., 2010).

Research done by the World Health Organization (WHO) and the U.S. Environmental Protection Agency (EPA) have set the safety levels for uranium in drinking water at $30 \mu \mathrm{g} \mathrm{L}^{-1}$ (EPA, 2001; WHO, 2012).

\subsection{Case study: Savannah River Site}

Uranium is one of the key contaminants of concern in groundwater as a result of past nuclear processing activities at the Department of Energy (DOE) facilities such as the Savannah River Site (SRS) in Aiken, South Carolina. SRS was one of the major nuclear processing facilities during the Cold War where plutonium was produced (Evans et al., 1992). As a result of that activity, large amounts of radioactive, acidic wastewater were discharged into earthen seepage basins in the SRS F-Area. From 1955 to 1988 , the F-Area seepage basin received approximately $7 \times 10^{6} \mathrm{~m}^{3}$ of acidic waste.

The wastewater contained radionuclides such as uranium $\left({ }^{235} \mathrm{U}\right.$ and $\left.{ }^{238} \mathrm{U}\right)$, plutonium 
$\left({ }^{238} \mathrm{Pu}\right.$ and $\left.{ }^{239} \mathrm{Pu}\right)$, tritium $\left({ }^{3} \mathrm{H}\right)$, strontium $\left({ }^{90} \mathrm{Sr}\right)$, iodine $\left({ }^{129} \mathrm{I}\right)$, americium $\left({ }^{241} \mathrm{Am}\right)$, and cesium $\left({ }^{137} \mathrm{Cs}\right)$. Also, large quantities of $\mathrm{HNO}_{3}$ and $\mathrm{NaOH}$ were discharged into the basins (Denham and Vangelas, 2008). At that time, it was thought that most of the radionuclides would seep into the subsurface and bind to the soil without significant migration with the groundwater. Several radionuclides including plutonium isotopes and ${ }^{137} \mathrm{Cs}$ sorbed to the soil beneath the basins, but other radionuclides such as uranium isotopes, ${ }^{90} \mathrm{Sr}$, ${ }^{129} \mathrm{I}$, and ${ }^{3} \mathrm{H}$ migrated down, contaminating the groundwater. The groundwater remains acidic with $\mathrm{pH}$ values between 3 in the center of the plume and 5.4 upgradient of the basins (Bea et al., 2013).

One of the remediation actions implemented at SRS was the pump-treat-reinject system. The pump-treat-reinject system was implemented from 1997 to 2003 to remove contaminants by precipitation/flocculation, reverse osmosis, and ion exchange (Wan et al., 2012). However, the pump-treat-reinject system became inefficient because of the high cost to operate and maintain. In addition, it produced radioactive solid waste that required disposal in a safe manner. The pump-treat-reinject system was replaced in 2004 by a funnel-and-gate system. With the funnel-and-gate system, walls were installed to direct the groundwater flow into a treatment zone, called the gate. At the gate, an alkaline solution was injected periodically to neutralize the acidic conditions of the groundwater. The funnel-and-gate system attenuated the migration of ${ }^{238} \mathrm{U}$ and ${ }^{90} \mathrm{Sr}$ as these contaminants were either sorbed to the sediments or formed precipitates (Denham and Vangelas, 2008). Despite these efforts to clean up the site and remediate the groundwater, uranium concentrations remain 10-1000 times higher than the drinking water standards (30 $\left.\mu \mathrm{g} \mathrm{L}^{-1}\right)$ (Wan et al., 2011). 


\subsection{Humic substances}

Humic substances are ubiquitous in the environment. They are found in soils, fresh water, marine water, and both marine and lacustrine sediments (Killops et al., 2004). Humic substances consist of complex organic molecules with no definite structure as they are formed from the biogeochemical degradation of dead biomass. Their structure is generally described as a hydrophobic framework of aromatic rings linked by carbon chains that possess different functional groups (Figure 1.5).

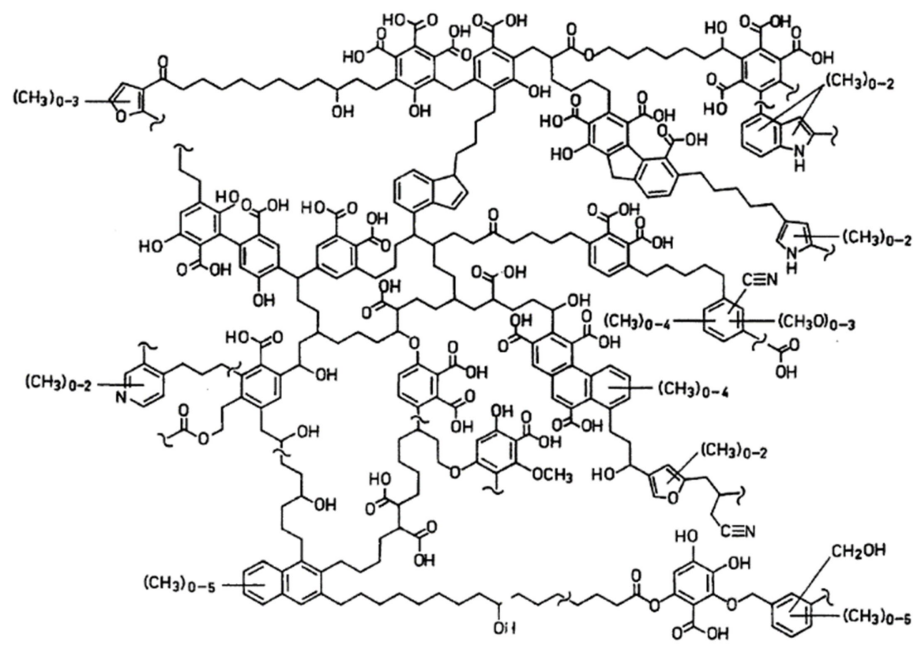

Figure 1.5 Proposed structure of humic substances from Schulten and Schnitzer (1993).

Different concepts have been proposed to describe the nature and the mechanisms of synthesis of humic substances. One of the oldest views described humic substances as biopolymeric compounds as early as 1835 by Jöns Jacob Berzelius. In the biopolymer concept, humic molecules were viewed as a polydisperse, long chain, randomly coiled macromolecules. At low ionic strength or basic conditions, humic molecules would adopt an elongated shape, while at high ionic strength or acidic conditions, humic molecules would adopt a coil shape. Many scientists have supported 
the biopolymer concept and proposed different theories such as the ligno-protein theory and the phenol/quinone dimer theory in order to explain the formation of humic substances through polymerization and condensation reactions using lignin and protein compounds (Flaig et al., 1975; Stevenson, 1982; Swift, 1999). In 1986, Wershaw introduced the micellar concept, claiming that humic substances can adopt a molecular structure in the form of micelles through the spontaneous aggregation of small broken fragments in the form of amphiphiles (compounds having both hydrophilic and hydrophobic characteristics) (Wershaw, 1986, 1999). In 2002, Piccolo introduced the supramolecular theory. The supramolecular concept describes the formation of humic substances as a spontaneous self-aggregation of small molecules into a supramolecular conformation. Several studies have indicated that humic substances might be composed of smaller and heterogeneous subunits held by hydrophobic forces and hydrogen bonds (Piccolo et al., 2001; Simpson, 2002; Sutton and Sposito, 2005). For instance, Piccolo et al. (2001) found that by adding an organic acid, the apparent aggregation of humic molecules was disrupted. Simpson (2002) observed both aggregation and disaggregation behavior of smaller size molecules in humic substances via nuclear magnetic resonance studies (NMR). However, other studies have identified different issues with the methodology used by Piccolo et al. (2001) to support his supramolecular concept. One of the issues deals with the sample pretreatment that could have led to the breakdown of humic molecules into smaller fragments by hydrolysis (Tan, 2014). There is also the matter of the anionic nature of humic substances. If it is assumed that humic substances possess a supramolecular conformation, it should be expected a disaggregation of the small subunits at basic conditions caused by like-charge repulsion 
(von Wandruszka, 2000). However, disaggregation of humic substances was not observed at basic conditions in Piccolo's results. A recent concept called the nanotube membrane concept was introduced by Tan in 2011. In his study, he noticed that fulvic acid was characterized by a network structure of nanotubes shown by scanning electron micrographs. He proposed that, through the decomposition of biopolymers in plant and animal tissues, nanoparticles are produced. Nanoparticles can self-assemble and form a network structure of nanotubes (Tan, 2011a, b). In summary, the nature of humic substances has been studied for a long time, but their nature and formation is still a subject of debate.

Generally, humic substances are classified on the basis of their solubilities as fulvic acids (FA), humic acids (HA), and humin. Fulvic acids are the fraction that is soluble at all $\mathrm{pH}$ values. They have a lower molecular weight ranging from 500 to 2000 Da and a higher content of carboxyl and phenolic groups. Humic acids are the fraction that is soluble under alkaline conditions but precipitates at $\mathrm{pH}<2$. They are known to have a high molecular weight ranging from 2 to $1300 \mathrm{kDa}$ and a higher content of aromatic rings. Humin is the fraction that is insoluble at all $\mathrm{pH}$ values, and it is known to be the most resistant fraction to biodegradation (von Wandruszka, 2000).

\subsubsection{Interaction of humic substances with uranium}

Humic substances have a diversity of functional groups. The nature of the major functional groups present in humic substances has been well characterized, which include carboxyl, phenols, ketones, aldehyde, aromatic rings, and aliphatic chains. The wide variety of functional groups allows humic substances to form complexes with 
metals including radionuclides (Lubal et al., 2000; Pacheco and Havel, 2001). Several studies have found that uranium is strongly retained in humic-rich environments such as peats and bogs (González A et al., 2006; Regenspurg et al., 2010). In general, carboxyl groups are thought to be the main functional groups that contribute to the complexation with uranium (Schmeide et al., 2003). Since carboxyl groups have low $\mathrm{p} K$ values ( 4), the deprotonation of carboxyl groups facilitates the interaction with positively charged U(VI) species. Besides carboxyl groups, other functional groups such as phenol and amino groups are believed to provide additional complexation sites for U(VI) to bind. Pompe et al. (2000) demonstrated that, by blocking phenolic $\mathrm{OH}$ groups, the complexation behavior between humic substances and $\mathrm{U}(\mathrm{VI})$ changed. It is believed that phenolic $\mathrm{OH}$ group serves to form intermolecular hydrogen bonds between the hydrogen atom of the phenolic $\mathrm{OH}$ group and the oxygen atom of uranyl ions (Kremleva et al., 2009; Schmeide et al., 2003). Other studies investigated the role of sulfur and nitrogen functionalities in humic substances on the complexation of U(VI). The studies found that sulfur and nitrogen only play a minor role in $\mathrm{U}(\mathrm{VI})$ complexation compared to carboxyl groups (Kremleva et al., 2012; Raditzky et al., 2010; Sachs et al., 2010).

Although positively charged U(VI) species interact strongly with carboxyl groups in humic substances, it is less clear that other U(VI) species interact in the same way with humic substances. Hydrolysis and carbonate complexation of U(VI) can affect the interactions of $\mathrm{U}(\mathrm{VI})$ species and with humic substances. For instance, Pashalidis and Buckau (2007) investigated the ternary complex $\mathrm{UO}_{2}(\mathrm{OH}) \mathrm{HA}$ formed by the reaction of $\mathrm{UO}_{2} \mathrm{OH}^{+}$with humic acid (HA), and the study found that the complexation constant 
$(\log \beta)$ of the ternary complex (Eq. 1.10) was higher than the complexation constant between humic acid and the non-hydrolyzed $\mathrm{UO}_{2}^{2+}$ (Eq. 1.9). Also, studies found that humic acid can form ternary complexes in the presence of carbonate species (Eq. 1.11) (Steudtner et al., 2011b).

$$
\begin{array}{ll}
\mathrm{UO}_{2}^{2+}+\mathrm{HA} \rightleftarrows \mathrm{UO}_{2} \mathrm{HA} & \log \beta=6.21 \mathrm{~mol}^{-1} \\
\mathrm{UO}_{2} \mathrm{OH}^{+}+\mathrm{HA} \rightleftarrows \mathrm{UO}_{2}(\mathrm{OH}) \mathrm{HA} & \log \beta=6.941 \mathrm{~mol}^{-1} \\
\mathrm{UO}_{2}\left(\mathrm{CO}_{3}\right)_{3}^{4-}+\mathrm{HA} \rightleftarrows \mathrm{UO}_{2}\left(\mathrm{CO}_{3}\right)_{2} \mathrm{HA}^{4-}+\mathrm{CO}_{3}^{2-} & \log \beta=2.831 \mathrm{~mol}^{-1}
\end{array}
$$

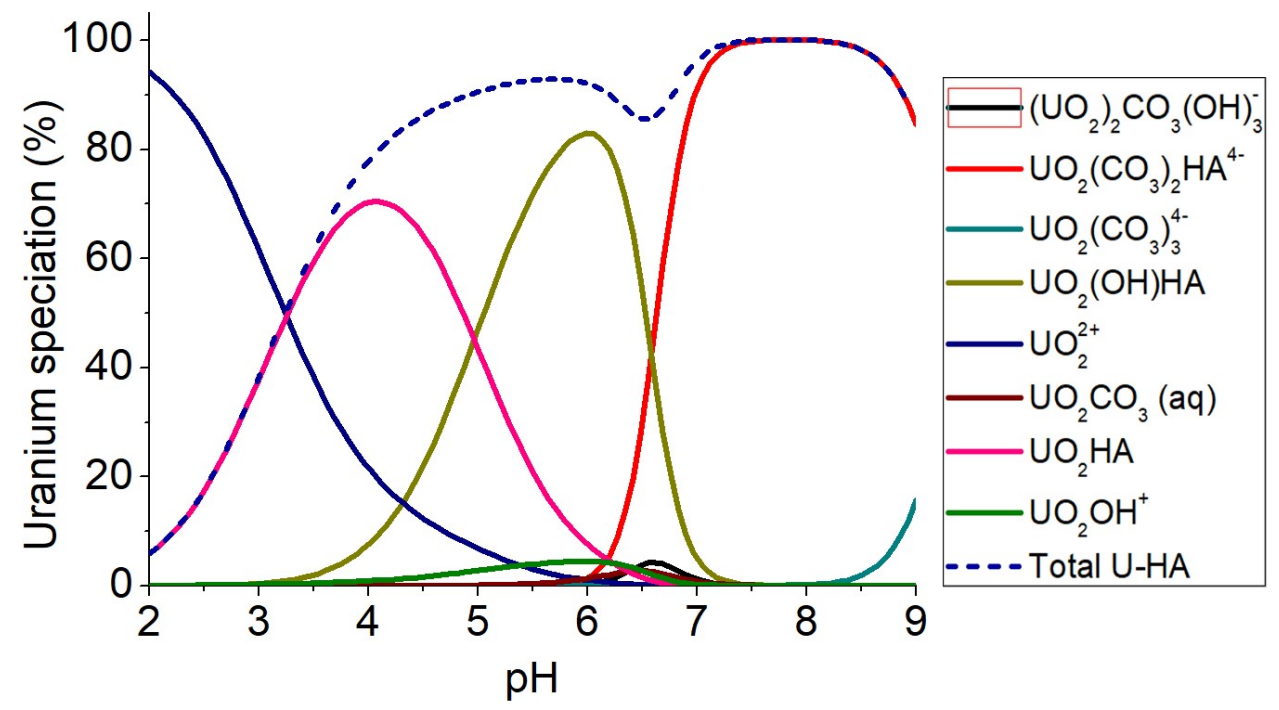

Figure 1.6 Aqueous speciation of U(VI) in the presence of humic acid (HA) was created by using Geochemist's Workbench using the following conditions: $\mathrm{U}(\mathrm{VI})=0.5 \mathrm{mg} \mathrm{L}^{-1}$; $\mathrm{HA}=10 \mathrm{mg} \mathrm{L}^{-1} ; \mathrm{P}_{\mathrm{CO} 2}=10^{-3.5} \mathrm{~atm}$.

The calculated predictions by using the thermodynamic database (thermo-minteq) updated by Katsenovich et al. (2018) and the complex stability constants in Eq. 1.9-1.11 indicate that uranyl-humic complexes dominate from $\mathrm{pH} 4$ to 9 (Figure 1.6). The uranyl ion dominates at $\mathrm{pH}$ below 3 . As the $\mathrm{pH}$ is increased up to 6 , the binary $\mathrm{UO}_{2} \mathrm{HA}$ and ternary $\mathrm{UO}_{2}(\mathrm{OH}) \mathrm{HA}$ complexes begin to dominate. Above $\mathrm{pH} 6$, the $\mathrm{UO}_{2}\left(\mathrm{CO}_{3}\right)_{2} \mathrm{HA}^{4-}$ complex becomes increasingly important. 


\subsection{Research gaps and significance of the present study}

Previous studies have shown that $\mathrm{U}(\mathrm{VI})$ species can be reduced to less soluble U(IV) species using a sulfate-reducing bacterium (Desulfovibrio desulfuricans) and an iron-reducing bacterium (Shewanella alga) when organic carbon (lactate and acetate) is injected. The injection of organic carbon is performed to stimulate the microbial reduction of U(VI) species into solid forms (Ganesh et al., 1997). Nevertheless, the disadvantage of using organic carbon is that its supply increases bicarbonate concentration as a result of microbial respiration and promotes the formation of soluble $\mathrm{U}(\mathrm{VI})$ carbonates. In addition, it is required to maintain permanent reducing conditions because $\mathrm{U}(\mathrm{IV})$ can be easily reoxidized to $\mathrm{U}(\mathrm{VI})$ when oxidizing conditions return (Tokunaga et al., 2008; Wan et al., 2005; Wan et al., 2008). Other remediation techniques have focused on the precipitation of $\mathrm{U}(\mathrm{VI})$ using phosphates or vanadates. Phosphates and vanadates can form precipitates with $\mathrm{U}(\mathrm{VI})$ but only at neutral $\mathrm{pH}$ (Tokunaga et al., 2009). To date, a reliable and sustainable remediation method to control $\mathrm{U}(\mathrm{VI})$ mobilization in the environment has not been developed for acidic conditions.

Křepelová et al. (2006) and Wan et al. (2011) studied U(VI) sorption onto kaolinite and goethite minerals and found that, in acidic conditions, $\mathrm{U}(\mathrm{VI})$ sequestration increased in the presence of laboratory-grade humic acid. In fact, Petrović et al. (1999) proposed that humic substances could be used to remediate sites contaminated with heavy metals by creating permeable reactive barriers. Permeable reactive barriers can be created by either injecting an aqueous solution of humic substances followed by the injection of an acid or salt solution to cause the precipitation of humic substances or by 
employing humic derivatives that more strongly adhere to mineral surfaces (Oeste and Kempfert, 1996; Perminova et al., 2012). In the case of an acidic plume, remediation could be accomplished by simply injecting an aqueous solution of humic substances.

Previous studies have shown that refined humic acid is effective in immobilizing U(VI) under acidic conditions (Křepelová et al., 2006; Wan et al., 2011). However, the use of refined humic acid as an amendment for full-scale remediation deployment can be expensive. Equivalent results might be achieved by using a low-cost unrefined humic substance. Therefore, the present study explores the use of an unrefined humic substance (Huma-K) and its sorption properties on sediments to evaluate the ability of Huma-K to act as a coating treatment in acidic aquifers for U(VI) sequestration.

\subsection{Huma-K}

In the present study, Huma-K was used as the source of humic substances. Huma$\mathrm{K}$ is a commercially available product sold by Land and Sea Organics located in Modesto, California, for improving agricultural soils; it is inexpensive and easily obtained in the quantities required for most groundwater remediation purposes. It contains more than $86 \%$ of humic substances extracted from Leonardite. Leonardite is a low ranking coal formed by the natural weathering and oxidation of lignite. The extraction of humic substances from Leonardite is performed in water with the addition of an alkaline solution of either sodium hydroxide $(\mathrm{NaOH})$ or potassium hydroxide $(\mathrm{KOH})$ to extract the soluble humic substances. Potassium hydroxide is often used to extract the humic substances because the extraction yield is higher compared to sodium hydroxide. The higher extraction yield of $\mathrm{KOH}$ is attributed to the smaller hydrated 
ionic radius of $\mathrm{K}^{+}(3000 \AA)$ compared to $\mathrm{Na}^{+}(4500 \AA)$, which allows $\mathrm{K}^{+}$to have more inter and intramolecular interactions to disrupt the bonds between humic substances and inorganic minerals present in the coal (Fong et al., 2006). The resulting extraction liquid, which contains humic and fulvic acid in their salt form, is dried to produce the amorphous crystalline black powder/shiny flakes known as Huma-K (Figure 1.7).
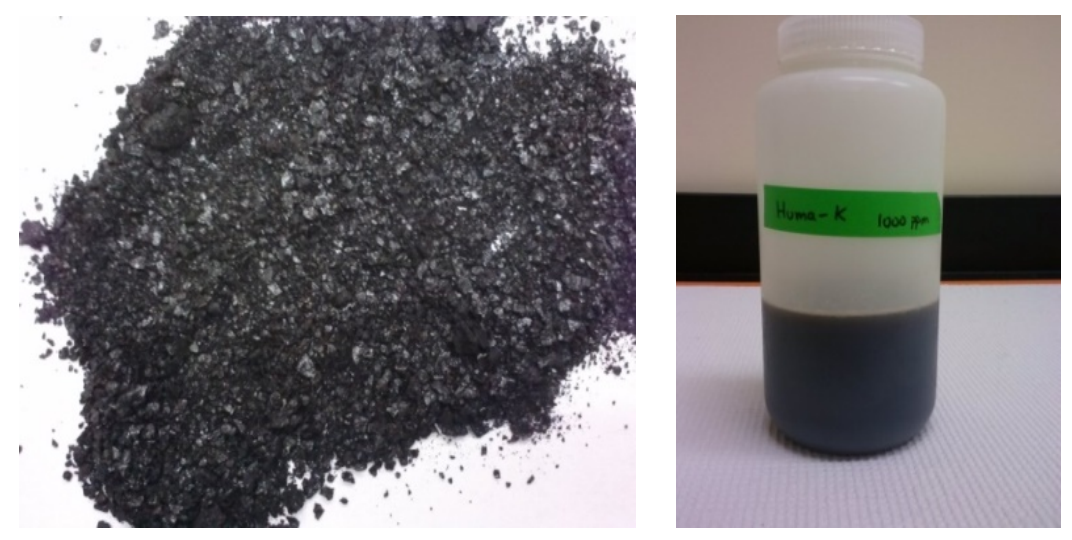

Figure 1.7 Huma-K dried (left) and dissolved in deionized water (right).

\subsection{Research objectives and hypothesis}

The goal of the present study was to determine if the low-cost unrefined humic substance known as Huma-K, which contains humic/fulvic acids of different molecular weights, can be used to facilitate $\mathrm{U}(\mathrm{VI})$ sorption to control the mobility of $\mathrm{U}(\mathrm{VI})$ in acidic groundwater (Figure 1.8). The following objectives for the present study were investigated:

The first objective was to perform a detailed characterization of SRS sediment and Huma-K by using X-ray diffraction (XRD), scanning electron microscopy equipped with energy dispersive spectroscopy (SEM-EDS), X-ray fluorescence (XRF), Fouriertransform infrared spectroscopy (FTIR), and potentiometric titrations. These techniques 
helped in the identification of the mineral and elemental composition of SRS sediment as well as the main functional groups present in Huma-K.

The second objective was to understand the sorption and precipitation behavior of Huma-K with sediments relevant to an acidic plume at SRS. Since there is a lack of studies investigating the sorption properties of unrefined materials on sediments, the present work provided a new perspective with respect to the interactions of complex humic materials with mineral surfaces by deconvoluting sorption, precipitation, and diffusion processes. It was hypothesized that Huma-K sorption onto sediments would be favorable because humic substances have a diversity of functional groups that can interact with mineral surfaces. However, the extent of sorption will vary depending on mineral composition, $\mathrm{pH}$, and Huma-K concentration.

The third objective was to study the influence of Huma-K on the sorption of U(VI) onto SRS sediment to evaluate whether or not Huma-K could sequester U(VI) under the environmental conditions present at SRS. It was hypothesized that sedimentbound Huma-K would provide additional binding sites for $\mathrm{U}(\mathrm{VI})$, facilitating the removal of $\mathrm{U}(\mathrm{VI})$ from the groundwater in acidic conditions. As long as the conditions remain acidic, it is hypothesized that uranyl-humic complexes would tend to remain bound to the sediment. However, if conditions change to more near-neutral conditions, uranyl-humic complexes might dissolve from the sediment, enhancing the migration of uranium. 


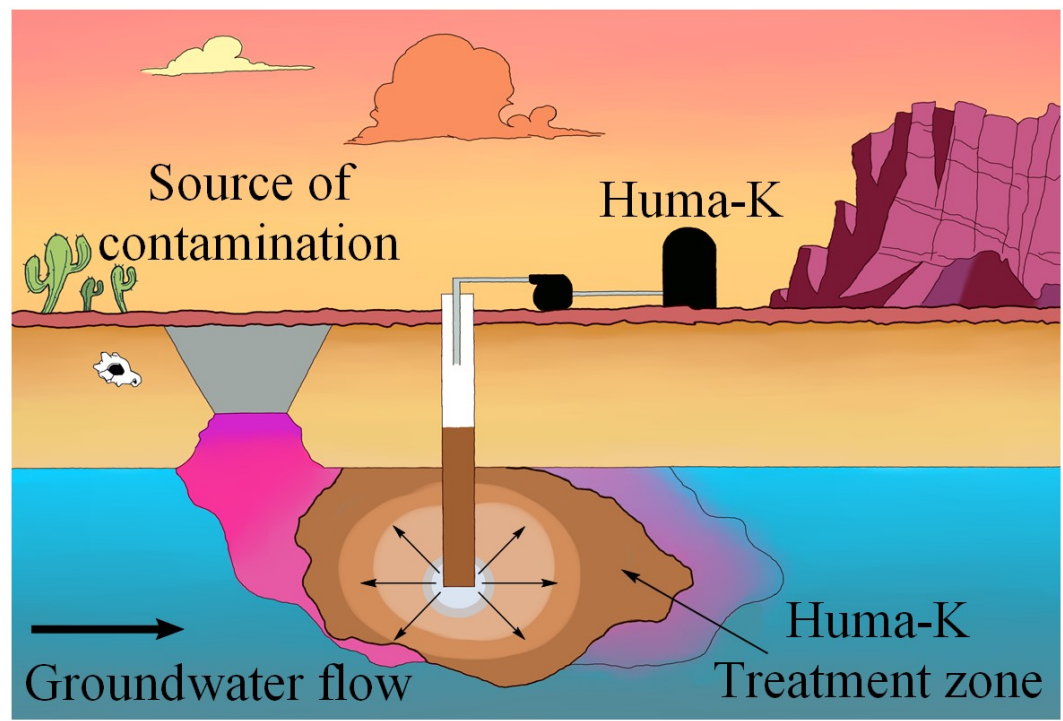

Figure 1.8 Huma-K treatment zone. 
Chapter 2. Evaluating the sorption behavior of Huma-K on SRS sediment

The work described in this chapter has been modified from Gonzalez-Raymat et al. (2018); Journal of Environmental Management, 212: 210-218. 


\begin{abstract}
The present study explores a novel application of Huma-K, a commercially available unrefined humic substance, as a promising low-cost source of organic matter for in situ remediation of contaminated acidic groundwater plumes. In situ remediation can be achieved by creating a humic-rich coating on the surface of minerals, which can enhance the sorption of contaminants from groundwater. Huma-K was characterized by means of scanning electron microscopy equipped with energy dispersive spectroscopy, Fourier-transform infrared analysis, and potentiometric titrations. Batch experiments were performed to investigate the sorption-desorption behavior of Huma-K and to evaluate what conditions ( $\mathrm{pH}$, contact time, and initial Huma-K concentration) affect these processes upon injection into aquifer sediments. As evidenced by potentiometric titrations, Huma-K possesses functional groups that have an acidic nature, with $\mathrm{p} K$ values in the range of 4-6 (carboxylic) and 9-10 (phenolic). Sorption, homogeneous precipitation, and surface-induced precipitation seem to be favored in the presence of sediment at $\mathrm{pH} 4$, where there is less deprotonation of acidic functional groups. As the $\mathrm{pH}$ is increased, functional groups become negatively charged, leading to electrostatic repulsion and dissolution of Huma-K from sediment. Kinetic experiments indicate that Huma-K sorption is a slow-rate process. The enhanced sorption of Huma-K in acidic conditions suggests that it may be used to create a subsurface treatment zone in acidic aquifers for the sequestration of contaminants such as uranium. The treatment zone will persist as long as the $\mathrm{pH}$ does not increase sufficiently to cause sediment-bound Huma$\mathrm{K}$ to be released, remobilizing aqueous contaminants.
\end{abstract}




\subsection{Introduction}

The role of nuclear energy in the production of electricity has increased globally from 684 billion kilowatt hour (kWh) in 1980 to 2440 billion kWh in 2015 (EIA, 2015). Since uranium provides the fuel for nuclear reactors, its demand has increased as well. However, mining of uranium and disposal of waste from the processing of uranium for nuclear energy production has created groundwater plumes, which are sometimes acidic. One source of contamination that comes from mining operations is acidic mine drainage. The residual sulfide minerals (such as pyrite) undergo oxidation upon exposure to atmospheric oxygen, generating acidic conditions that can increase uranium mobility. For instance, acidic waste effluents with $\mathrm{pH}$ between 1.5 and 3.5 at the Central Ran goldfield in South Africa and the Bear Creek uranium mill in Wyoming, U.S. were disposed in unlined ponds, resulting in an acidic groundwater plume (Tutu et al., 2005; Zhu et al., 2002). Another source that has led to the creation of groundwater plumes contaminated with uranium includes past nuclear weapons production activities; the U.S. Department of Energy Savannah River Site (SRS) outside Aiken, SC being one example (Denham and Vangelas, 2008).

In the past, pump-treat-reinject system was used as the conventional method for contaminated groundwater clean-up. However, pump-treat-reinject system loses effectiveness over time, has very high operational and maintenance costs, and creates secondary radioactive waste streams that need to be managed. Other remediation techniques have also been considered, including bioreduction and sequestration via injection of organic carbon to stimulate microbial reduction of uranium (VI), as well as injection of phosphates and vanadates to promote uranium precipitation (Tokunaga et 
al., 2009; Tokunaga et al., 2008). However, with these remediation techniques, there were concerns with the reoxidation of uranium (IV) and formation of soluble uranylcarbonate complexes in the treatment zones over time (Wan et al., 2008). Furthermore, insoluble uranyl-phosphate and uranyl-vanadate precipitates are formed under circumneutral conditions (Tokunaga et al., 2009; Tokunaga et al., 2012). To date, a reliable and sustainable remediation method to control uranium mobilization in the environment has not been developed for acidic conditions.

Humic substances have been recognized for some time as having a significant impact on the behavior and fate of uranium in the environment (Perminova et al., 2005). Humic substances are organic molecules formed by the microbial decomposition of plants and animal tissues. They bear functional groups such as aromatic rings, carboxyl groups, and phenols, which can interact both with metals and mineral surfaces (Philippe and Schaumann, 2014; Tipping, 2002). The interaction of humic substances with mineral surfaces may create a humic-rich coating on the surface of minerals that can enhance the sequestration of metals from aqueous solution (Perminova et al., 2005). Křepelová et al. (2006) and Wan et al. (2011) studied uranium (VI) sorption onto kaolinite and goethite minerals and found that, in acidic conditions, uranium sequestration increased in the presence of laboratory-grade humic acid. In fact, humic substances have been proposed to remediate sites contaminated with heavy metals by creating permeable reactive barriers (Petrović et al., 1999). Permeable reactive barriers can be created by either injecting an aqueous solution of humic substances followed by the injection of an acid or salt solution to cause precipitation or by employment of humic derivatives that more strongly adhere to the mineral surfaces (Oeste and 
Kempfert, 1996; Perminova et al., 2012). In the case of an acidic plume, remediation can be accomplished by simply injecting an aqueous solution of humic substances.

Previous studies have shown that refined humic acid is effective in immobilizing uranium at acidic conditions (Křepelová et al., 2006; Wan et al., 2011). However, the use of refined humic acid as an amendment for full-scale remediation deployment can be expensive. Equivalent results might be achieved by using a low-cost unrefined humic substance. Therefore, the present study explores the use of unrefined humic substances (Huma-K) and its sorption properties on sediments; so, they can act as a coating treatment in acidic aquifers for the sequestration of uranium. Huma-K is a commercially available product sold for improving agricultural soils; it is inexpensive and easily obtained in the quantities required for most groundwater remediation purposes. The objective of the present work was to understand the sorption and precipitation behavior of Huma-K with sediments relevant to an acidic plume at the SRS. Since there is a lack of studies investigating the sorption properties of unrefined materials on sediments, the present work will provide a new perspective with respect to the interactions of complex humic materials with mineral surfaces by deconvoluting sorption, precipitation, and diffusion processes. The research results address knowledge gaps for the successful management of groundwater plumes with contaminants such as uranium.

\subsection{Experimental methods}

\subsubsection{Materials}

Huma-K (Land and Sea Organics) was extracted from Leonardite. Clean SRS sediment used in sorption experiments (field borehole sampling FAW-1, depth interval 
21.3-27.4 m) was collected from the aquifer near the F-Area seepage basins. The collected background sediment was selected because of similarities in mineral composition with the uranium contaminated aquifer sediment. The SRS sediment was sieved (U.S. Standard Testing Sieves, Fisher Scientific), and the sediment fraction with a particle diameter $\leq 2 \mathrm{~mm}$ was retained and used throughout the experiments. For comparison reasons, quartz (Ottawa Sand Standard 20-30 mesh, Fisher Scientific), and kaolinite (Alfa Aesar) were used as reference minerals.

\subsubsection{Characterization of SRS sediment and Huma-K}

The mineral composition of SRS sediment was analyzed by using X-ray powder diffraction (XRD) via a Siemens D5000 XRD instrument. The SRS sediment fraction with a particle diameter $\leq 63 \mu \mathrm{m}$ was used for the analysis. The sample was packed gently into a sample holder by using a glass slide. Excess powder was removed from the sample holder to create a smooth surface, and the sample was carefully placed in the XRD slot. Diffraction patterns were obtained using a $\mathrm{Cu}-\mathrm{K} \alpha$ radiation source, and the data collection was carried out in the 2 -theta $(2 \theta)$ range from 10 to $80^{\circ}$ (operation mode: $\lambda=0.154 \mathrm{~nm}, 0.02^{\circ}$ step size, $3 \mathrm{~s}$ step time). The identification of the mineral phase was done by means of MATCH! 3 software, which compares the diffraction pattern of the sample with a database containing reference patterns from the International Center for Diffraction Data (ICDD).

The morphology and elemental composition of Huma-K as well as SRS sediment characteristics were investigated using X-ray fluorescence (XRF) and scanning electron microscopy equipped with energy dispersive spectroscopy (SEM-EDS). The SEM 
system used was a JOEL-5910-LV with acceleration potentials ranging from 10 to 20 $\mathrm{kV}$. A small amount of sample was placed on a stainless steel stub, and it was coated with a thin layer of gold using an SPI-Module Control and Sputter unit for 2 min. By coating the samples, it is created a conducting layer that inhibits electrostatic charge accumulation and enhances the secondary electron signal required for topographic examination in the SEM. Energy dispersive spectroscopy analysis was produced using an EDAX Sapphire detector with UTW Window controlled through Genesis software.

For Fourier-transform infrared (FTIR) analysis, a Perkin Elmer Spectrum 100 FTIR Spectrometer coupled with an attenuated total reflectance (ATR) was used to collect the spectra from 4000 to $600 \mathrm{~cm}^{-1}$ with 4 scans at a resolution of $4 \mathrm{~cm}^{-1}$. Fouriertransform infrared was used for the identification of functional groups present in Huma$\mathrm{K}$ and SRS sediment fraction with a particle diameter $\leq 63 \mu \mathrm{m}$, which were oven dried $\left(80{ }^{\circ} \mathrm{C}, 48 \mathrm{~h}\right)$ before analysis. Preliminary experiments showed a good contact of SRS sediment fraction with a particle diameter $\leq 63 \mu \mathrm{m}$ with ATR crystal for FTIR analysis. In the case of Huma-K, $10 \mathrm{mg}$ of Huma-K were mixed with $150 \mathrm{mg}$ of $\mathrm{KBr}$ (FT-IR grade, Sigma Aldrich) in order to avoid quantitative beam absorbance. Background was subtracted from each sample and spectral analysis was performed by means of Spekwin32 software.

Potentiometric titrations of Huma-K and SRS sediment were performed in order to investigate their acido-basic properties (Bourikas et al., 2006a). The SRS sediment sample of $1 \mathrm{~g}$ and Huma-K sample of $0.5 \mathrm{~g}$ were separately titrated. First, the sample was suspended in $100 \mathrm{~mL}$ of $0.01 \mathrm{M} \mathrm{NaNO}_{3}$ in a double-walled beaker kept at $25^{\circ} \mathrm{C}$. Inert atmosphere was ensured by bubbling nitrogen at constant magnetic stirring to 
avoid $\mathrm{CO}_{2}$ partitioning from air. Sodium hydroxide $(1 \mathrm{M})$ solution was added into the beaker for the adjustment of the suspension $\mathrm{pH}$ to 11 . Once the $\mathrm{pH}$ of the solution was stable, the titration was conducted by adding small aliquots of $\mathrm{HNO}_{3}$ solution $(0.1 \mathrm{M})$, and the corresponding $\mathrm{pH}$ values were recorded. At the end of the titration $(\mathrm{pH} \sim 3)$, the supernatant of the sediment suspension was collected by vacuum filtration (Whatman 542 filter paper, pore size: $2.7 \mu \mathrm{m}$ ). Sodium hydroxide solution was added into the collected liquid phase for the $\mathrm{pH}$ adjustment to 11 , which was subsequently titrated in the exact same way. The purpose of the last step was to estimate the functional groups possibly leaching out from the sediment to the supernatant. The net $\left[\mathrm{H}^{+}\right]$consumption was calculated using Eq. 2.1 at each $\mathrm{pH}$ value by subtracting the $\left[\mathrm{H}^{+}\right]$supernatant consumption (second titration) from the total $\left[\mathrm{H}^{+}\right]$consumption (first titration) (Anagnostopoulos et al., 2015; Bourikas et al., 2006b). In the case of Huma-K, the net $\left[\mathrm{H}^{+}\right]$consumption of Huma-K was calculated at each $\mathrm{pH}$ value by subtracting the $\left[\mathrm{H}^{+}\right]$ consumption of the blank solution $\left(100 \mathrm{~mL}\right.$ of $\left.0.01 \mathrm{M} \mathrm{NaNO}_{3}\right)$ from the total $\left[\mathrm{H}^{+}\right]$consumption of the suspension.

$$
\left[\mathrm{H}^{+}\right]_{\text {cons }}=\left[\mathrm{H}^{+}\right]_{\text {cons, susp }}-\left[\mathrm{H}^{+}\right]_{\text {cons, blank }}
$$

where $\left[\mathrm{H}^{+}\right]_{\text {cons }}=$ concentration of hydrogen ions consumed by the material, $\left[\mathrm{H}^{+}\right]_{\text {cons, susp }}=$ concentration of hydrogen ions consumed by the suspension of a given amount of material, and $\left[\mathrm{H}^{+}\right]_{\text {cons, blank }}=$ concentration of hydrogen ions consumed by the blank solution. 


\subsubsection{Huma-K sorption experiments on SRS sediment}

For sorption experiments, a Huma-K stock solution of $1000 \mathrm{mg} \mathrm{L}^{-1}$ was prepared by dissolving $1000 \mathrm{mg}$ of Huma-K in $1 \mathrm{~L}$ of deionized (DI) water (Barnstead Nanopure Diamond Water Purification System, resistivity $\geq 18 \mathrm{M} \Omega \cdot \mathrm{cm})$. All batch experiments were conducted in triplicate under atmospheric $\left(\mathrm{P}_{\mathrm{CO} 2}=10^{-3.5}\right)$ and ambient temperature $\left(25^{\circ} \mathrm{C}\right)$ conditions.

Batch sorption experiments were conducted with $20 \mathrm{~mL}$ of aqueous suspension in DI water using $50 \mathrm{~mL}$ polypropylene centrifuge tubes, containing $1 \mathrm{~g}$ of SRS sediment (49 $\left.\mathrm{g} \mathrm{L}^{-1}\right)$ spiked with an initial Huma-K concentration specified below. Samples were vortex mixed (Maxi Mix Plus, Barnstead Thermolyne) for $30 \mathrm{sec}$ and then rotated for 5 days on a platform shaker at $100 \mathrm{rpm}$ (New Brunswick Scientific Innova 2000) to ensure thorough fluid-mineral contact throughout the sorption period. All samples were centrifuged for $30 \mathrm{~min}$ at $2700 \mathrm{rpm}$ (Thermo Scientific Sorvall ST 16R centrifuge), and the residual Huma-K in the supernatant was measured spectrophotometrically at $254 \mathrm{~nm}$ using an ultraviolet-visible (UV/Vis) spectrophotometer (Thermo Scientific Genesys 10S) (Khan et al., 2014). The effect of $\mathrm{pH}$ on the total removal of Huma-K by SRS sediment as a result of sorption and precipitation was studied at a $\mathrm{pH}$ range of 4-7 with a reaction time of 5 days and an initial Huma-K concentration of $50 \mathrm{mg} \mathrm{L}^{-1}$. Also, control experiments using sediment-free batches of Huma-K (50 $\left.\mathrm{mg} \mathrm{L}^{-1}\right)$ were conducted to estimate the precipitated fraction of Huma- $\mathrm{K}$ at $\mathrm{pH}$ range $4-7$. The fraction attributed to sorption was calculated from the difference between the total removal and the homogeneous precipitation fraction. For the kinetic studies, an initial Huma-K concentration of $50 \mathrm{mg} \mathrm{L}^{-1}$ was allowed to equilibrate with SRS sediment for different 
time periods at $\mathrm{pH} 4$. The $\mathrm{pH} 4$ was chosen on the basis of the sorption edge of variable $\mathrm{pH}$ experiments. For the equilibrium studies, the initial Huma-K concentration ranged from 10-500 $\mathrm{mg} \mathrm{L}^{-1}$, and samples were reacted at $\mathrm{pH} 4$ for a period of 5 days (past equilibrium time based on the kinetic study). Control experiments using sediment-free batches of Huma-K (10-500 $\left.\mathrm{mg} \mathrm{L}^{-1}\right)$ were also conducted to estimate the precipitated fraction of Huma-K at $\mathrm{pH} 4$.

\subsubsection{Desorption experiments of Huma-K from SRS sediment}

Batch desorption experiments were conducted at a $\mathrm{pH}$ range of 4-8. Initially, 20 $\mathrm{mL}$ of DI water with an initial Huma-K concentration $\left(50 \mathrm{mg} \mathrm{L}^{-1}\right)$ was brought in contact with $1 \mathrm{~g}$ of SRS sediment $\left(49 \mathrm{~g} \mathrm{~L}^{-1}\right)$ at $\mathrm{pH} 4$ and $25^{\circ} \mathrm{C}$. After 5 days of rotation, samples were centrifuged, the residual Huma-K concentration in the supernatant was determined, and the supernatant was replaced with an equal volume of DI water prepared at different $\mathrm{pH}$ values (4-8). Samples were kept on a platform shaker, then centrifuged as previously described for the sorption experiments and the desorbed concentration of Huma-K in the aqueous phase was determined.

\subsection{Results and discussion}

\subsubsection{Characterization of Huma-K and SRS sediment}

The X-ray diffraction pattern of SRS sediment (Figure 2.1) indicated that SRS sediment is composed of quartz $\left(\mathrm{SiO}_{2}, \mathrm{XRD}\right.$ peaks at $20.85^{\circ}$ and $\left.26.65^{\circ} 2 \theta\right)$, kaolinite $\left(\mathrm{Al}_{2} \mathrm{Si}_{2} \mathrm{O}_{5}(\mathrm{OH})_{4}, \mathrm{XRD}\right.$ peak at $12.34^{\circ}$ and $\left.24.9^{\circ} 2 \theta\right)$, and goethite $(\alpha-\mathrm{FeOOH}, \mathrm{XRD}$ peaks at $21.34,33.49,34.81,36.79$, and $\left.53.53^{\circ} 2 \theta\right)$. These results are in good agreement with the XRD analysis of SRS sediment reported elsewhere (Dong and Wan, 2014). 


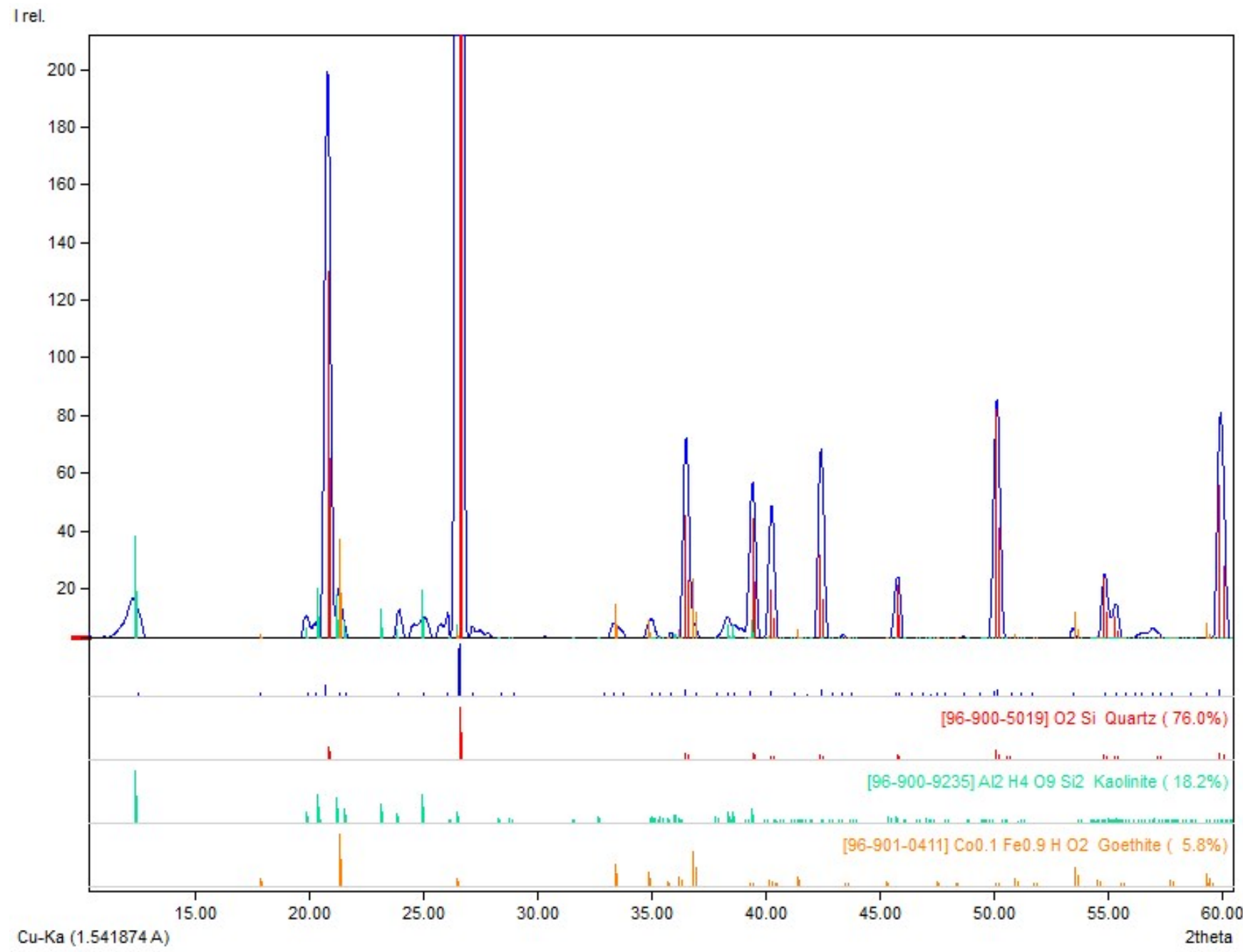

Figure 2.1 X-ray diffraction of SRS sediment. 
Elemental analysis of Huma-K (Figure 2.2) indicated that the primary metal in Huma-K was potassium, the result of the treatment of leonardite with $\mathrm{KOH}$ for the extraction of humic substances (García et al., 1996). The elements carbon (C) and oxygen $(\mathrm{O})$ were related to the different functional groups present in humic substances, such as aromatic rings, carboxyl groups, phenols, and aliphatic chains (Tan, 2003). It was also detected the presence of silicon $(\mathrm{Si})$, aluminum $(\mathrm{Al})$, and calcium $(\mathrm{Ca})$ in Huma-K. Since Huma-K is an unrefined commercial product, it is expected to contain impurities that may have leached out during the alkaline treatment of Leonardite (Kalaitzidis et al., 2003).

SEM-EDS analysis of SRS sediment (Figure 2.2) showed that SRS sediment is composed mostly of $\mathrm{Si}, \mathrm{Al}$, and iron $(\mathrm{Fe})$, which can be traced back to quartz, kaolinite, and goethite minerals observed in the XRD results. In addition, the mineral composition of SRS sediment estimated by XRF yielded an oxide composition that was converted to a normative mineralogy of quartz $(93.2 \%)$, kaolinite $(5.1 \%)$, and goethite $(1.1 \%)$. The percentage of quartz was estimated by assuming that $\mathrm{Si}$ in quartz was from the difference between the total measured Si using XRF and the Si from kaolinite. The percentage of kaolinite and goethite was estimated by assuming that the total measured $\mathrm{Al}$ and Fe was from kaolinite and goethite, respectively (Table 2.1).

Table 2.1 X-ray fluorescence analysis of SRS sediment.

\begin{tabular}{ccccccccccc}
\hline Sample ID & $\begin{array}{c}\mathrm{SiO}_{2} \\
(\mathrm{wt} \%)\end{array}$ & $\begin{array}{c}\mathrm{Al}_{2} \mathrm{O}_{3} \\
(\mathrm{wt} \%)\end{array}$ & $\begin{array}{c}\mathrm{Fe}_{2} \mathrm{O}_{3} \\
(\mathrm{wt} \%)\end{array}$ & $\begin{array}{c}\mathrm{MnO} \\
(\mathrm{wt} \%)\end{array}$ & $\begin{array}{c}\mathrm{MgO} \\
(\mathrm{wt} \%)\end{array}$ & $\begin{array}{c}\mathrm{CaO} \\
(\mathrm{wt} \%)\end{array}$ & $\begin{array}{c}\mathrm{Na}_{2} \mathrm{O} \\
(\mathrm{wt} \%)\end{array}$ & $\begin{array}{c}\mathrm{K}_{2} \mathrm{O} \\
(\mathrm{wt} \%)\end{array}$ & $\begin{array}{c}\mathrm{TiO}_{2} \\
(\mathrm{wt} \%)\end{array}$ & $\begin{array}{c}\mathrm{P}_{2} \mathrm{O}_{5} \\
(\mathrm{wt} \%)\end{array}$ \\
\hline FAW-1 & 95.61 & 2.03 & 0.96 & 0.003 & 0.082 & 0.044 & 0.051 & 0.068 & 0.115 & 0.044 \\
\hline
\end{tabular}



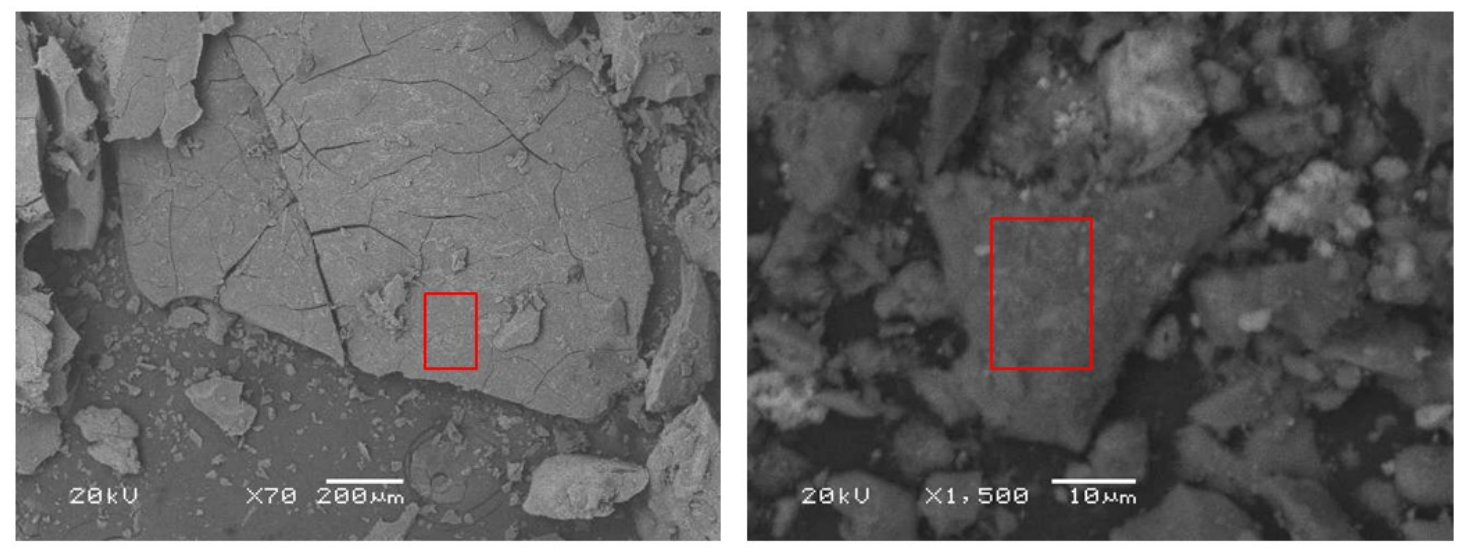

\begin{tabular}{|l|l|l|}
\hline Element & Wt\% & At\% \\
\hline CK & 43.29 & 59.87 \\
\hline OK & 23.60 & 24.50 \\
\hline NaK & 01.39 & 01.01 \\
\hline AIK & 03.67 & 02.26 \\
\hline SiK & 05.03 & 02.98 \\
\hline KK & 16.05 & 06.82 \\
\hline CaK & 04.26 & 01.76 \\
\hline FeK & 02.71 & 00.81 \\
\hline Matrix & Correction & ZAF \\
\hline
\end{tabular}

\begin{tabular}{|l|l|l|}
\hline Element & Wt\% & At\% \\
\hline OK & 42.00 & 59.76 \\
\hline FeL & 11.06 & 04.51 \\
\hline AIK & 07.70 & 06.50 \\
\hline SiK & 32.87 & 26.64 \\
\hline FeK & 06.37 & 02.60 \\
\hline Matrix & Correction & ZAF \\
\hline
\end{tabular}

Figure 2.2 SEM-EDS of Huma-K (left column) and SRS sediment (right column). Red square indicates the location where spot analysis was performed.

The FTIR spectrum of Huma-K (Figure 2.3a) showed a broad peak in the region of $3600-3000 \mathrm{~cm}^{-1}$. The broad peak can be attributed to the O-H stretching of phenols and carboxyl groups and N-H stretching groups of amines, whereas the aliphatic $\mathrm{C}-\mathrm{H}$ stretching of methyl and methylene groups is most probably responsible for the peak at $2926 \mathrm{~cm}^{-1}$ (Giovanela et al., 2010). Carboxyl groups constitute a major functional group of humic substances (Hessen and Tranvik, 1998). The $\mathrm{C}=\mathrm{O}$ stretching of carboxyl groups appears at $1700 \mathrm{~cm}^{-1}$. However, if carboxyl groups are either dissociated $\left(\mathrm{COO}^{-}\right)$or forming a complex with a metal ion (COO - metal), two peaks at $1600 \mathrm{~cm}^{-1}$ and $1380 \mathrm{~cm}^{-1}$ for the symmetric and antisymmetric stretching vibration of the $\mathrm{COO}^{-}$ 
group are expected (Erdogan et al., 2007; Gondar et al., 2005). The absence of a peak at $1700 \mathrm{~cm}^{-1}$ and the presence of both 1567 and $1383 \mathrm{~cm}^{-1}$ peaks in Huma-K (Figure 2.3a) implies that carboxyl groups in Huma-K are found in their dissociated form $\left(\mathrm{COO}^{-}\right)$as a result of the alkaline treatment of leonardite. The peaks at 1030 and $914 \mathrm{~cm}^{-1}$ correspond to the $\mathrm{C}-\mathrm{O}$ and $\mathrm{C}-\mathrm{C}$ stretching vibrations of carbohydrates, and/or it may correspond to silicate impurities leached from leonardite during the alkaline extraction of humic substances (Enev et al., 2014).
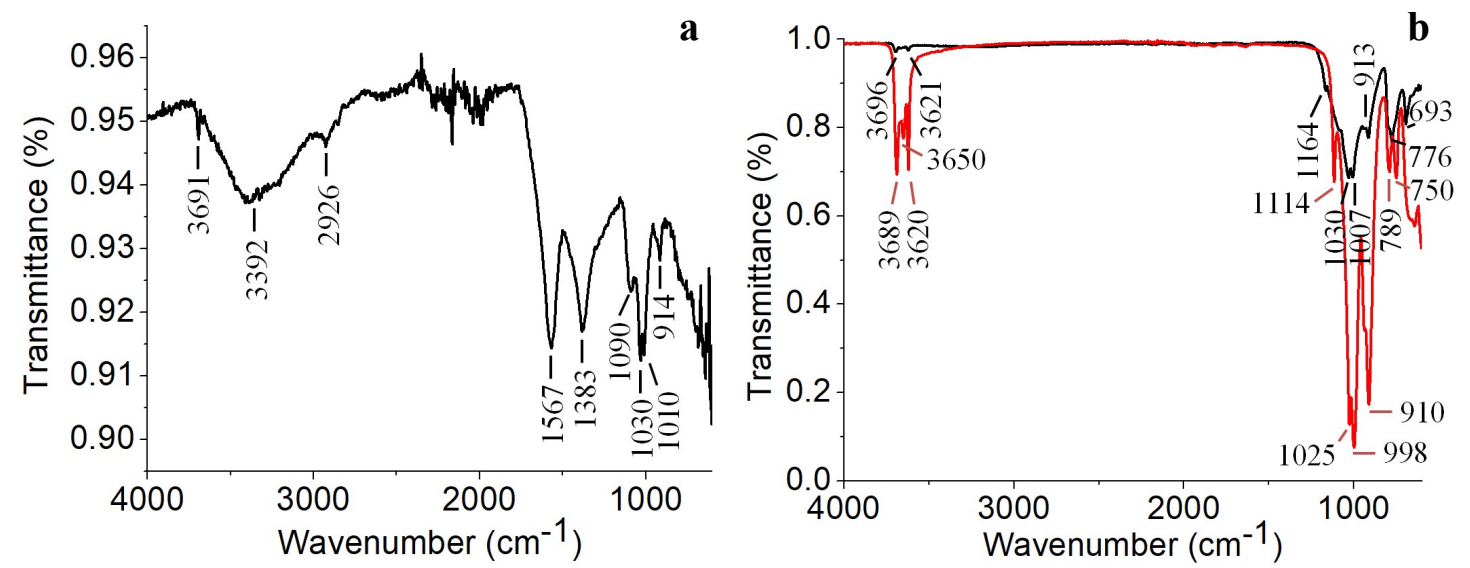

Figure 2.3 Fourier-transform infrared spectra of: (a) Huma-K, and (b) kaolinite (red line) and SRS sediment fine fraction (mean particle diameter $\leq 63 \mu \mathrm{m}$ ) (black line).

The FTIR spectrum of a kaolinite standard material was collected along with the FTIR spectrum of SRS sediment fine fraction for the reason of comparison (Figure 2.3b). Kaolinite has a distinctive pattern in the region of $3700-3620 \mathrm{~cm}^{-1}$, where two peaks (3650 and $3689 \mathrm{~cm}^{-1}$ ) are attributed to the stretching vibration of the surface hydroxyl groups. The third peak at $3620 \mathrm{~cm}^{-1}$ belongs to the inner-surface $\mathrm{O}-\mathrm{H}$ group stretching vibration, which is found in kaolinite as well as in other Al-rich minerals. In addition, the peak at $910 \mathrm{~cm}^{-1}$ arises from the $\mathrm{O}-\mathrm{H}$ bending vibration of the inner surface hydroxyl groups of kaolinite and the presence of any dioctahedral mineral (Madejová, 
2003). In the FTIR spectrum of SRS sediment, the peaks for the O-H group stretching vibration at $3696 \mathrm{~cm}^{-1}$ and $3621 \mathrm{~cm}^{-1}$ are present but not very notable. Also, the peak for the $\mathrm{O}-\mathrm{H}$ bending vibration was found at $913 \mathrm{~cm}^{-1}$. With the XRD results, it was able to confirm that those peaks found in the FTIR spectrum of SRS sediment belong to kaolinite and not to other Al-rich mineral. On the other hand, the peak at $776 \mathrm{~cm}^{-1}$ can be attributed to the Si-O symmetrical stretching vibration of both quartz and kaolinite. The peak at $693 \mathrm{~cm}^{-1}$ was attributed to the Si-O symmetrical bending vibration of quartz. In summary, the XRD analysis along with the XRF and FTIR results provide evidence that the mineral composition of SRS sediment consist of quartz, kaolinite, and goethite.

Differential potentiometric titrations (DPT) provide useful information on the protonation/deprotonation properties of functional groups, which can be involved in the sorption process. Reverse peaks in the DPT correspond to the $\mathrm{p} K$ values of the functional groups present in Huma-K and SRS sediment that have acid/base properties and can be ionized (Bourikas et al., 2006a). The DPT curve of Huma-K (Figure 2.4d) revealed a broad peak between $\mathrm{pH} 4$ and 6 . The broad peak is attributed to the presence of carboxyl groups arranged in different configurations, which have similar $\mathrm{p} K$ values. For instance, aliphatic acids and aromatic acids have $\mathrm{p} K$ values between 4.5-6 and close to 4 , respectively, which can be correlated with the broad peak found in the $\mathrm{pH}$ range of 4-6 (Thurman, 1985). The peaks found between $\mathrm{pH} 9$ and 10 are attributed to the presence of phenolic groups (Stumm and Morgan, 1996). On the other hand, the two peaks at $\mathrm{pH} 6.5$ and 10.5 could be attributed to the $\mathrm{p} K_{\mathrm{a} 1}$ and $\mathrm{p} K_{\mathrm{a} 2}$ values of carbonic acid $\left(\mathrm{H}_{2} \mathrm{CO}_{3}\right)$ (Langmuir, 1997). Carbonic acid in Huma-K could have been formed 
during the extraction of Huma-K from leonardite as a result of highly alkaline conditions where atmospheric $\mathrm{CO}_{2}$ reacts with $\mathrm{OH}^{-}$to form $\mathrm{HCO}_{3}^{-}$in solution that eventually could have been precipitated with Huma-K when dried.
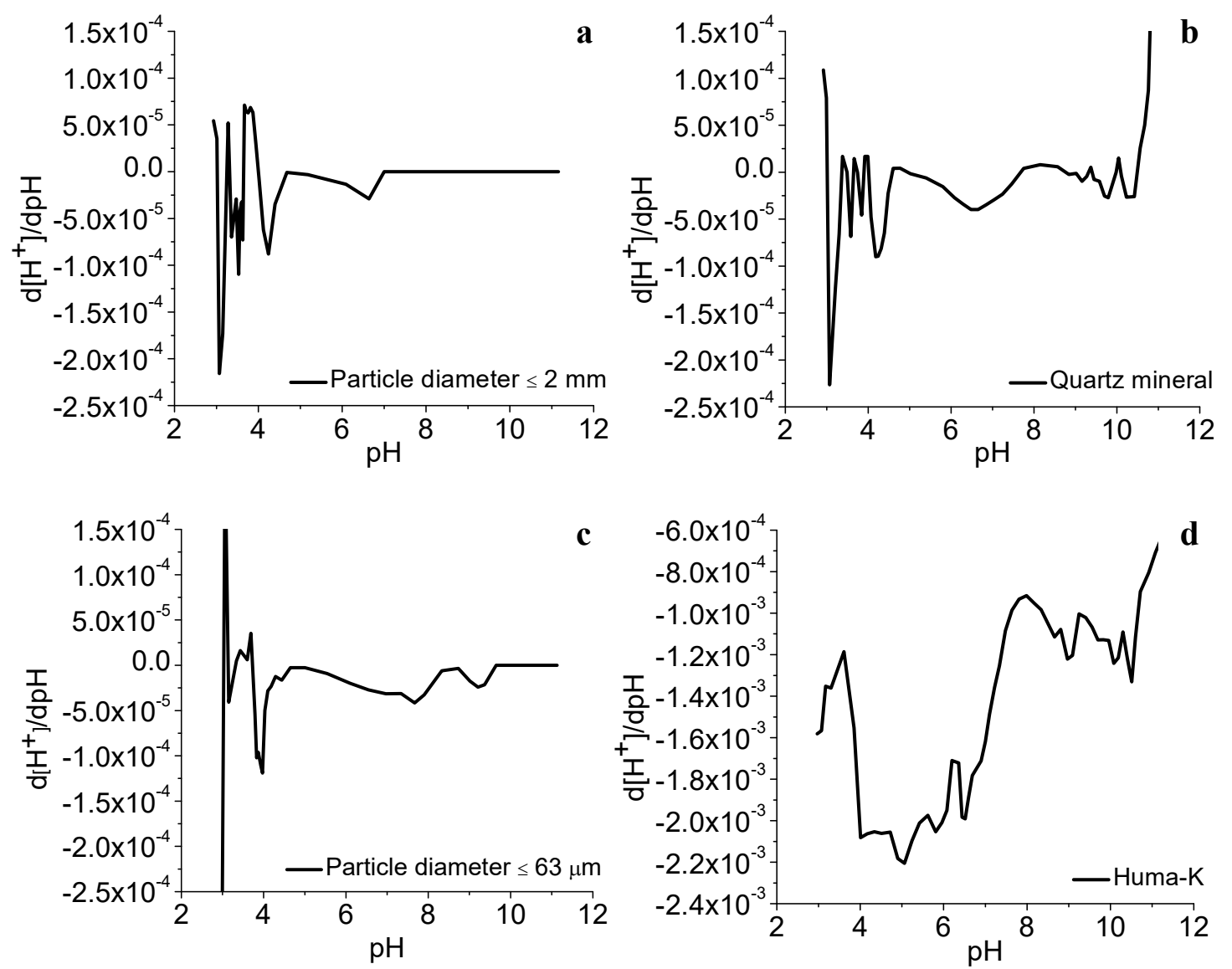

Figure 2.4 Differential potentiometric titration of: (a) SRS sediment (mean particle diameter $\leq 2 \mathrm{~mm}$ ), (b) quartz mineral, (c) SRS sediment (mean particle diameter $\leq 63$ $\mu \mathrm{m})$, and (d) Huma-K.

The DPT curve of SRS sediment revealed a reverse peak at pH 4.24 (Figure 2.4a), which is attributed to the acid/basic properties of quartz and more specifically to silanol groups ( $\equiv \mathrm{SiOH}$ ) (Leung et al., 2009; Liu et al., 2014; Ong et al., 1992). The DPT results suggest that for $\mathrm{pH}>4.2$, the surface charge of SRS sediment will be predominantly negative because of the deprotonation of silanol groups $\left(\equiv \mathrm{SiO}^{-}\right)$. In 
addition, a quartz standard material (Figure 2.4b) was titrated for the reason of comparison. The results of the titration yielded a very similar DPT, denoting that SRS sediment has a very similar acido-basic behavior to quartz. Duval et al. (2002) reported similar $\mathrm{p} K$ values for the behavior of quartz in contact with water (Eq. 2.2 and 2.3). The DPT curves of both SRS sediment and quartz revealed a small peak around pH 6.8 that could correspond to the silanol groups of amorphous silica. In fact, a study showed that when the quartz surface is in contact with water, an amorphous layer may be formed (Li et al., 2004).

$$
\begin{array}{ll}
\equiv \mathrm{SiOH}+\mathrm{H}^{+} \rightarrow \equiv \mathrm{SiOH}_{2}^{+} & \mathrm{p} K_{1}=-1.0 \\
\equiv \mathrm{SiOH} \rightarrow \equiv \mathrm{SiO}^{-}+\mathrm{H}^{+} & \mathrm{p} K_{2}=4.0
\end{array}
$$

SRS sediment also contains kaolinite and goethite. However, the determination of the $\mathrm{p} K$ values of kaolinite and goethite by DPT was not able to be obtained for the sediment fraction with a particle diameter $\leq 2 \mathrm{~mm}$. Probably, the amount of $\mathrm{H}^{+}$ consumed by the solution is much higher than that consumed by the surface of kaolinite and goethite, whose presence is in low amounts (XRF results). On the other hand, the DPT of the sediment fraction with a particle diameter $\leq 63 \mu \mathrm{m}$ (Figure 2.4c) did showed small reverse peaks at $\mathrm{pH} 7.7$ and 9.2 that may correspond to aluminol $(\equiv \mathrm{AlOH})$ and silanol $(\equiv \mathrm{SiOH})$ in kaolinite and hydroxyl groups coordinated to iron $(\equiv \mathrm{FeOH})$ in goethite. Overall, it is expected the sorption of Huma-K on SRS sediment to be more favorable in acidic conditions. Since there is little or no deprotonation of the acidic functional groups of Huma-K at $\mathrm{pH}$ less than 4, electrostatic repulsion between Huma$\mathrm{K}$ and SRS sediment should be low. Therefore, sorption, homogeneous precipitation, and surface-induced precipitation at the surface of SRS sediment should be favored. As 
the $\mathrm{pH}$ is increased, functional groups start deprotonating and becoming negatively charged. As a result, electrostatic repulsion and dissolution of Huma-K from SRS sediment will increase as well.

\subsubsection{Effect of pH on Huma-K sorption on SRS sediment}

Batch experiments for the $\mathrm{pH}$ range studied were performed under identical conditions with and without SRS sediment in order to determine the percentage of Huma-K removal from solution. The total removal of Huma-K (sorption + precipitation) and the homogeneous precipitated fraction were measured in different experiments. The sorption (estimated value) was the difference between the total removal and the homogeneous precipitated fraction (Figure 2.5).

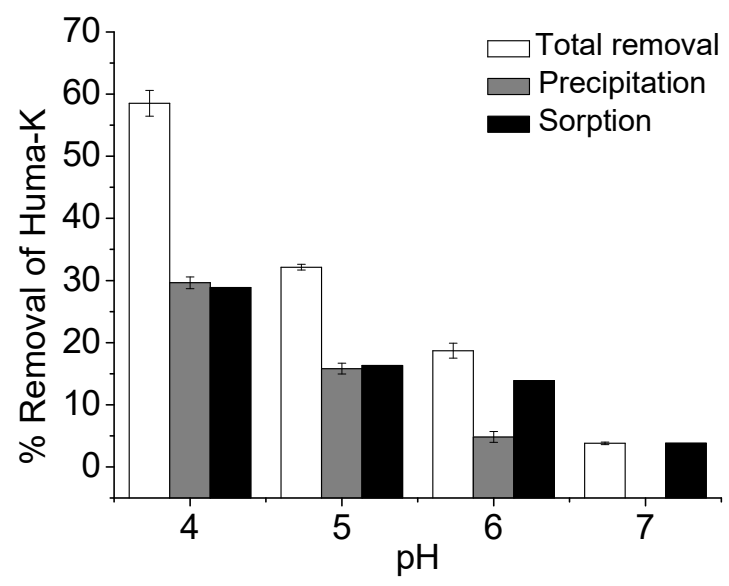

Figure 2.5 \% Removal of Huma-K $\left(C_{i}=50 \mathrm{mg} \mathrm{L}^{-1}\right)$ from the aqueous phase as a function of $\mathrm{pH}$ ( $49 \mathrm{~g} \mathrm{~L}^{-1}$ of sediment, $\mathrm{T}=25^{\circ} \mathrm{C}$, and 5 days).

The removal of Huma-K without SRS sediment as a function of $\mathrm{pH}$ showed that at $\mathrm{pH} 4$, the homogeneous precipitation fraction of Huma-K ( $\sim 30 \%)$ plays an important role, whereas homogeneous precipitation accounts for $\sim 5 \%$ or less at circumneutral conditions $(\mathrm{pH}=6)$. It is believed that there was some surface-induced precipitation 
besides homogeneous precipitation of Huma-K in the presence of sediment. Therefore, the precipitated fraction of Huma-K should be higher in samples that include sediment than in samples without sediment.

The homogeneous precipitation of Huma-K at low $\mathrm{pH}$ is probably caused by the protonation of the functional groups in humic molecules, which induces humic molecules to adopt a collapsed conformational structure. As a result, humic molecules form aggregates and ultimately precipitate (Zhou et al., 1994). von Wandruszka (2000) indicated that humic molecules can rearrange in a micelle-like organization in which the hydrophobic portions are in the interior while the hydrophilic portions are in contact with the solution. With an increase of $\mathrm{pH}$, humic molecules become less hydrophobic as a result of the deprotonation of the different functional groups such as carboxyl groups. The deprotonation of carboxyl groups increases inter- and intramolecular repulsion, causing a decrease in the aggregation-flocculation phenomena between humic molecules (Alvarez-Puebla and Garrido, 2005; Ko et al., 2005; Saab et al., 2010).

In the presence of SRS sediment, there was a gradual decrease in Huma-K removal as a function of $\mathrm{pH}$ : at $\mathrm{pH} 4$, removal accounted for $59 \%$, whereas at $\mathrm{pH} 7$, only $3.5 \%$ of Huma-K was retained (Figure 2.5 ). It is believed that sorption of Huma-K to SRS sediment is decreased with an increase of $\mathrm{pH}$ because of surface complexation likely controlled by electrostatic attractions and ligand exchange interactions. For instance, SRS sediment is composed of quartz, kaolinite and goethite. Quartz has a point of zero charge (pzc) of 2.91 (Langmuir, 1997). The deprotonation of the silanol groups at the quartz surface can result in electrostatic repulsion with the negatively charged humic molecules in Huma-K at $\mathrm{pH}$ values above the pzc of quartz (Eq. 2.4). On 
the other hand, the presence of kaolinite with a pzc of 5-5.5 (Huertas et al., 1998; Schroth and Sposito, 1997) and goethite with a pzc of 9.2 in the sediment can contribute to the sorption of Huma- $\mathrm{K}$ as the $\mathrm{pH}$ is increased. The binding mechanism between humic molecules and hydroxyl groups on the surface of kaolinite and goethite is believed to be through ligand exchange, where the $-\mathrm{OH}_{2}^{+}$and $-\mathrm{OH}$ groups at the mineral surface are exchanged with carboxyl groups $\left(\mathrm{COO}^{-}\right)$in humic molecules as shown in Eq. 2.5-2.7 (Fairhurst et al., 1995; Petrović et al., 1999; Philippe and Schaumann, 2014). As the $\mathrm{pH}$ is increased, fewer $-\mathrm{OH}_{2}^{+}$and $-\mathrm{OH}$ groups are available for the binding of humic molecules as a result of deprotonation, which causes electrostatic repulsion between the surface and the anionic functional groups in humic molecules. Therefore, complexation through ligand exchange is less favorable as soon as the $\mathrm{pH}$ exceeds the pzc. It seems that the presence of kaolinite and goethite in SRS sediment may play an important role in the sorption process because of their higher pzc. However, quartz may not contribute much to the sorption of Huma-K through electrostatic attractions or ligand exchange mechanisms because of its low pzc. In addition, the deprotonation of carboxyl groups in Huma-K with an increase of $\mathrm{pH}$ favors sorption onto neutral and positively charged surfaces whereas the protonation of carboxyl groups with a decrease in $\mathrm{pH}$ favors surface-induced precipitation.

$$
\begin{aligned}
& \equiv \mathrm{SiO}^{-}+\mathrm{HA}-\mathrm{COO}^{-} \rightarrow \text { no surface complexation } \\
& \equiv \mathrm{AlOH}_{2}^{+}+\mathrm{HA}-\mathrm{COO}^{-} \rightarrow \equiv \mathrm{Al}-\mathrm{OOC}-\mathrm{HA}+\mathrm{H}_{2} \mathrm{O} \\
& \equiv \mathrm{FeOH}_{2}^{+}+\mathrm{HA}-\mathrm{COO}^{-} \rightarrow \equiv \mathrm{Fe}-\mathrm{OOC}-\mathrm{HA}+\mathrm{H}_{2} \mathrm{O} \\
& \equiv \mathrm{FeOH}+\mathrm{HA}-\mathrm{COO}^{-} \rightarrow \equiv \mathrm{Fe}-\mathrm{OOC}-\mathrm{HA}+\mathrm{OH}^{-}
\end{aligned}
$$


Sorption of humic molecules to minerals can also be influenced by surface area, especially in the case of non-specific sorption where minerals with a higher surface area are expected to remove greater amounts of humic molecules. On the other hand, if sorption is specific (chemisorption) in which chemical binding dominates the sorption process, minerals with larger surface area do not necessarily contribute to the increase in the sorption of humic molecules when compared to minerals that have lower surface area (Chotzen et al., 2016; Feng et al., 2005). For instance, Feng et al. (2005) studied the sorption of humic acid onto two types of clay minerals (kaolinite and montmorillonite) that have different surface area. Kaolinite, having a lower surface area (10.05 $\left.\mathrm{m}^{2} \mathrm{~g}^{-1}\right)$, showed a higher sorption capacity for humic acid compared to montmorillonite $\left(97.42 \mathrm{~m}^{2} \mathrm{~g}^{-1}\right)$, having a higher surface area. When selective sorption dominates the sorption process, surface area does not play an important role in the sorption of humic acid. In the present study, the sorption of Huma-K onto quartz, kaolinite, and goethite is believed to occur via ligand exchange mechanism. Since the binding mechanism is similar for the three minerals, it is expected that the higher surface area of kaolinite and goethite contribute more to the sorption of Huma-K compared to quartz. In addition, the amount of Huma-K sorbed onto each mineral change as the $\mathrm{pH}$ is increased because of their various pzc values.

\subsubsection{Kinetic studies of Huma-K sorption on SRS sediment}

\subsubsection{Reaction-based kinetic models}

The kinetic studies at $\mathrm{pH} 4$ revealed a fast initial uptake of Huma-K onto SRS sediment, followed by a slower uptake with equilibrium reached within $96 \mathrm{~h}$ (4 days), as 
shown in Figure 2.6a. Pitois et al. (2008) obtained a similar kinetic behavior for the humic acid uptake onto quartz sand, and their study showed a fractionation during the sorption process. Small humic molecules were observed to sorbed initially followed by the sorption of humic molecules of higher molecular weight (less aromatic/more aliphatic) at slower rate.

Sorption is a combination of different processes such as external mass transfer, film diffusion, intra-particle diffusion, and sorption. In order to elucidate the sorption process, different models are usually employed. For instance, kinetic models can determine if sorption is the rate-limiting while diffusion models can determine if diffusion is the rate-limiting step in the sorption process (Largitte and Pasquier, 2016). Therefore, the sorption reaction of Huma-K on SRS sediment was evaluated on the basis of various kinetic models including pseudo-first and pseudo-second order model.

The pseudo-first order model was introduce by Lagergren (1898). It describes an irreversible reaction, in which a metal ion $\left(\mathrm{UO}_{2}^{2+}\right)$ is adsorbed by one sorption site on a surface ( $\equiv A)$ (Eq. 2.8). The assumptions for the pseudo-first order model are: sorption occurs only at localized sites, there are no interactions between the sorbed ions, the concentration of the surface is constant, and the metal ion $\left(\mathrm{UO}_{2}^{2+}\right)$ uptake is governed by first order rate.

$$
\equiv \mathrm{A}+\mathrm{UO}_{2}^{2+} \rightarrow \equiv \mathrm{AUO}_{2}^{2+}
$$

Generally, the equation used to represent the pseudo-first order kinetics is as shown in Eq. 2.9:

$$
\ln \left(\mathrm{q}_{\mathrm{e}}-\mathrm{q}_{\mathrm{t}}\right)=\ln \left(\mathrm{q}_{\mathrm{e}}\right)-\mathrm{k}_{1} \mathrm{t}
$$




$$
\mathrm{F}=\frac{\mathrm{q}_{\mathrm{t}}}{\mathrm{q}_{\mathrm{e}}}=1-\mathrm{e}^{-\mathrm{k}_{1} \mathrm{t}}
$$

where $\mathrm{q}_{\mathrm{e}}$ and $\mathrm{q}_{\mathrm{t}}$ are the amounts of solute sorbed at equilibrium and at time $\mathrm{t} . \mathrm{k}_{1}$ is the pseudo-first order rate constant.
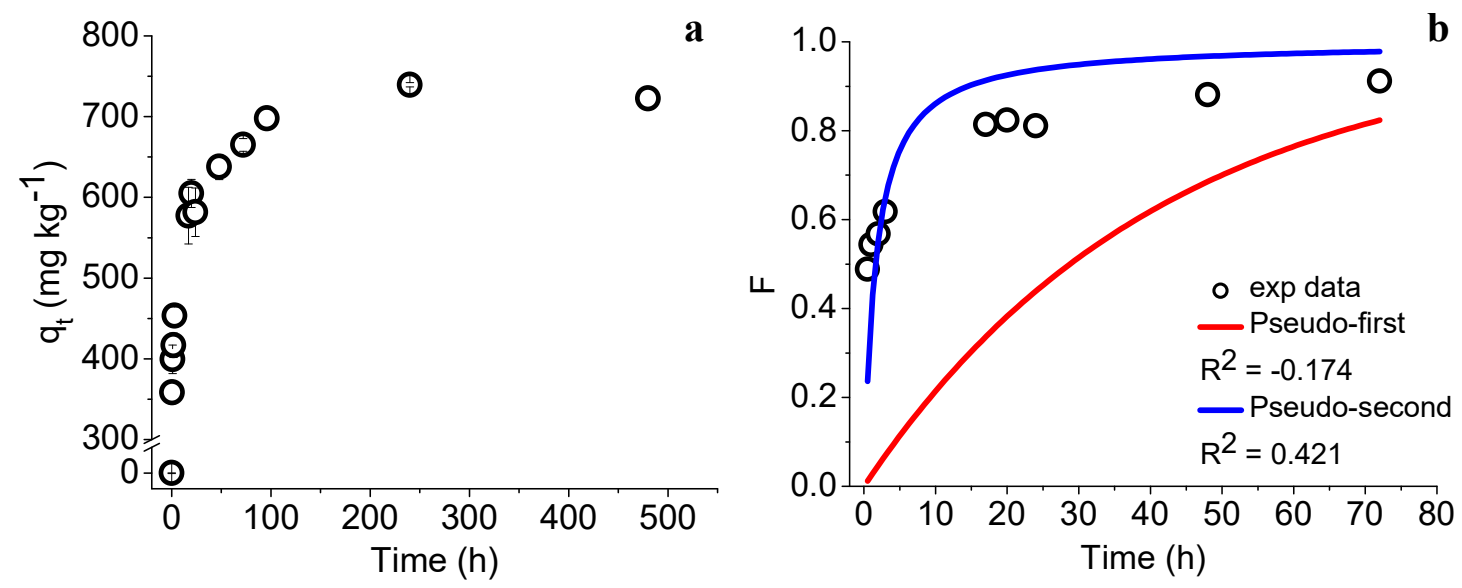

Figure 2.6 (a) Kinetics of Huma-K $\left(\mathrm{C}_{\mathrm{i}}=50 \mathrm{mg} \mathrm{L}^{-1}\right)$ sorption on SRS sediment $\left(49 \mathrm{~g} \mathrm{~L}^{-1}\right.$ of sediment, $\mathrm{pH} 4$, and $\left.\mathrm{T}=25^{\circ} \mathrm{C}\right)$. (b) Non-linear fit of fractional uptake $\left(\mathrm{F}=\mathrm{q}_{\mathrm{t}} / \mathrm{q}_{\mathrm{e}}\right)$ data for $\mathrm{t}<100 \mathrm{~h}$.

The pseudo-second order model for the sorption processes (Eq. 2.11) was proposed by Ho and McKay (1999). The assumptions for the pseudo-second order model are the same as pseudo-first model with the exception that the metal ion is adsorbed by two sorption sites on the surface and the uptake is governed by a second order rate.

$$
\equiv 2 \mathrm{~A}+\mathrm{UO}_{2}^{2+} \rightarrow \equiv \mathrm{A}_{2} \mathrm{UO}_{2}^{2+}
$$

The equation for the pseudo-second order model is generally employed as shown in Eq. 2.12:

$$
\begin{aligned}
& \frac{\mathrm{t}}{\mathrm{q}_{\mathrm{t}}}=\frac{1}{\mathrm{k}_{2} \mathrm{q}_{\mathrm{e}}^{2}}+\frac{1}{\mathrm{q}_{\mathrm{e}}} \mathrm{t} \\
& \mathrm{F}=\frac{\mathrm{q}_{\mathrm{t}}}{\mathrm{q}_{\mathrm{e}}}=\frac{\mathrm{k}_{2}^{*} \mathrm{t}}{1+\mathrm{k}_{2}^{*} \mathrm{t}}
\end{aligned}
$$


where $k_{2}$ is the pseudo-second order rate constant and $k_{2}^{*}=k_{2} q_{e}$.

The experimental data were evaluated using the linear (Eq. 2.9 and 2.12) and nonlinear (Eq. 2.10 and 2.13) form of the kinetic models. The linear models showed that the experimental data were best described by the pseudo-second order kinetic model $\left(\mathrm{R}^{2}\right.$ $=0.998$ ), as shown in Fig. 2 S-1 and Table $2 \mathrm{~S}-1$ in the supplementary information. There was a very good agreement between the calculated maximum uptake value $\mathrm{q}_{\mathrm{e}}$, calculated $=$ $714 \mathrm{mg} \mathrm{kg}{ }^{-1}$ obtained by the pseudo-second order model and the equivalent experimental value $\mathrm{q}_{\mathrm{e}}$, experimental $=734 \mathrm{mg} \mathrm{kg}^{-1}$. Other studies of humic acid sorption onto adsorbents such as hematite and kaolinite (Shaker et al., 2012), acid-activated Greek bentonite (Doulia et al., 2009), and chitosan- $\mathrm{H}_{2} \mathrm{SO}_{4}$ beads (Ngah et al., 2011) have reported that the kinetics follow a pseudo second order reaction and the mechanism of sorption is chemisorption (Esmaeili et al., 2012; Shaker et al., 2012).

However, Simonin (2016) pointed out that the method of data analysis generally used to determine which kinetic model best fit the experimental data has several issues. One of the issues is to take into account experimental data points at or close to equilibrium. When the data points at or close to equilibrium are plotted using the linear form of the pseudo-second order model, the points aligned well, giving a correlation coefficient $\left(\mathrm{R}^{2}\right)$ close to 1 , which tends to favor pseudo-second over pseudo-first order. Another issue is to compare the $\mathrm{R}^{2}$ values obtained by using different functions in the kinetic models. Instead, it should be used a parameter such as the fractional uptake $\mathrm{F}=\left(\frac{\mathrm{q}_{\mathrm{t}}}{\mathrm{q}_{\mathrm{e}}}\right)$ from the pseudo-first (Eq. 2.10) and pseudo-second (Eq. 2.13) that is able to describe the same quantity for comparison reasons. 
The kinetic data for the sorption of Huma-K on SRS sediment were re-plotted for pseudo-first and pseudo-second order using the nonlinear model. The experimental data points at and near equilibrium were not included. The plot in Figure 2.6b showed that neither pseudo-first nor the pseudo-second order model were able to fit well the experimental data. It is important to note that kinetic models have been developed or employed to describe mostly binary systems (one sorbing compound and one sorbent). In the present study, it is a more complex system where the sorbent is a mixture of minerals with multiple sorption sites and a complex sorbing material (Huma-K) with a mixture of compounds (fulvic and humic acids). In addition, it was demonstrated that the use of kinetic models in the linear form can lead to erroneous conclusions.

\subsubsection{Diffusion-based models}

Since sorption is a complex process where different mechanisms may be occurring at the same time, the Weber-Morris intra-particle diffusion and the Boyd film diffusion models were used in an effort to determine the rate-limiting step of the sorption process.

The intra-particle diffusion model was developed by Weber and Morris (1963). They discovered that the solute uptake $\left(\mathrm{q}_{\mathrm{t}}\right)$ has a linear correlation with respect to the square root of time $\left(\mathrm{t}^{1 / 2}\right)$, and it can be described by the Eq. 2.14 :

$$
\mathrm{q}_{\mathrm{t}}=\mathrm{k}_{\mathrm{d}} * \mathrm{t}^{\frac{1}{2}}+\mathrm{C}
$$

where $\mathrm{k}_{\mathrm{d}}$ is the intra-particle diffusion rate constant, and $\mathrm{C}$ reflects the resistance of mass transfer in the boundary layer. 
In the intra-particle diffusion model, the $\mathrm{C}$ value is obtained from the intercept of the straight-line plot $\left(q_{t}\right.$ vs. $\left.t^{1 / 2}\right)$. If the intercept $C=0$, intra-particle diffusion is the ratelimiting step, whereas if the intercept $\mathrm{C} \neq 0$, intra-particle is not the rate-controlling step, but film diffusion has a greater boundary layer effect (Cheung et al., 2007; Qiu et al., 2009). In some cases, the intra-particle diffusion plot seems to show multi-linearity. Multi-linearity has been attributed to the presence of multiple steps that influence the kinetics of sorption. The first step is attributed to either external mass transfer from the solution to the surface of the adsorbent. The second step is the internal diffusion where intra-particle is the rate-limiting step, and the third step is the final equilibrium stage, where $\mathrm{q}_{\mathrm{t}}$ does not change with time (Cheung et al., 2007; Lorenc-Grabowska and Gryglewicz, 2005).

In their work, Schwaab et al. (2017) compare the Weber and Morris intra-particle diffusion model with models that either consider external mass transfer resistance or not. The authors found that the intra-particle diffusion model is only valid for very restrictive conditions (e.g., absence of external mass transfer), which are not likely to be achieved in batch sorption experiments. In addition, the use of multiple lines in the plot of adsorbed quantity as a function of $t^{1 / 2}$ to attempt to describe the different stages in the adsorption process is very subjective. There is no mathematical evidence that supports multi-linearity in the intra-particle diffusion process.

In the present study, the intra-particle diffusion plot of Huma-K showed that the sorption of Huma-K on SRS sediment at $\mathrm{pH} 4$ likely occurred in three steps (Figure 2.7a). However, it cannot be implied that the apparent linear segments are caused by mass transfer, intra-particle diffusion, and final equilibrium sorption stage. One could 
assume that all the data points correspond to a curve and not to linear segments. Therefore, it was not possible to determine if intra-particle diffusion controls the sorption process of Huma-K onto SRS sediment.

The Boyd film diffusion model (Boyd et al., 1947) assumes that the main resistance to diffusion is the boundary layer that surrounds the particles, and it is expressed as:

for $\mathrm{F}$ values $>0.85 \quad \mathrm{Bt}=-0.4997-\ln (1-\mathrm{F})$

and for $F$ values $<0.85 \quad \mathrm{Bt}=\left(\sqrt{\pi}-\sqrt{\pi-\left(\pi^{2} \mathrm{~F} / 3\right)}\right)^{2}$

where $F=\left(\frac{q_{t}}{q_{e}}\right)$ is the fractional uptake.

In the Boyd film diffusion model, if the plot (Bt vs. $\mathrm{t}$ ) is linear and passes through the origin, intra-particle diffusion is the rate-limiting step. If the plot is nonlinear or linear, but does not pass through the origin, then film diffusion is the rate-limiting step (Qiu et al., 2009). The results showed a linear plot (Figure 2.7b) that did not pass through the origin, indicating that film diffusion controls the sorption rate.
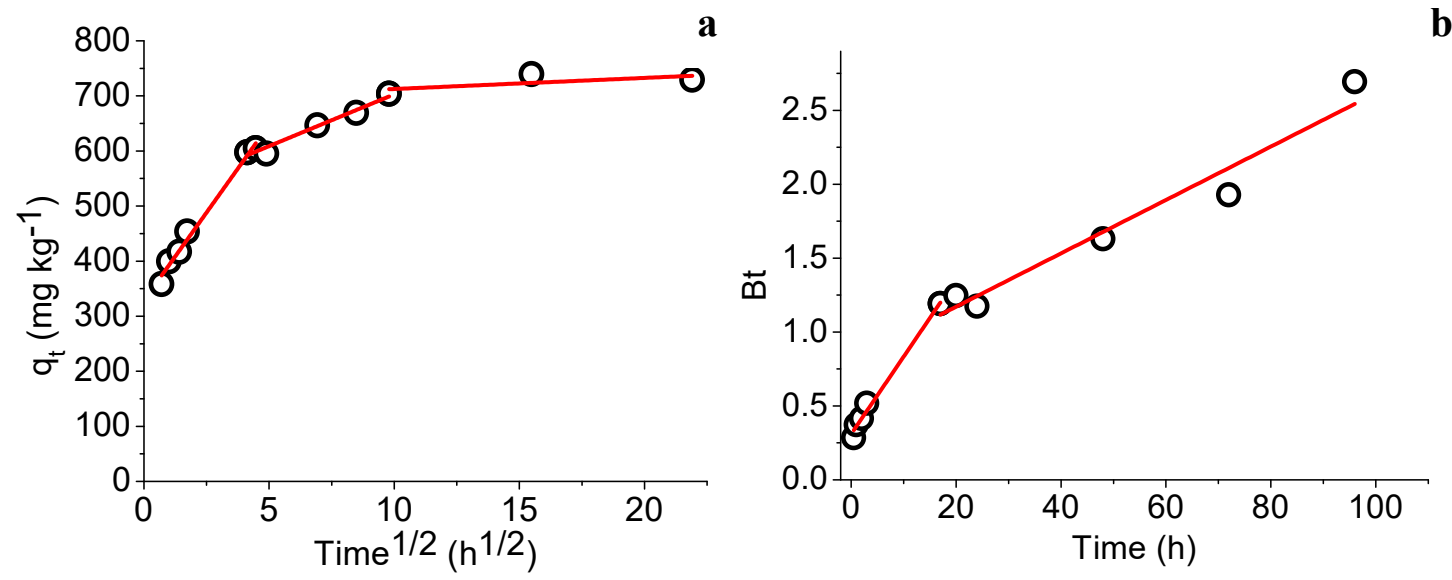

Figure 2.7 (a) Weber and Morris plot of Huma-K. (b) Boyd plot of Huma-K. Bt = $0.4977-\ln (1-F)$ where $F$ represents the fractional uptake $\left(F=q_{t} / q_{e}\right)$. 


\subsubsection{Equilibrium studies on Huma-K sorption}

Equilibrium studies (Figure 2.8a) showed that removal of Huma-K from solution increased with increasing initial Huma-K concentration. An initial plateau seems to be formed probably as a result of saturation of all the binding sites in the SRS sediment by humic molecules in Huma-K. As the concentration of Huma-K further increased, the sorbed Huma-K increased. A possible explanation for the increase in Huma-K sorption is the formation of a multilayer where humic molecules are sorbed on top of the existing ones by hydrophobic interactions (Elfarissi and Pefferkorn, 2000). Hydrophobic interactions are attributed to the charge neutralization (protonation of functional groups) of humic molecules at low $\mathrm{pH}$ and its hydrophobic moiety, allowing humic molecules in Huma-K to not only accumulate on the surface of SRS sediment, but also interact with the already sorbed humic molecules (Jada et al., 2006). Agglomeration and hydrophobic interactions can lead to surface-induced precipitation.
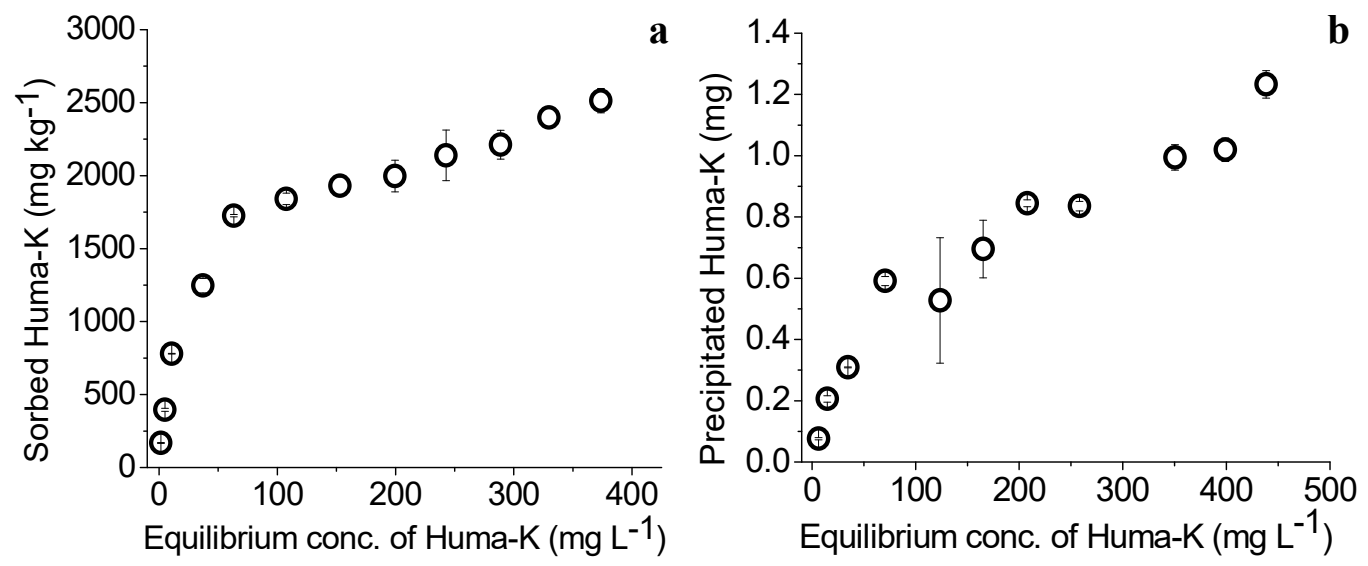

Figure 2.8 (a) Sorption isotherm of Huma-K $\left(\mathrm{C}_{\mathrm{i}}=10-500 \mathrm{mg} \mathrm{L}^{-1}\right)$ on SRS sediment (49 $\mathrm{g} \mathrm{L}^{-1}$ of sediment). (b) Precipitation of Huma-K without SRS sediment $\left(\mathrm{pH} 4, \mathrm{~T}=25^{\circ} \mathrm{C}\right.$, and 5 days). 
The results of the control experiments using sediment-free batches of Huma-K removal (Figure 2.8b) indicated that besides sorption, homogeneous precipitation increased with increasing initial Huma-K concentration at $\mathrm{pH}$ 4. The hydrophobic character of humic molecules in Huma-K allows the formation of aggregates, enhancing its precipitation. Therefore, removal of Huma-K at $\mathrm{pH} 4$ may be attributed to sorption as well as surface-induced and homogeneous precipitation. Similar results have been reported in studies of aquatic fulvic acid: at $\mathrm{pH} 3$, fulvic molecules formed agglomerates at the surface of a mica sheet because most of the fulvic molecules were uncharged (Saab et al., 2010). Balnois et al. (1999) studied the agglomeration of a hydrophilic humic acid from the Suwannee River and a peat humic acid on a surface of muscovite mica. The study revealed that between $\mathrm{pH} 3$ and 10 no aggregates were formed for the hydrophilic Suwannee humic, but peat humic acid, which is more hydrophobic, did form aggregates at $\mathrm{pH}$ less than 5 for a concentration of $10 \mathrm{mg} \mathrm{L}^{-1}$.

The data from the equilibrium studies were fitted with Langmuir and Freundlich isotherm models. The Langmuir and Freundlich models are frequently used to interpret the sorption process on a surface. The Langmuir isotherm was proposed by Langmuir (1918). The assumptions of the Langmuir model are: monolayer sorption, uniform sorption across the surface, finite sorption sites, and no interactions between already sorbed molecules. Once all the sorption sites have been occupied, sorption ceases. The nonlinear (Eq. 2.17) and linear (Eq. 2.18) form are expressed as:

$$
\begin{aligned}
& \mathrm{q}_{\mathrm{e}}=\frac{\mathrm{q}_{\mathrm{m}} \mathrm{K}_{\mathrm{L}} \mathrm{C}_{\mathrm{e}}}{1+\mathrm{K}_{\mathrm{L}} \mathrm{C}_{\mathrm{e}}} \\
& \frac{\mathrm{C}_{\mathrm{e}}}{\mathrm{q}_{\mathrm{e}}}=\frac{1}{q_{m} K_{\mathrm{L}}}+\frac{\mathrm{C}_{\mathrm{e}}}{q_{m}}
\end{aligned}
$$


where $\mathrm{q}_{\mathrm{e}}$ and $\mathrm{C}_{\mathrm{e}}$ are the amount of adsorbate sorbed at equilibrium. $\mathrm{K}_{\mathrm{L}}$ is the Langmuir equilibrium constant, and $\mathrm{q}_{\mathrm{m}}$ is the maximum sorption capacity.

The Freundlich isotherm model was proposed by Freundlich (1906), and it is usually considered to be an empirical equation that describes both multilayer and heterogeneous sorption. The nonlinear (Eq. 2.19) and linear (Eq. 2.20) form are expressed as:

$$
\begin{aligned}
& \mathrm{q}_{\mathrm{e}}=\mathrm{K}_{\mathrm{F}} \mathrm{C}_{\mathrm{e}}^{1 / \mathrm{n}} \\
& \log \mathrm{q}_{\mathrm{e}}=\log \mathrm{K}_{\mathrm{F}}+\frac{1}{\mathrm{n}} \log \mathrm{C}_{\mathrm{e}}
\end{aligned}
$$

where $\mathrm{K}_{\mathrm{F}}$ is the Freundlich constant and $\mathrm{n}$ is an indication of how favorable is the sorption process.

The experimental data were evaluated using the linear and nonlinear form of the models. For the linear model, both the Langmuir and Freundlich models fit well the experimental data (Table $2 \mathrm{~S}-2$ in the supplementary information), despite the first being a theoretical model and the latter an empirical one.

Several studies have investigated common data analysis errors when different models are used to describe the experimental data. For instance, El-Khaiary and Malash (2011) highlighted that the linearization of a nonlinear equation can affect the errorstructure of the data. Also, the use of the correlation coefficient $\left(\mathrm{R}^{2}\right)$ to determine which model fit best the experimental data can result in misleading indication of the quality of the fit. The $\mathrm{R}^{2}$ value can be influenced by extreme data points, the range of independent variables, and the number of parameters in the equation of the model. Osmari et al. (2013) found that the plot $\left(\frac{C_{e}}{q_{e}} v s . C_{e}\right)$ of the linear form of the Langmuir model can 
artificially create a high correlation between the model predictions and the experimental data. The reason for the artificial high correlation is that $\mathrm{C}_{\mathrm{e}}$ is use in both dependent and independent variables. For the Freundlich isotherm, the logarithmic transformation of the experimental data changes the statistical measurement of the error. However, the nonlinear form of both models seems to provide more consistent and reliable results. Therefore, experimental data were evaluated for Langmuir and Freundlich isotherm using the nonlinear model (Figure 2.9). The results showed that sorption of Huma-K cannot be described by a single isotherm model. Initially, the sorption of Huma-K onto SRS sediment fitted the Langmuir model, which assumes that a monolayer is formed. As the concentration of Huma- $\mathrm{K}$ is increased, the experimental data fitted better the Freundlich model, which assumes a multilayer formation. Other studies have also reported that the sorption of humic acid involves the formation of multiple adsorption layers caused by aggregation (Murphy et al., 1994; Petteys and Schimpf, 1998).

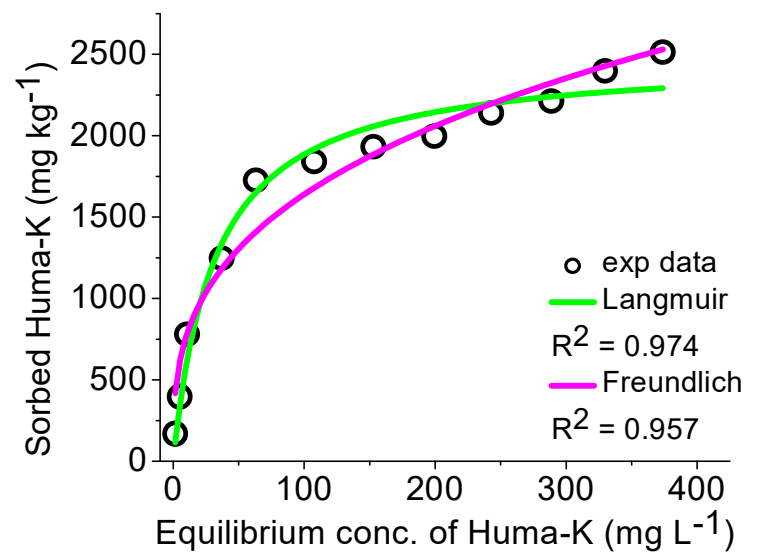

Figure 2.9 Non-linear fit of sorption isotherm of Huma-K on SRS sediment. 


\subsubsection{Desorption of Huma-K from SRS sediment}

Desorption studies were performed at the end of the sorption procedure of HumaK onto SRS sediment conducted at $\mathrm{pH} 4$ using DI water as the desorbing agent adjusted in a $\mathrm{pH}$ range between 4 and 8 (Figure 2.10a) to determine the effect of acidity on the desorption of Huma-K from SRS sediment. Desorption of Huma-K increased gradually with an increase of $\mathrm{pH}$ from $25 \%$ at $\mathrm{pH} 4$ to $65 \%$ at $\mathrm{pH} 8$. At $\mathrm{pH} 4$, the interactions in the sorbed layer remained relatively the same. Therefore, there is no increase in negative charges in humic molecules or the surface charge of sediments that could stimulate the desorption process (Avena and Koopal, 1998). As the $\mathrm{pH}$ is increased, the concentration of hydroxyl ions increases, which may enhance the detachment of carboxylic and phenolic groups of humic molecules from the surface of the sediment particles through a fast exchange with hydroxyl ions. Also, it was observed a slowly increase in Huma-K desorption from $\mathrm{pH} 4$ to 6 and then a sudden increase in Huma-K desorption at $\mathrm{pH} \geq 7$. Since carboxyl groups in Huma-K were found to have $\mathrm{p} K$ values in the range of 4-6 (obtained from DPT studies), it is expected that most of them to be fully deprotonated at $\mathrm{pH}$ 7. The deprotonation of carboxyl groups increases the net negative charge of humic molecules, which leads to a repulsion between humic molecules and the surface of the sediment and among humic molecules laterally, thus promoting desorption (Avena and Koopal, 1998).

Desorption of Huma-K did not reached completion when $\mathrm{pH}$ was change to less favorable conditions. There was a fraction of Huma-K still sorbed at $\mathrm{pH} 8$. Avena and Koopal (1998) suggested that two desorption processes occur when desorption of humic molecules is induced by changing the $\mathrm{pH}$. The first desorption process is fast because of 
the increase in repulsion between humic molecules and the decreased in attraction between humic molecules and the surface. The desorption process takes place until equilibrium is reached to the new $\mathrm{pH}$. The second desorption process is slow because once equilibrium is reached, the interactions in the adsorbed layer remains the same. There is no increase in the negative charges of humic molecules that could enhance desorption. The only driving force that promotes desorption is the decrease of humic molecules concentration in solution, which it is insufficient to promote a fast desorption. Therefore, it is believed that desorption of Huma-K at $\mathrm{pH} 8$ already reached an equilibrium, and further desorption will take place but a slow rate.
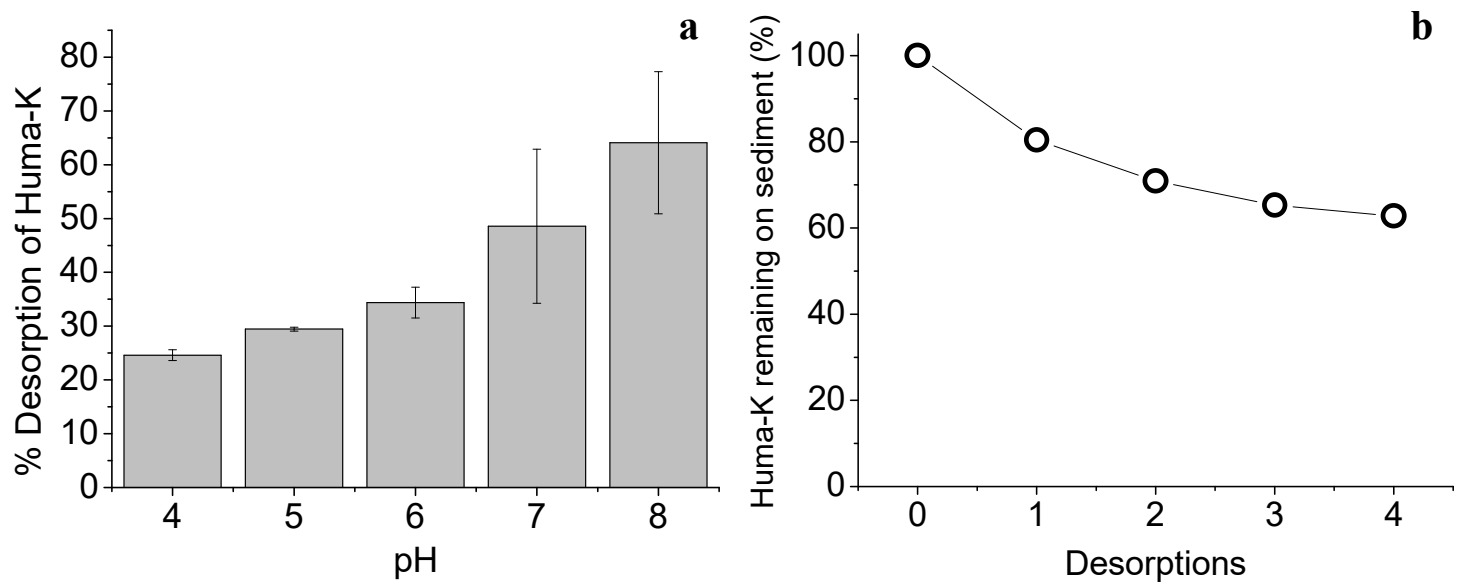

Figure 2.10 (a) Desorption of Huma-K from SRS sediment ( $\left.49 \mathrm{~g} \mathrm{~L}^{-1}\right)$ was conducted by first sorbing Huma-K $\left(\mathrm{C}_{\mathrm{i}}=50 \mathrm{mg} \mathrm{L}^{-1}\right)$ at $\mathrm{pH} 4$ and then desorbing Huma-K with DI water adjusted to $\mathrm{pH}$ ranging from $4-8\left(\mathrm{~T}=25^{\circ} \mathrm{C}, 5\right.$ days $)$. (b) Huma-K desorption from SRS sediment using DI water at $\mathrm{pH} 4$ in four desorption cycles.

In order to determine if Huma-K would be desorbed completely from SRS sediment, a four desorption cycle was performed at $\mathrm{pH} 4$ (Figure 2.10b). The results showed that after 4 desorption cycles, no significant loss of Huma-K from the sediment was observed. Since the $\mathrm{pH}$ of the DI water that replaced the supernatant was the same 
$(\mathrm{pH} 4)$, the interactions in the sorbed layer at the sediment surface remains relatively the same. Therefore, there is no increase in negative charges in humic molecules or the surface charge of sediments that could stimulate the desorption process. In addition, the ratios of absorbance from each desorption step at 465 and $665 \mathrm{~nm}\left(\mathrm{E}_{4} / \mathrm{E}_{6}\right.$ ratio $)$ were determined to explore the fractionation of Huma-K. The $\mathrm{E}_{4} / \mathrm{E}_{6}$ ratio is related to the humification degree (decomposition of organic matter) and molecular weight. A low ratio indicates a relative high degree of condensation of aromatic constituents while a high ratio indicates a low degree of aromatic condensation and the presence of relative large proportions of aliphatic structures. Fulvic acids, with lower molecular weight, have higher ratios (6-8). Humic acids, with a higher molecular weight, have lower ratios (3.3-5) (Tan, 2003). In Table 2.2, the $\mathrm{E}_{4} / \mathrm{E}_{6}$ ratios for the four desorption cycles were between $\sim 4$, so the fraction desorbed from SRS sediment correspond to humic acids. As the third desorption is reached, the $\mathrm{E}_{4} / \mathrm{E}_{6}$ ratio is lower compared to the first desorption. Humic acid molecules of higher molecular weight are more likely to resist desorption probably because they occupy more sorption sites compared to humic acid molecules of lower molecular weight. Also, it was observed that the fraction of Huma-K remaining in solution after sorption showed a $\mathrm{E}_{4} / \mathrm{E}_{6}$ ratio of 5.79 . The $\mathrm{E}_{4} / \mathrm{E}_{6}$ ratio of 5.79 indicates that humic molecules of lower molecular weight remain in solution while humic molecules of high molecular weight are preferentially sorbed onto the sediment.

Table 2.2 $\mathrm{E}_{4} / \mathrm{E}_{6}$ ratio of Huma-K desorption from SRS sediment.

\begin{tabular}{cccccc}
\hline & Sorption & \multicolumn{4}{c}{ Desorption cycles } \\
\hline & & 1 & 2 & 3 & 4 \\
\hline $\mathrm{E}_{4} / \mathrm{E}_{6}$ & 5.79 & 4.64 & 4.39 & 3.91 & 4.33 \\
\hline
\end{tabular}




\subsection{Conclusions}

The results of the present study indicate that Huma-K sorption and homogeneous precipitation are enhanced in acidic conditions similarly to purified humic acid materials; therefore, it is not justifiable using more expensive refined materials for remediation purposes in highly acidic conditions. The characterization of Huma-K indicates the presence of a diverse assemblage of functional groups, which can provide a broad range of chemical interactions with minerals and/or metals. The data suggest that sorption of Huma-K on SRS sediment in acidic conditions is governed by several mechanisms such as electrostatic interactions, ligand exchange surface complexation, hydrophobic interactions, homogeneous precipitation, and surface-induced precipitation. More importantly, desorption studies showed that in acidic conditions, desorption of Huma-K will be low unless a change in $\mathrm{pH}$ occurs that will promote desorption and mobilization of Huma-K. Therefore, the deployment of Huma-K is likely to be more effective in systems that have naturally acidic environment, such as at the SRS where background $\mathrm{pH}$ levels are 5.5. As such, there would be a natural tendency for the system to remain acidic and less prone to the release of bound-Huma$\mathrm{K}$. Huma-K is a promising low-cost amendment that could be used to remediate acidic groundwater plumes contaminated with heavy metals and radionuclides. 


\subsection{Supplementary information}
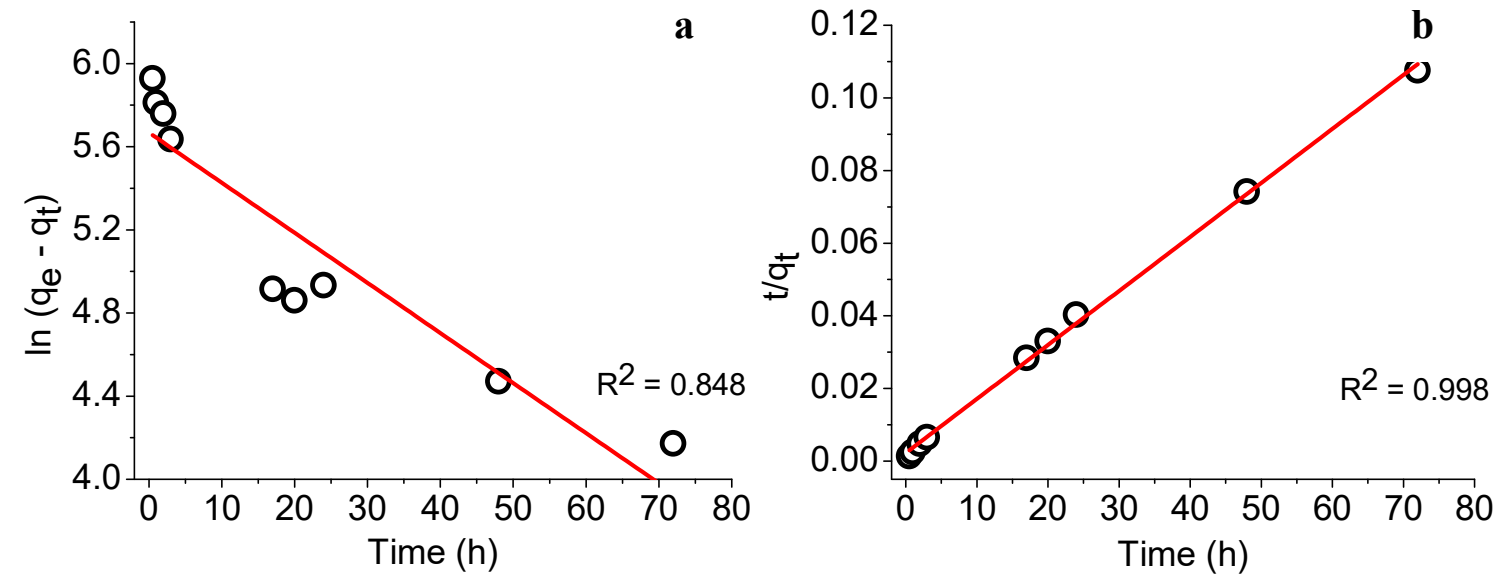

Figure 2S-1 Kinetic linear model plot of: (a) pseudo-first and (b) pseudo-second order. 
Table 2S-1 Kinetic Models

\begin{tabular}{|c|c|c|c|c|}
\hline $\begin{array}{l}\text { Kinetic } \\
\text { model }\end{array}$ & Linear equation & $\begin{array}{l}\text { Amount calculated } \\
\text { at equilibrium } \\
(\mathrm{mg} / \mathrm{kg})\end{array}$ & Plot & $\mathrm{R} 2$ \\
\hline $\begin{array}{l}\text { Pseudo-first } \\
\text { order }\end{array}$ & $\ln \left(q_{e}-q_{t}\right)=\ln \left(q_{e}\right)-k_{1} t$ & $\mathrm{q}_{\mathrm{e}, \mathrm{cal}}=178$ & $\ln \left(q_{e}-q_{t}\right)$ vs.t & 0.848 \\
\hline $\begin{array}{l}\text { Pseudo- } \\
\text { second order }\end{array}$ & $\frac{\mathrm{t}}{\mathrm{q}_{\mathrm{t}}}=\frac{1}{\mathrm{k}_{2} \mathrm{q}_{\mathrm{e}}^{2}}+\frac{1}{\mathrm{q}_{\mathrm{e}}} \mathrm{t}$ & $\mathrm{q}_{\mathrm{e}, \mathrm{cal}}=714$ & $\frac{\mathrm{t}}{\mathrm{q}_{\mathrm{t}}}$ vs.t & 0.998 \\
\hline
\end{tabular}

Table 2S-2 Isotherm Models

\begin{tabular}{|c|c|c|c|c|}
\hline $\begin{array}{l}\text { Isotherm } \\
\text { model }\end{array}$ & Linear equation & Parameters & Plot & $\mathrm{R} 2$ \\
\hline Langmuir & $\frac{\mathrm{C}_{\mathrm{e}}}{\mathrm{q}_{\mathrm{e}}}=\frac{1}{\mathrm{q}_{\mathrm{m}} \mathrm{K}_{\mathrm{L}}}+\frac{\mathrm{C}_{\mathrm{e}}}{\mathrm{q}_{\mathrm{m}}}$ & $\begin{array}{l}\mathrm{q}_{\mathrm{m}}=2500 \\
\mathrm{~K}_{\mathrm{L}}=0.0292\end{array}$ & $\frac{\mathrm{C}_{\mathrm{e}}}{\mathrm{q}_{\mathrm{e}}}$ vs. $\mathrm{C}_{\mathrm{e}}$ & 0.988 \\
\hline Freundlich & $\log q_{e}=\log K_{F}+\frac{1}{n} \log C_{e}$ & $\begin{array}{l}\mathrm{K}_{\mathrm{F}}=197.2 \\
\mathrm{n}=2.22\end{array}$ & $\log q_{e} v s \cdot \log C_{e}$ & 0.944 \\
\hline
\end{tabular}


Chapter 3. Evaluation of SRS sediment amended with Huma-K to enhance uranium sequestration 


\section{Abstract}

Despite the discontinuation of nuclear weapons production and the efforts to remediate contaminated areas, elevated levels of uranium $(\mathrm{U}(\mathrm{VI}))$ in groundwater are still found in many U.S. Department of Energy (DOE) facilities such as the Savannah River Site (SRS). In the present study, it was proposed to use a low-cost unrefined humic substance as an in situ amendment for the sequestration of $\mathrm{U}(\mathrm{VI})$ in acidic conditions. The sorption behavior of U(VI) with SRS sediment was investigated before and after amendment with Huma-K. None of the commonly used kinetic and adsorption models were able to describe the sorption of U(VI) onto SRS sediment. Only the Langmuir model for the sorption of U(VI) onto SRS sediment amended with Huma-K seems to provide a good fit with the experimental data. The results of the equilibrium studies indicate that $\mathrm{U}(\mathrm{VI})$ sorption onto SRS sediment amended with Huma-K exhibited significantly higher sorption capacity $\left(39.2 \mathrm{mg} \mathrm{kg}^{-1}\right)$ compared to plain sediment $\left(3.76 \mathrm{mg} \mathrm{kg}^{-1}\right)$. The presence of Huma-K strongly influences the sorption of $\mathrm{U}(\mathrm{VI})$ onto SRS sediment over the $\mathrm{pH}$ range studied. At $\mathrm{pH}$ below $6, \mathrm{U}(\mathrm{VI})$ sorption onto SRS sediment amended with Huma-K is enhanced compared to plain sediment. At circumneutral conditions, desorption of Huma-K from SRS sediment and the formation of dissolved uranium-humic complexes contribute to the decrease in U(VI) sorption. Desorption studies show high desorption of $\mathrm{U}(\mathrm{VI})$ at $\mathrm{pH} 3(\sim 70 \%)$, low desorption at pH 4-6 ( 10\%), and moderately desorption at pH $7(\sim 40 \%)$. The results indicate that Huma-K could be used to enhance attenuation of U(VI) in acidic plume. 


\subsection{Introduction}

For many years, anthropogenic activities associated with uranium mining and milling, nuclear weapons manufacturing and testing, and waste disposal practices have resulted in the contamination of soil and groundwater by radionuclides ( $\mathrm{Hu}$ et al., 2010). Although most of these practices were stopped years ago, there are still abandoned mine and tailing sites in existence today, such as the Taboshar and the Digmai site in Tajikistan. Studies have found that stream water emerging from the tailing mountain is characterized by elevated concentrations of uranium (Skipperud et al., 2013). Uranium mill tailings are known to exhibit a high sulfide content, which may acidify the groundwater and accelerate the dissolution of uranium and other heavy metals (Abdelouas, 2006). Also, groundwater at different DOE facilities have been contaminated by acidic plumes containing uranium (Wan et al., 2012; Wu et al., 2006).

Of the DOE facilities, the Savannah River Site in South Carolina is the location of interest in the present study. From the 1950s until the 1990s, groundwater was contaminated at multiple locations as a result of the release of acidic waste in unlined seepage basins from the production of nuclear weapons materials. The groundwater plume remains acidic and contains a large number of radionuclides including uranium isotopes, tritium $\left({ }^{3} \mathrm{H}\right)$, strontium $\left({ }^{90} \mathrm{Sr}\right)$, iodine $\left({ }^{129} \mathrm{I}\right)$, and other contaminants such as nitrate $\left(\mathrm{NO}_{3}^{-}\right)$, whose concentrations remain many times higher than drinking water standards (Wan et al., 2012).

Several remedial actions have been employed for the remediation of groundwater at the site, including a pump-and-treat systems and bioremediation methods. Pump-andtreat has often proven to be an expensive method and generate large quantities of 
radioactive solid waste (Denham and Vangelas, 2008). In situ stimulation of microorganisms to reduce soluble $\mathrm{U}(\mathrm{VI})$ to insoluble $\mathrm{U}(\mathrm{IV})$ solids have been investigated (Tokunaga et al., 2008). The in situ stimulation of microorganisms requires a continuous supply of organic carbon to maintain reducing conditions, and in order to be applied to acidic groundwaters, neutralization pretreatment is required to favor microbial activity (Wan et al., 2008; Wu et al., 2006). Therefore, the development of a cost-effective remediation technology is of vital importance to address uranium contamination in acidic groundwater plumes.

Humic substances have been proposed as a remediation technology for groundwater remediation (Perminova et al., 2005; Petrović et al., 1999). Humic substances are ubiquitous in the environment. They are characterized by a complex structure composed of a variety of different functional groups (Sachs and Bernhard, 2011). The presence of a variety of functional groups enables humic substances to interact with metal ions and organic molecules through ion exchange, complexation, redox transformation, and hydrophobic interactions. When sorbed to mineral surfaces, humic substances can retard the migration of metals (Perminova et al., 2005). Nonetheless, a potential challenge to the use of humic substances is the cost of materials. Since the remediation of contaminated groundwaters requires large quantities of the material, the processing and purification of humic substances can be expensive (Denham et al., 2015). Therefore, the objective of the present study is to explore the potential use of a low-cost unrefined humic substance (Huma-K) that could be used as an in situ amendment for the sequestration of uranium in acidic plumes. 


\subsection{Experimental methods}

\subsubsection{Materials}

Huma-K (Land and Sea Organics) a commercially available humic material extracted from Leonardite, was used in these experiments. Clean SRS sediment used in the sorption experiments (field borehole sampling FAW-1, depth interval 21.3-27.4 m) was collected from the aquifer near the F-Area seepage basins. The collected background sediment was selected because of similarities in mineral composition with the uranium contaminated aquifer sediment. The SRS sediment was sieved (U.S. Standard Testing Sieves, Fisher Scientific), and the sediment fraction with a particle diameter $\leq 2 \mathrm{~mm}$ was retained and used throughout the experiments. For comparison reasons, quartz (Ottawa Sand Standard 20-30 mesh, Fisher Scientific), kaolinite (Alfa Aesar), and goethite (Alfa Aesar) were used as reference minerals.

\subsubsection{Sorption of U(VI) onto SRS sediment with and without Huma-K amendment}

For the sorption experiments, a Huma-K stock solution of $1000 \mathrm{mg} \mathrm{L}^{-1}$ was prepared by dissolving $1000 \mathrm{mg}$ of Huma-K in $1 \mathrm{~L}$ of deionized (DI) water (Barnstead Nanopure Diamond Water Purification System, resistivity $\geq 18 \mathrm{M} \Omega \cdot \mathrm{cm})$. A commercial $1000 \mathrm{mg} \mathrm{L}^{-1}$ uranyl nitrate stock solution in $2 \%$ nitric acid (Fisher Scientific) was used as a source of $U(V I)$. All batch experiments were conducted in triplicate under normal atmospheric conditions $\left(\mathrm{P}_{\mathrm{CO} 2}=10^{-3.5}\right.$ atm and $\left.25^{\circ} \mathrm{C}\right)$.

In the first step, SRS sediment amended with Huma-K was prepared by bringing the sediment into contact with a Huma-K solution. Batch sorption experiments were conducted with $20 \mathrm{~mL}$ of aqueous suspension in DI water using $50 \mathrm{~mL}$ polypropylene 
centrifuge tubes, containing $200 \mathrm{mg}$ of SRS sediment $\left(10 \mathrm{~g} \mathrm{~L}^{-1}\right)$ spiked with a fixed concentration of Huma-K $\left(20 \mathrm{mg} \mathrm{L}^{-1}\right)$ at constant ionic strength $\left(\mathrm{I}=0.01 \mathrm{M} \mathrm{NaClO}_{4}\right)$ at pH 4. Samples were mixed with a vortex mixer (Maxi Mix Plus, Barnstead Thermolyne) for $30 \mathrm{sec}$ and then rotated for 5 days on a platform shaker at $100 \mathrm{rpm}$ (New Brunswick Scientific Innova 2000) to ensure thorough fluid-mineral contact throughout the sorption period. All samples were centrifuged for $30 \mathrm{~min}$ at $2700 \mathrm{rpm}$ (Thermo Scientific Sorvall ST 16R centrifuge), and the supernatant was withdrawn.

In the second step, samples containing $200 \mathrm{mg}$ of sediment (with and without Huma-K amendment) were brought in contact with a $20-\mathrm{mL}$ solution of DI water ( $\mathrm{I}=$ $0.01 \mathrm{M} \mathrm{NaClO}_{4}$ ) spiked with an initial U(VI) concentration specified below. Samples were vortex mixed, placed on a platform shaker, and centrifuged in a similar way as described above. The aqueous $\mathrm{U}(\mathrm{VI})$ concentration in the aqueous phase was measured by using kinetic phosphorescence analyzer (KPA-11, Chemchek). For the kinetic studies, an initial $\mathrm{U}(\mathrm{VI})$ concentration of $0.5 \mathrm{mg} \mathrm{L}^{-1}$ was allowed to equilibrate with the sediment for different time periods at $\mathrm{pH} 4$. For the equilibrium studies, the initial $\mathrm{U}(\mathrm{VI})$ concentration ranged from 0.025 to $1 \mathrm{mg} \mathrm{L}^{-1}$, and samples were reacted at $\mathrm{pH} 4$ for a period of 7 days (based on the kinetic study). The effect of $\mathrm{pH}$ on U(VI) sorption onto sediment was studied at a $\mathrm{pH}$ range of 3-8 for 7 days and an initial U(VI) concentration of $0.5 \mathrm{mg} \mathrm{L}^{-1}$. The $\mathrm{pH}$ was adjusted with $0.1 \mathrm{M} \mathrm{HCl}$ or $0.1 \mathrm{M} \mathrm{NaOH}$ during the reaction period. 


\subsubsection{Desorption experiments of U(VI) from SRS sediment with and without Huma-}

\section{K amendment}

Batch desorption experiments were conducted at a range of $\mathrm{pH}$ values (3-8). First, the sorption of $\mathrm{U}(\mathrm{VI})$ onto SRS sediment with and without Huma-K amendment at $\mathrm{pH} 4$ was done in a similar procedure as described in section 3.2.2. At the end of the sorption procedure, $\mathrm{U}(\mathrm{VI})$ desorption was carried out by replacing the supernatant with an equal volume of DI water at different $\mathrm{pH}$ values (3-8) and constant ionic strength $(\mathrm{I}=0.01 \mathrm{M}$ $\mathrm{NaClO}_{4}$ ). The $\mathrm{pH}$ was monitored daily and adjusted with $0.1 \mathrm{M} \mathrm{HCl}$ or $0.1 \mathrm{M} \mathrm{NaOH}$. Samples were rotated for 7 days and centrifuged as previously described, and the desorbed U(VI) concentration in the aqueous phase was determined.

\subsection{Results and discussions}

\subsubsection{Kinetic studies of U(VI) sorption onto SRS sediment with and without Huma- K amendment}

\subsubsection{Reaction-based kinetic models}

Kinetics experiments were conducted using SRS sediment with and without Huma-K amendment (Figure 3.1). Uranium (VI) sorption onto SRS sediment in the absence of Huma-K was characterized by a fast initial uptake, reaching equilibrium within 8 hours (0.33 days). The fast initial uptake is typical of many metal-mineral systems, in which the rapid initial sorption step is associated with reaction-controlled sorption. Then, it follows a slower sorption step attributed to diffusion-controlled sorption, sorption on sites of low reactivity, and surface precipitation (Bruemmer et al., 1988; Scheinost et al., 2001). For SRS sediment amended with Huma-K, a much slower 
$\mathrm{U}(\mathrm{VI})$ sorption was observed, reaching equilibrium within 7 days. It seems that the sorbed Huma-K alters the characteristics of the SRS sediment. On the other hand, the removal of $\mathrm{U}(\mathrm{VI})$ by Huma-K was higher $\left(30.5 \mathrm{mg} \mathrm{kg}^{-1}\right)$ compared to plain sediment (4.6 $\mathrm{mg} \mathrm{kg}^{-1}$ ). The slower $\mathrm{U}(\mathrm{VI})$ uptake could be attributed to the presence of humic molecules sorbed at the sediment surface, which might act as a physical barrier to the diffusion of $\mathrm{U}(\mathrm{VI})$ to the reactive sites. The interactions of $\mathrm{U}(\mathrm{VI})$ with humic molecules are assumed to occur mostly with carboxyl groups. Since carboxyl groups have $\mathrm{p} K$ values between 4 and 6 , the deprotonation of carboxyl groups facilitates the attraction and complexation with metal cations such as $\mathrm{U}(\mathrm{VI})$. The complexation of $\mathrm{U}(\mathrm{VI})$ with carboxyl groups in humic molecules causes a neutralization of the negative charges and induces coiling and folding of the humic molecules. As U(VI) sorption is continued, humic molecules adopt a more collapsed structure, making the diffusion of $\mathrm{U}(\mathrm{VI})$ to the remaining reactive sites more difficult. As a result, $\mathrm{U}(\mathrm{VI})$ uptake becomes slower, requiring more time in order to reach equilibrium.
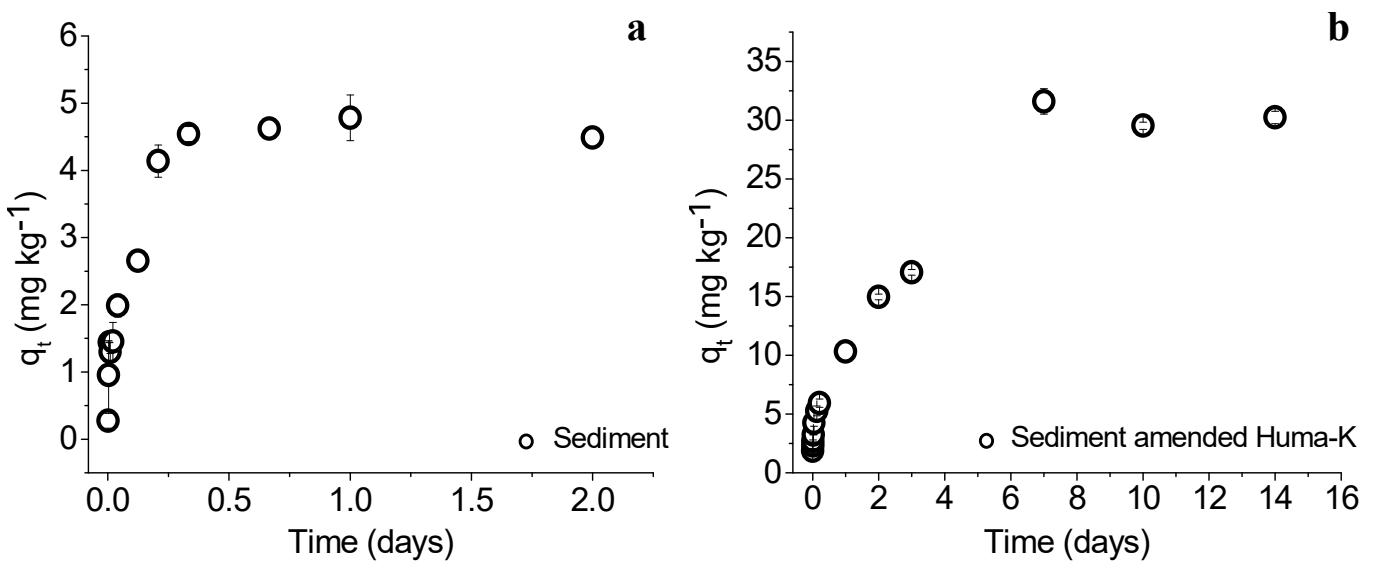

Figure 3.1 Kinetic study of U(VI) $\left(\mathrm{C}_{\mathrm{i}}=0.5 \mathrm{mg} \mathrm{L}^{-1}\right)$ sorption on (a) SRS sediment and (b) SRS sediment amended with Huma-K $\left(10 \mathrm{~g} \mathrm{~L}^{-1}\right.$ of sediment, $\mathrm{pH}$, I $=0.01 \mathrm{M} \mathrm{NaClO}_{4}$, and $\left.\mathrm{T}=25^{\circ} \mathrm{C}\right)$. 
The experimental data were evaluated on the basis of various nonlinear kinetic models including pseudo-first and pseudo-second order models as explained in Chapter 2. The results from the nonlinear kinetic models for SRS sediment with and without Huma-K amendment showed that neither pseudo-first nor pseudo-second order models were able to provide a good fit with the experimental data (Figure 3.2). Kinetic models have been developed to describe binary systems (one sorbing compound and one sorbent). In the present study, the system is more complex, consisting of a mixture of different minerals in the SRS sediment and different organic compounds in the HumaK. For that reason, kinetic models were not able to provide a good fit with the experimental data.
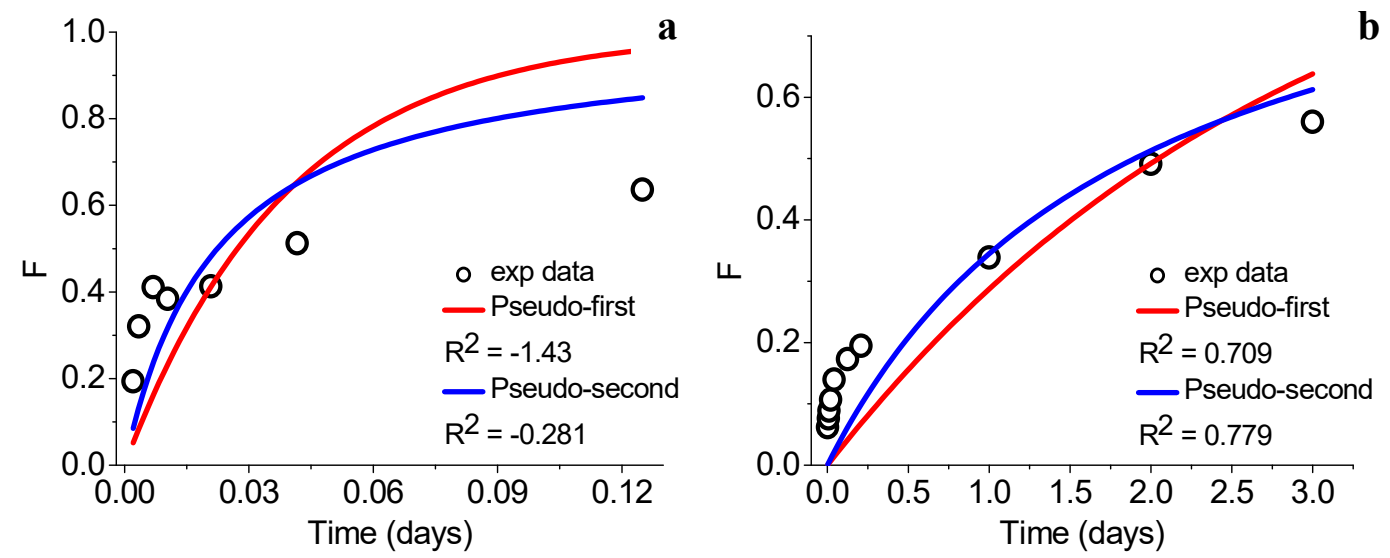

Figure 3.2 Non-linear fit of F data for (a) SRS sediment ( $t \leq 0.125$ days) and (b) SRS sediment amended with Huma-K ( $\mathrm{t} \leq 3$ days).

\subsubsection{Equilibrium studies of U(VI) sorption onto SRS sediment with and without \\ Huma-K amendment}

Equilibrium studies of U(VI) sorption onto SRS sediment with and without Huma$\mathrm{K}$ amendment were investigated to determine the sorption capacity for both systems in acidic conditions (Figure 3.3). The experimental data showed that SRS sediment 
amended with Huma-K $\left(39.2 \mathrm{mg} \mathrm{kg}^{-1}\right)$ has a significantly higher sorption capacity compared to plain sediments $\left(3.76 \mathrm{mg} \mathrm{kg}^{-1}\right)$ for the range of $\mathrm{U}(\mathrm{VI})$ concentrations studied. The low sorption capacity of plain sediment is attributed to a low abundance of binding sites available at the sediment surface in acidic conditions. On the other hand, the increased sorption capacity in sediments amended with Huma-K could be attributed to the presence of carboxyl and phenolic $\mathrm{OH}$ groups, which are considered to be mainly responsible for the complexation of U(VI) (Kremleva et al., 2009; Pompe et al., 2000). Complexation of humic substances with U(VI) can occur in monodentate, bidentate, and chelate form (Figure 3.4) (Sundararajan et al., 2011). Extended X-ray absorption fine structure (EXAFS) spectroscopy studies have shown that the complexation between uranyl ions and the carboxyl groups of humic acid occurs in a monodentate fashion at low pH (Denecke et al., 1997; Schmeide et al., 2003).

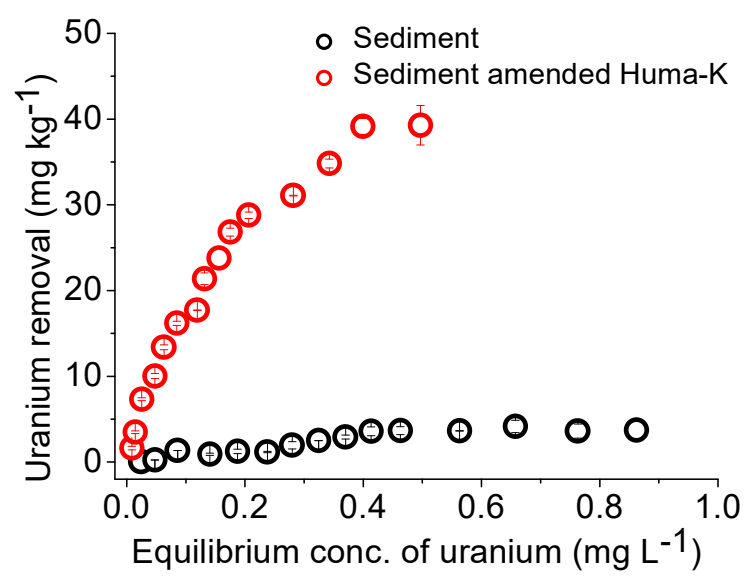

Figure 3.3 Sorption isotherm of U(VI) $\left(C_{i}=0.025-1 \mathrm{mg} \mathrm{L}^{-1}\right)$ on SRS sediment with and without Huma-K amendment for 7 days $\left(10 \mathrm{~g} \mathrm{~L}^{-1}\right.$ of sediment, $\mathrm{pH} 4, \mathrm{I}=0.01 \mathrm{M}$ $\mathrm{NaClO}_{4}$, and $\mathrm{T}=25^{\circ} \mathrm{C}$ ). 
a

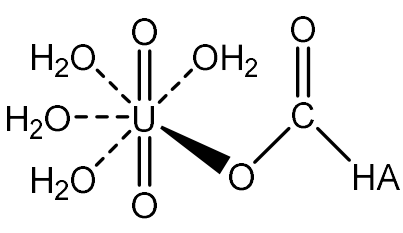

b

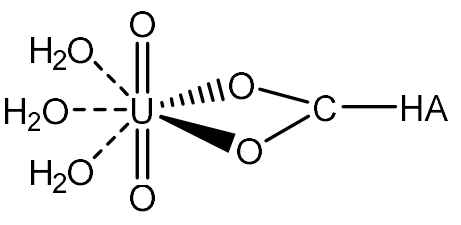

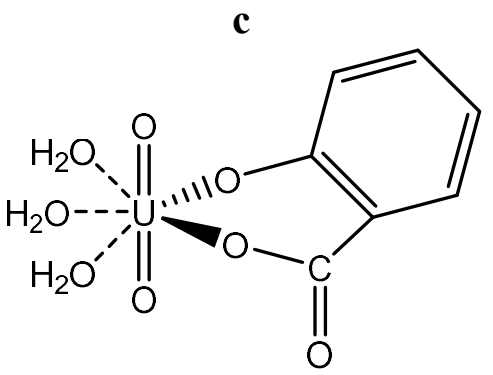

Figure 3.4 Coordination modes of carboxyl and phenolic $\mathrm{OH}$ groups of humic acid (HA) with the uranyl ion: (a) monodentate, (b) bidentate, and (c) chelate form.

In order to describe the sorption equilibrium, the Langmuir and Freundlich sorption isotherm models were applied as explained in Chapter 2. The Langmuir model assumes that adsorption takes place at specific homogeneous sites, and the surface contains a finite number of adsorption sites. The Freundlich model assumes a heterogeneous surface site as well as multilayer sorption. For SRS sediment, the Langmuir and Freundlich models were not able to describe the sorption process of $\mathrm{U}(\mathrm{VI})$ because sediments are heterogeneous (mixture of different minerals), and the Langmuir and Freundlich model work better for more homogeneous materials (Figure 3.5a). In the case of SRS sediment amended with Huma-K, the Langmuir model better described the sorption of U(VI) compared to the Freundlich model (Figure 3.5b). The good fit by the Langmuir model indicates that $\mathrm{U}(\mathrm{VI})$ might be interacting with a single class of binding sites (e.g., carboxyl groups), resulting in the good fit with the Langmuir model. Once all the binding sites in Huma-K are occupied, no further sorption should take place. 

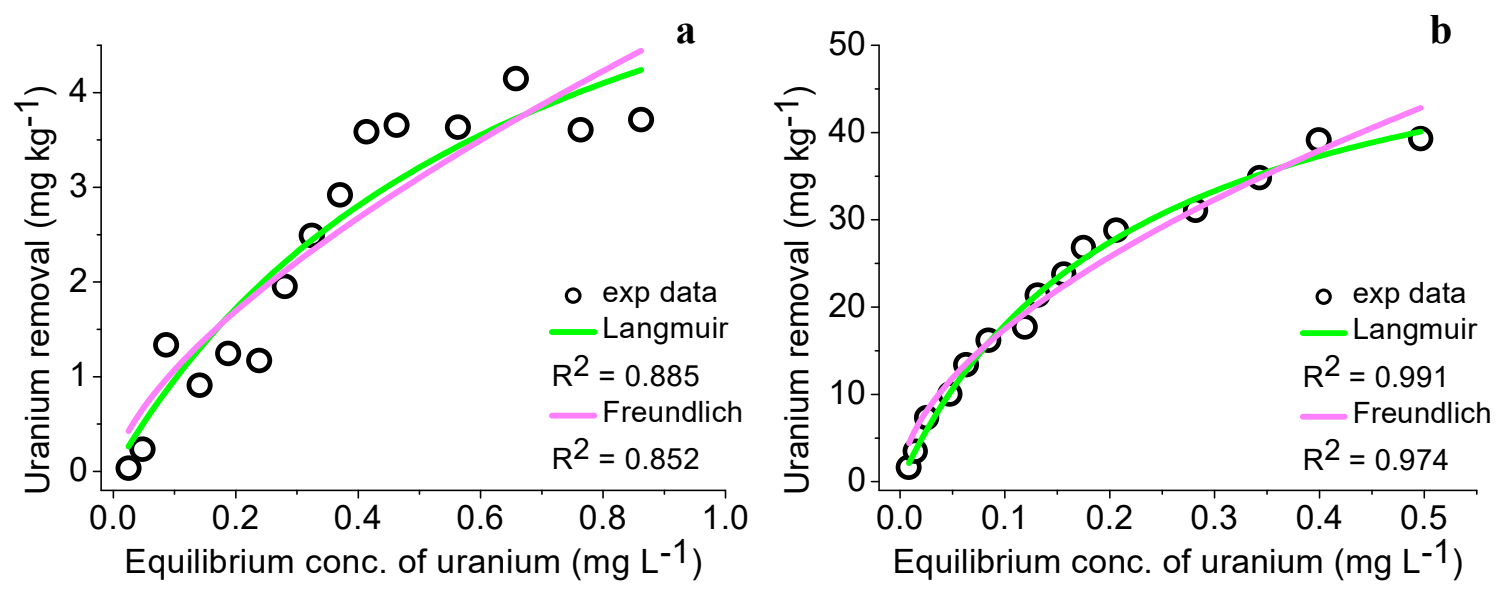

Figure 3.5 Non-linear fit adsorption isotherm for (a) SRS sediment and (b) SRS sediment amended with Huma-K.

\subsubsection{Effect of pH on U(VI) sorption on SRS sediment with and without Huma-K}

\section{amendment}

The interactions between U(VI) and SRS sediment with and without Huma-K amendment was investigated as a function of $\mathrm{pH}$ (Figure 3.6). In the case of $\mathrm{U}(\mathrm{VI})$ sorption onto SRS sediment, a three $\mathrm{pH}-$ dependent region can be distinguished. For $\mathrm{pH}$ $\leq 4$, the $\mathrm{U}(\mathrm{VI})$ sorption was very low $(\sim 10 \%)$. At low $\mathrm{pH}$, there is a competition between $\mathrm{H}^{+}$and $\mathrm{UO}_{2}^{2+}$ for the binding sites, thus limiting the sorption of $\mathrm{U}(\mathrm{VI})$. For $4 \leq$ $\mathrm{pH} \leq 7$, the sorption of $\mathrm{U}(\mathrm{VI})$ increased up to $\sim 88 \%$, indicating an increase in the chemical affinity between $\mathrm{U}(\mathrm{VI})$ species and SRS sediment. For $\mathrm{pH}>7.5$, the sorption of U(VI) seemed to start to decrease. In basic conditions, carbonate ions compete for the complexation with $\mathrm{U}(\mathrm{VI})$ in solution, hindering its sorption.

The SRS sediment amended with Huma-K showed a strong influence in the sorption of $\mathrm{U}(\mathrm{VI})$, and a three $\mathrm{pH}-$ dependent region could be distinguished (Figure 3.6). For $3 \leq \mathrm{pH} \leq 5, \mathrm{U}(\mathrm{VI})$ sorption increased from $26 \%$ up to $\sim 74 \%$. Since $\mathrm{U}(\mathrm{VI})$ is strongly sorbed by the carboxyl groups, the increase in $\mathrm{U}(\mathrm{VI})$ sorption is attributed to 
the increasing ionization of the carboxyl groups in humic molecules. When compared to plain sediment, the sediment amended with Huma-K showed a higher U(VI) sorption capacity. One could think that the amendment of SRS sediment with Huma-K would block the binding sites at the sediment surface, causing a reduction in U(VI) sorption. However, the numbers of binding sites that may have been lost at the sediment surface from the amendment are overcompensated by the additional binding sites from the Huma-K. Several studies have identified the formation of the binary complex between $\mathrm{U}(\mathrm{VI})$ and humic acid (HA) in acidic conditions (Eq. 3.1) (Pashalidis and Buckau, 2007; Steudtner et al., 2011a). For $5 \leq \mathrm{pH} \leq 7$, the sorption of $\mathrm{U}(\mathrm{VI})$ remained relatively the same $(\sim 70 \%)$. It is believed that the ternary complexes between $\mathrm{U}(\mathrm{VI})$ with humic acid and inorganic ligands such as $\mathrm{OH}^{-}$start to form (Eq. 3.2). Above $\mathrm{pH}$ 7, $\mathrm{U}(\mathrm{VI})$ sorption started to decrease. At basic conditions, carbonate species compete with humic molecules for the complexation of U(VI). According to Steudtner et al. (2011b), ternary carbonato humate complexes can form (Eq. 3.3). However, the formation of the ternary carbonato humate complexes might be prevented because of electrostatic repulsion between inorganic carbonate $\left(\mathrm{CO}_{3}^{2-}\right)$ and the negative charges of the functional groups in humic molecules charges (Efstathiou and Pashalidis, 2017).

$$
\begin{array}{ll}
\mathrm{UO}_{2}^{2+}+\mathrm{HA} \rightleftarrows \mathrm{UO}_{2} \mathrm{HA} & \log \beta=6.21 \mathrm{~mol}^{-1} \\
\mathrm{UO}_{2} \mathrm{OH}^{+}+\mathrm{HA} \rightleftarrows \mathrm{UO}_{2}(\mathrm{OH}) \mathrm{HA} & \log \beta=6.941 \mathrm{~mol}^{-1} \\
\mathrm{UO}_{2}\left(\mathrm{CO}_{3}\right)_{3}^{4-}+\mathrm{HA} \rightleftarrows \mathrm{UO}_{2}\left(\mathrm{CO}_{3}\right)_{2} \mathrm{HA}^{4-}+\mathrm{CO}_{3}^{2-} & \log \beta=2.831 \mathrm{~mol}^{-1}
\end{array}
$$

Aliquots of the supernatant of the samples containing SRS sediment with Huma-K amendment were filtered using a $0.45 \mu \mathrm{m}$ PTFE filter. It was observed that the filtration of the samples increased the removal of $\mathrm{U}(\mathrm{VI})$ for the range of $\mathrm{pH}$ studied (Figure 3.6). 
The removal of $\mathrm{U}(\mathrm{VI})$ by filtration indicates that there is a fraction of $U(V I)$ in the suspended particulate matter form that is associated with either mineral particles or humic molecules being desorbed, which can form aqueous complexes with U(VI). With an increase of $\mathrm{pH}$, carboxyl groups in humic molecules become more and more deprotonated. The deprotonation of carboxyl groups increases the negative charges in humic molecules and enhances the desorption of humic molecules from sediments (see results in Figure 2.10 of Chapter 2). Even thought, there is a fraction of U(VI) in the suspended particulate matter form, SRS sediment can act as a natural filter to stop the migration of U(VI) because SRS sediment has a total porosity ranging from 0.4 to 0.6 (Looney et al., 1987).

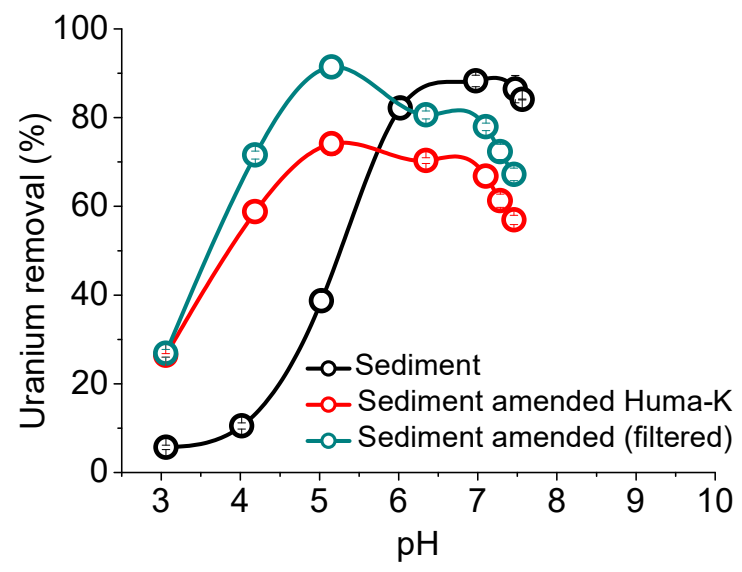

Figure 3.6 \%Removal of $U(V I)\left(C_{i}=0.5 \mathrm{mg} \mathrm{L}^{-1}\right)$ from the aqueous phase as a function of $\mathrm{pH}\left(10 \mathrm{~g} \mathrm{~L}^{-1}\right.$ of sediment, 7 days, $\mathrm{I}=0.01 \mathrm{M} \mathrm{NaClO}_{4}$, and $\left.\mathrm{T}=25^{\circ} \mathrm{C}\right)$.

\subsubsection{Comparison of U(VI) sorption onto quartz, kaolinite, goethite, and SRS}

\section{sediment}

The SRS sediment is composed of quartz (93.2\%), kaolinite (5.1\%), and goethite $(1.1 \%)$ on the basis of the characterization studies in section 2.2.2 in Chapter 2. For comparison reasons, quartz, kaolinite and goethite were used as a reference mineral to 
determine their contributions for the removal of $\mathrm{U}(\mathrm{VI})$. Quartz $\left(\mathrm{SiO}_{2}\right)$ consists of a $\mathrm{SiO}_{4}$ tetrahedra, in which the silicon atom is bonded to four oxygen atoms and each oxygen is bonded to two silicon atoms. The quartz surface is characterized for having silanol groups with $\mathrm{p} K$ values of -1.0 and 4.0 (Eq. 3.4 and 3.5) (Duval et al., 2002).

$$
\begin{array}{ll}
\equiv \mathrm{SiOH}+\mathrm{H}^{+} \rightarrow \equiv \mathrm{SiOH}_{2}^{+} & \mathrm{p} K_{1}=-1.0 \\
\equiv \mathrm{SiOH} \rightarrow \equiv \mathrm{SiO}^{-}+\mathrm{H}^{+} & \mathrm{p} K_{2}=4.0
\end{array}
$$
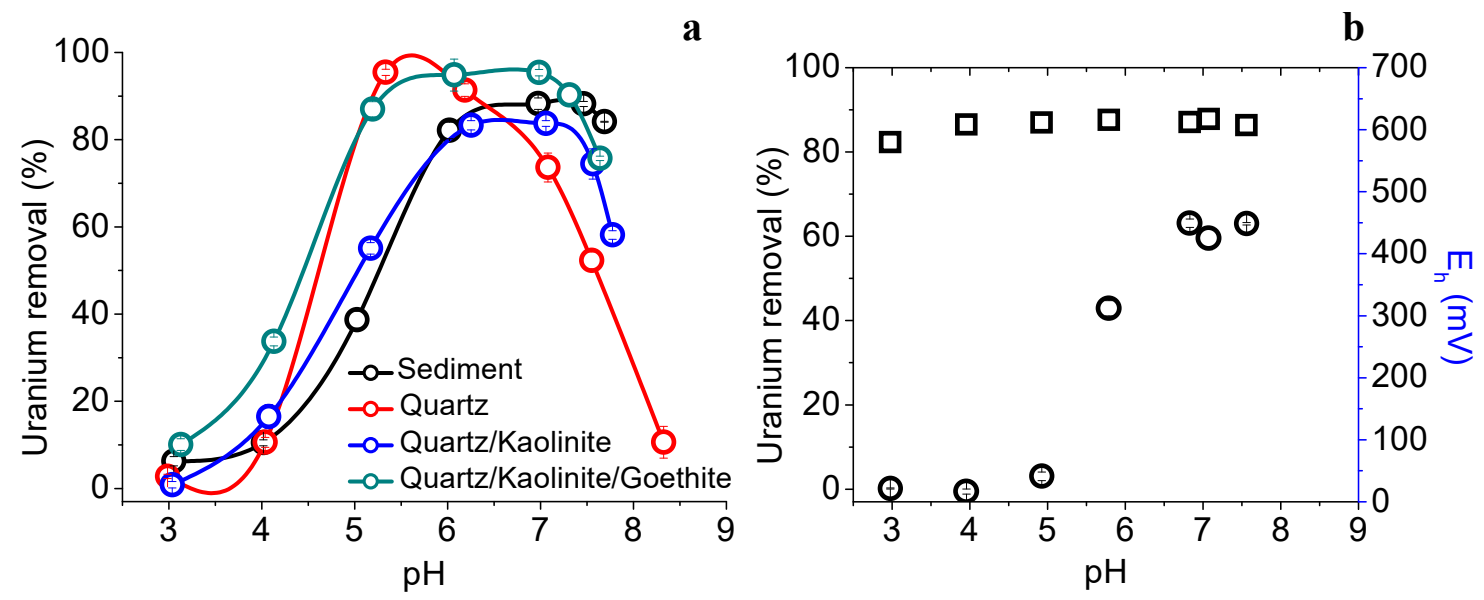

Figure 3.7 (a) Comparison of $\mathrm{U}(\mathrm{VI})\left(\mathrm{C}_{\mathrm{i}}=0.5 \mathrm{mg} \mathrm{L}^{-1}\right)$ removal for SRS sediment, quartz (100\%), quartz/kaolinite (95\%:5\%), quartz/kaolinite/goethite (93\%:5\%:2\%). (b) Control samples with no sediment (circles) and $\mathrm{E}_{\mathrm{h}}$ (squares). ( 7 days, $\mathrm{I}=0.01 \mathrm{M} \mathrm{NaClO}_{4}$, and $\mathrm{T}=$ $\left.25^{\circ} \mathrm{C}\right)$.

The results in Figure 3.7a showed that for quartz, U(VI) sorption was very low at $\mathrm{pH} \leq 4(\sim 10 \%)$. At low $\mathrm{pH}, \mathrm{SiOH}$ sites outnumber $\mathrm{SiO}^{-}$sites. According to Greathouse et al. (2002), an outer-sphere sorption mechanism seems to be favored on the protonated quartz surface. With an increase of $\mathrm{pH}$, it was observed a sharp increase in the sorption of $\mathrm{U}(\mathrm{VI})$ at $\mathrm{pH} 5(\sim 95 \%)$. The sharp increase is attributed to the deprotonation of the silanol groups $\left(\mathrm{SiO}^{-}\right)$, which makes the quartz surface to become more negatively charged. The deprotonation of the silanol groups at the quartz surface and the formation of aqueous U(VI) hydroxyl complexes contribute to the formation of 
surface complexes between quartz and U(VI) (Prikryl et al., 2001). Above pH 6, a significant decline in the sorption of U(VI) was observed. The formation of uraniumcarbonate complexes can suppress the sorption onto quartz because of electrostatic repulsion between negatively charged species. Molecular dynamic simulations have indicated that inner-sphere surface complex can be formed between U(VI) and the quartz surface when only one carbonate ion is coordinated to U(VI). However, when $\mathrm{U}(\mathrm{VI})$ is coordinated with two carbonate ions, inner-sphere complexation is not favorable (Greathouse et al., 2002). When compared to SRS sediment, quartz did not follow the same $\mathrm{pH}$-dependent trend on $\mathrm{U}(\mathrm{VI})$ removal. It is believed that other minerals might be contributing to the removal of $\mathrm{U}(\mathrm{VI})$ in the range of $\mathrm{pH}$ studied.

Kaolinite $\left(\mathrm{Al}_{2} \mathrm{Si}_{2} \mathrm{O}_{5}(\mathrm{OH})_{4}\right)$ is a 1:1 dioctahedral aluminosilicate mineral whose structure is composed of an $\mathrm{Al}$ octahedral sheet connected to one Si tetrahedral sheet by bridging oxygens. The interaction between the layers is primarily through hydrogen bonds. The Si tetrahedral surface is considered to be hydrophobic characterized by a small permanent (non-pH dependent) negative charge. On the other hand, the $\mathrm{Al}$ octahedral surface is considered to be hydrophilic characterized by a positive charge. It is believed that the $\mathrm{Al}$ octahedral surface is more reactive than the $\mathrm{Si}$ tetrahedral surface because the Al octahedral surface contains hydroxyl groups while the Si tetrahedral surface contains only coordinatively saturated oxygen centers (Kremleva et al., 2008). At the $\mathrm{Al}$ octahedral surface, there are $\equiv \mathrm{Al}_{2} \mathrm{OH}$ groups that can be protonated at $\mathrm{pH}<3$ and deprotonated at $\mathrm{pH}>9$ (Huertas et al., 1998). In addition, kaolinite possesses edge surfaces, in which the exposed $\mathrm{Al}$ and $\mathrm{Si}$ are usually terminated by hydroxyl groups. The edge surfaces are generally considered to be more reactive than the Al octahedral or 
the Si tetrahedral surface as their charge is affected by changing the $\mathrm{pH}$ (Wang and Siu, 2006). The $\mathrm{pK}$ values for the $\mathrm{AlOH}_{2}^{+}, \mathrm{AlOH}$, and $\mathrm{SiOH}$ found at the edge surface of kaolinite are estimated to be 2.33, 5.28, and 8.23, respectively (Brady et al., 1996).

The results for the mix quartz/kaolinite in Figure 3.7a showed that U(VI) sorption was very similar $(\sim 16 \%)$ at $\mathrm{pH} \leq 4$ as in the case of quartz. The low contribution of kaolinite to the sorption of $\mathrm{U}(\mathrm{VI})$ at low $\mathrm{pH}$ is attributed to the presence of protonated aluminol groups $\left(\equiv \mathrm{Al}_{2} \mathrm{OH}_{2}^{+}\right)$, which causes an electrostatic repulsion between the kaolinite surface and the positively charged $\mathrm{UO}_{2}^{2+}$ species. Silanol groups from the quartz surface contribute only to negative charges. Therefore, sorption of $\mathrm{UO}_{2}^{2+}$ through electrostatic attraction should be favorable at the silanol surface sites. With an increase of $\mathrm{pH}$, the sorption of $\mathrm{U}(\mathrm{VI})$ increased, reaching a saturation at $\mathrm{pH} 6(\sim 83 \%)$. The formation of hydrolyzed U(VI) species and the presence of neutral aluminol groups at the kaolinite surface should facilitate the sorption of $U(V I)$. Above $p H$ 7, U(VI) sorption started to decline. The formation of negatively charged uranyl-carbonate species decreases the U(VI) onto the negatively charged surface of both quartz and kaolinite. In the presence of carbonate species, uranyl dicarbonate surface complexes are unfavorable at the surface of kaolinite because of steric hindrance caused by the two carbonate ions (Kerisit and Liu, 2014). When compared to SRS sediment, the quartz/kaolinite mix followed a very similar pH-dependent trend for U(VI) removal. Above $\mathrm{pH} 6$, there is a slight difference in $\mathrm{U}(\mathrm{VI})$ for both systems, probably caused by the presence of goethite in SRS sediment.

Goethite $(\alpha-\mathrm{FeOOH})$ is an oxyhydroxide mineral characterized for having a needle-shape morphology. The goethite surface contains singly coordinated $(\mathrm{FeOH})$, 
doubly coordinated $\left(\mathrm{Fe}_{2} \mathrm{OH}\right)$, and triply coordinated $\left(\mathrm{Fe}_{3} \mathrm{OH}\right)$ hydroxyl groups (Cornell and Schwertmann, 2003). Villalobos and Pérez-Gallegos (2008) suggested that the doubly coordinated groups tend to be nonreactive except when present on the (210) and (010) faces of the goethite crystal, while the triply coordinated groups are considered to be nonreactive. Kevin and Louise (2012) estimated a $\mathrm{pK}$ value of 7 for the $\mathrm{FeOH}_{2}^{+}$ group on the (101) face of the goethite crystal. Also, Lövgren et al. (1990) reported similar pK values for the behavior of goethite interaction with water (Eq. 3.6 and 3.7).

$$
\begin{array}{ll}
\equiv \mathrm{FeOH}_{2}^{+} \rightleftarrows \equiv \mathrm{FeOH}+\mathrm{H}^{+} & \mathrm{p} K_{1}=7.47 \\
\equiv \mathrm{FeOH} \rightleftarrows \equiv \mathrm{FeO}^{-}+\mathrm{H}^{+} & \mathrm{p} K_{2}=9.51
\end{array}
$$

The results for the quartz/kaolinite/goethite mix in Figure 3.7a showed that at $\mathrm{pH}$ $\geq 4$, goethite became an important sorbent for $\mathrm{U}(\mathrm{VI})$. At $\mathrm{pH}<4$ goethite is not believed to contribute to the sorption of $\mathrm{U}(\mathrm{VI})$ because there is an electrostatic repulsion between the protonated sites $\left(\mathrm{FeOH}_{2}^{+}\right)$at the goethite surface and the positively charged $\mathrm{UO}_{2}^{2+}$ species. With an increase of $\mathrm{pH}$, the sorption of $\mathrm{U}(\mathrm{VI})$ increased and reached a maximum at $\mathrm{pH} \sim 6(95 \%)$ in spite of the fact that both uranyl species and the surface of goethite are positively charged. Sherman et al. (2008) proposed that in the presence of $\mathrm{CO}_{2}, \mathrm{U}(\mathrm{VI})$ sorption is enhanced thorough the formation of ternary complexes such as $\equiv \mathrm{FeOCO}_{2} \mathrm{UO}_{2}$ and $(\equiv \mathrm{FeOH})_{2} \mathrm{UO}_{2} \mathrm{CO}_{3}$ on the goethite surface. Above $\mathrm{pH} 7.5$, the sorption of $\mathrm{U}(\mathrm{VI})$ started to decline most likely caused by the formation of strong uranyl-carbonate complexes in solution. When compared to SRS sediment, the quartz/kaolinite/goethite mix showed an increase in $\mathrm{U}(\mathrm{VI})$ sorption. It is believed that the content of goethite in SRS sediment used in the batch experiments may be less than in the quartz/kaolinite/goethite mix. 
In addition, control experiments using sediment-free batches were conducted to monitor $\mathrm{U}(\mathrm{VI})$ loss in the range of $\mathrm{pH}$ studied. It was observed that at $\mathrm{pH} \leq 5, \mathrm{U}(\mathrm{VI})$ loss was minimal $(\sim 3 \%)$. On the other hand, $\mathrm{U}(\mathrm{VI})$ removal $(\sim 60 \%)$ started to become significant at $\mathrm{pH} \geq 6$, which is believed to be caused by precipitation (Figure $3.7 \mathrm{~b}$ ). A possible explanation is that with an increase in $\mathrm{pH}, \mathrm{U}(\mathrm{VI})$ becomes increasingly hydrolyzed and forms oligomeric species that might have led to the precipitation of $\mathrm{U}(\mathrm{VI})$ as schoepite $\left(\mathrm{UO}_{3} \cdot 2.25 \mathrm{H}_{2} \mathrm{O}\right)$ (Eq. 3.8). Precipitation of $\mathrm{U}(\mathrm{VI})$ is favored in the absence of $\mathrm{CO}_{2}$ while in the presence of $\mathrm{CO}_{2}, \mathrm{U}(\mathrm{VI})$ precipitation is suppressed because of the high metal-complexing ability of carbonates, which results in the increased solubility of $\mathrm{U}(\mathrm{VI})$. In the present study, the samples were likely not in complete equilibrium with atmospheric $\mathrm{CO}_{2}$ even though the samples were open to atmospheric $\mathrm{CO}_{2}$ daily. The failure to achieved full equilibration with $\mathrm{CO}_{2}$ might have caused the precipitation of $\mathrm{U}(\mathrm{VI})$.

$$
\mathrm{UO}_{2}^{2+}+3 \mathrm{H}_{2} \mathrm{O} \rightleftarrows \mathrm{UO}_{3} \cdot 2.25 \mathrm{H}_{2} \mathrm{O}_{(\mathrm{s})}+2 \mathrm{H}^{+}
$$

Thermodynamic modeling calculations were performed with Geochemist's Workbench 12.0 for mineral saturation by using the experimental conditions in the present study in the presence and absence of $\mathrm{CO}_{2}$. The model uses the mineral saturation index $\left(S I=\log \left(\frac{\mathrm{Q}}{\mathrm{K}}\right)\right)$ to predict the tendency of a mineral to dissolve or form. If $\frac{\mathrm{Q}}{\mathrm{K}}$ is less than 1 , the system is undersaturated, so the mineral is not formed. If $\frac{\mathrm{Q}}{\mathrm{K}}$ is greater than 1 , the system is supersaturated, favoring the precipitation and formation of the mineral. The results of the modeling shown in Fig. 3S-1 in the supplementary information indicate that, in the presence of $\mathrm{CO}_{2}$, no precipitation and formation of 
minerals occur. On the other hand, in the absence of $\mathrm{CO}_{2}$, the mineral $\mathrm{UO}_{2} \mathrm{OH}_{2}$ (beta) is formed at $\mathrm{pH} 8$-9. In our study, most of the U(VI) lost in the control samples were at $\mathrm{pH}$ $7-8$, very close to the region were mineral saturation occurs.

Redox potential $\left(E_{h}\right)$ was measured in all of the samples at the end of the experiment to verify that reducing conditions had not developed, which could favor the reduction of $U(V I)$ to $U(I V)$, a less soluble form. The samples in Figure $3.7 b$ showed a

constant $\mathrm{E}_{\mathrm{h}}$ value $(\sim 600 \mathrm{mV})$, indicating that uranium in the experimental conditions of the study was in the oxidation state (VI) (Fig. 3S-2 in the supplementary information).

\subsubsection{Dissolution of ions from SRS sediment}

The dissolution of aluminum (Al) was observed at $\mathrm{pH}<4$ and at $\mathrm{pH}>6$, whereas the dissolution of silicon ( $\mathrm{Si}$ ) was at $\mathrm{pH}>6$ (Figure 3.8). Iron (Fe) was not detected in solution. Lövgren et al. (1990) studied Al sorption onto goethite, and the study observed surface complexation of $\mathrm{Al}$ onto goethite, starting to occur already at $\mathrm{pH} 3.5$. It is believed that the presence of $\mathrm{Al}$ in solution might decrease the sorption of U(VI) through binding competition. In the case of Si, Hiemstra et al. (2007) observed that dissolved Si can be sorbed in the goethite surface, reaching a maximum sorption around $\mathrm{pH}$ 9. The authors suggested that from the interaction of $\mathrm{Si}$ with a protonated surface $\left(\equiv \mathrm{SH}_{m}\right)$, a net amount of protons are released per mole of Si bound. According to the equation 3.9, if there is an increase in the protons concentration, the equilibrium of the reaction will shift to the left, not favoring the sorption of $\mathrm{Si}$ as the $\mathrm{pH}$ is decreased. It is believed that silicate ions might influence in the sorption of U(VI) onto goethite through 
binding competition at circumneutral and basic conditions. However, still there is no evidence that can support the effect of Si on U(VI) sorption onto goethite.

$$
\equiv \mathrm{SH}_{m}+\mathrm{H}_{n} \mathrm{SiO}_{4}^{n-4} \rightleftarrows \equiv \mathrm{SH}_{m+n-p} \mathrm{SiO}_{4}^{n-4-p}+p \mathrm{H}^{+}
$$

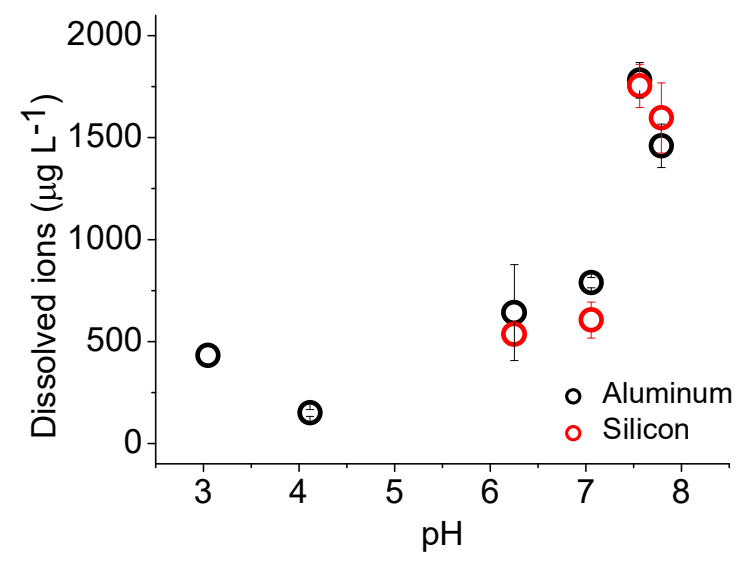

Figure 3.8 Dissolution of aluminum and silicon from SRS sediment.

\subsubsection{Desorption of U(VI) from SRS sediment with and without Huma-K amendment}

Desorption is a very important parameter in the understanding of the mobility, bioavailability and fate of metals in the environment. Desorption studies were conducted by first sorbing U(VI) onto SRS sediment with and without Huma-K amendment at $\mathrm{pH} 4$. To evaluate the desorption process, DI water adjusted to different $\mathrm{pH}$ values was used (Figure 3.9a). For SRS sediment, the maximum desorption of $\mathrm{U}(\mathrm{VI})(100 \%)$ was observed at $\mathrm{pH}$ 3. Above $\mathrm{pH} \mathrm{3}$, desorption of $\mathrm{U}(\mathrm{VI})$ was not observed. In acidic conditions, $\mathrm{H}^{+}$have the ability to displace cations such as $\mathrm{UO}_{2}^{2+}$ from their binding site and reduce the cation exchange capacity of minerals. Also, metals are more soluble under acidic conditions. In the case of SRS sediment amended with Huma-K, a similar maximum desorption of $\mathrm{U}(\mathrm{VI})(71.4 \%)$ was observed at $\mathrm{pH} 3$. 
At $\mathrm{pH} 4$, desorption had a sudden decrease (12.5\%), and then desorption continued to increase with an increase of $\mathrm{pH}$, reaching $37.4 \%$ desorption at $\mathrm{pH}$ 7.5. The high desorption of $\mathrm{U}(\mathrm{VI})$ in acidic conditions is related to the displacement uranyl ions by $\mathrm{H}^{+}$. On the other hand, when the $\mathrm{pH}$ is increased, humic molecules become more soluble as a result of the deprotonation of functional groups in humic molecules and the increase in negative charges that leads to their repulsion from the surface of the sediment, enhancing the desorption of $\mathrm{U}(\mathrm{VI})$ that is associated to Huma-K. However, the amount of $\mathrm{U}(\mathrm{VI})$ that remained sorbed to the SRS sediment amended with Huma-K was higher than in plain sediments for the $\mathrm{pH}$ range studied (Figure 3.9b). The results indicate that although an increase in $\mathrm{pH}$ promotes the soil-bound Huma-K to be released, remobilizing uranium, the SRS sediment amended with Huma-K performs better at the sequestration of $\mathrm{U}(\mathrm{VI})$.

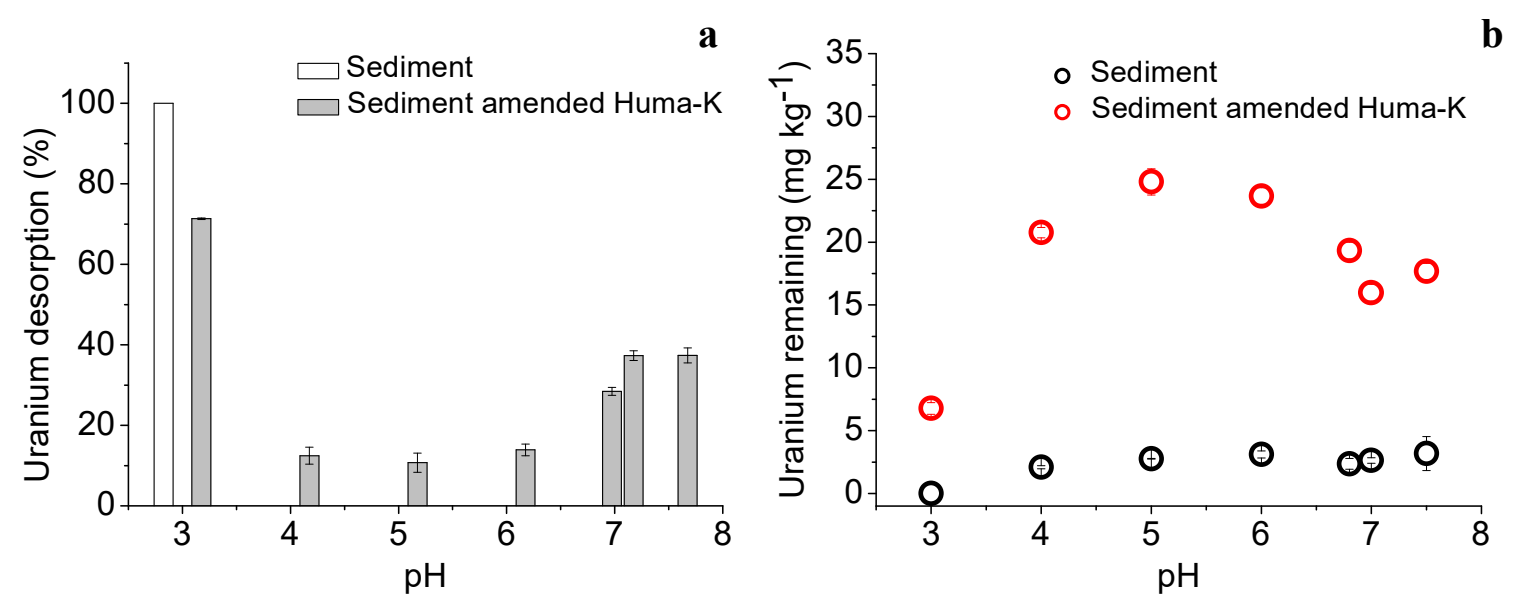

Figure 3.9 (a) Desorption of U(VI) from SRS sediment with and without Huma-K amendment removal $\left(10 \mathrm{~g} \mathrm{~L}^{-1}\right.$ of sediment, 14 days, $\mathrm{I}=0.01 \mathrm{M} \mathrm{NaClO}_{4}$, and $\left.\mathrm{T}=25^{\circ} \mathrm{C}\right)$. (b) Uranium remaining sorbed in SRS sediment after desorption. 


\subsection{Conclusions}

The present study was conducted to evaluate the sorption of U(VI) onto SRS sediment with and without Huma-K amendment. Kinetic studies for SRS sediment in the absence of Huma-K revealed a fast U(VI) uptake while, in the presence of Huma-K, U(VI) uptake was slower. The slower U(VI) uptake in the case of SRS sediment amended with Huma-K indicates a diffusion-controlled sorption process. Isotherm studies showed that SRS sediment amended with Huma-K has a higher sorption capacity compared to plain sediment at $\mathrm{pH}$ 4. The higher affinity is attributed to the presence of carboxyl and phenol groups, which can provide additional binding sites for U(VI) to form surface complexes. Generally, SRS sediment amended with Huma-K showed an increase in $\mathrm{U}(\mathrm{VI})$ removal at $\mathrm{pH} 3-5$, but a decrease at $\mathrm{pH} 6-8$. As the $\mathrm{pH}$ is increased, humic molecules can be dissolved from sediments and form aqueous complexes with $\mathrm{U}(\mathrm{VI})$ inhibiting its sorption. Desorption studies demonstrate that $\mathrm{U}(\mathrm{VI})$ desorption is minimal at $\mathrm{pH}$ 4-6. At very acidic ( $\mathrm{pH} 3$ ) or circumneutral conditions (7-8), desorption is enhanced. Overall, the results from the present study demonstrate the potential use of a low-cost unrefined humic substance (Huma-K) as an in situ amendment for the sequestration of uranium in acidic conditions. 


\subsection{Supplementary information}

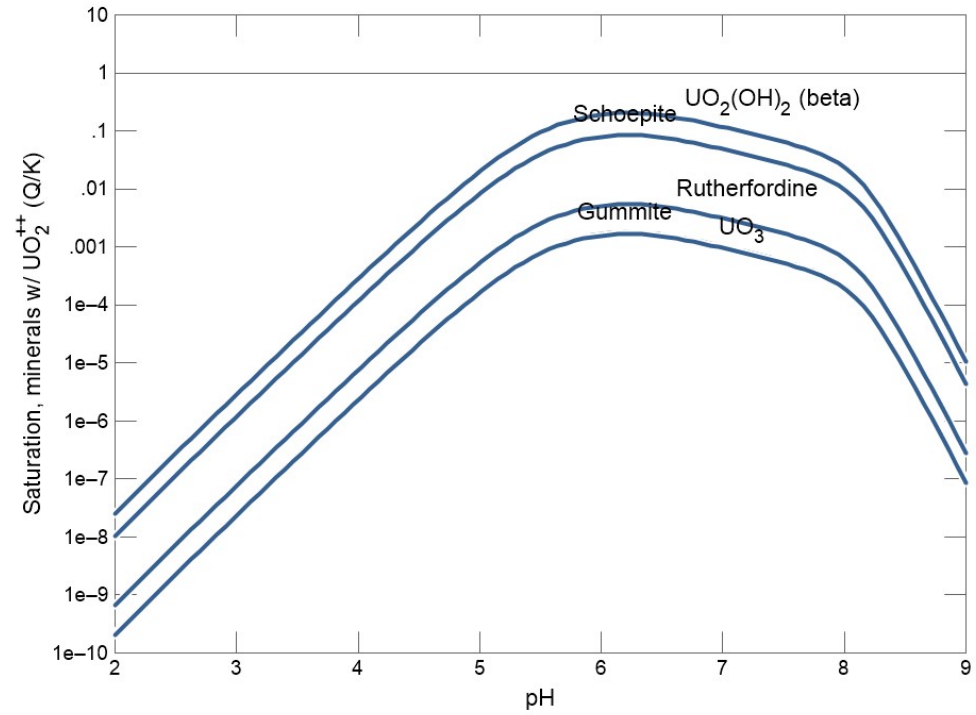

$\mathbf{a}$

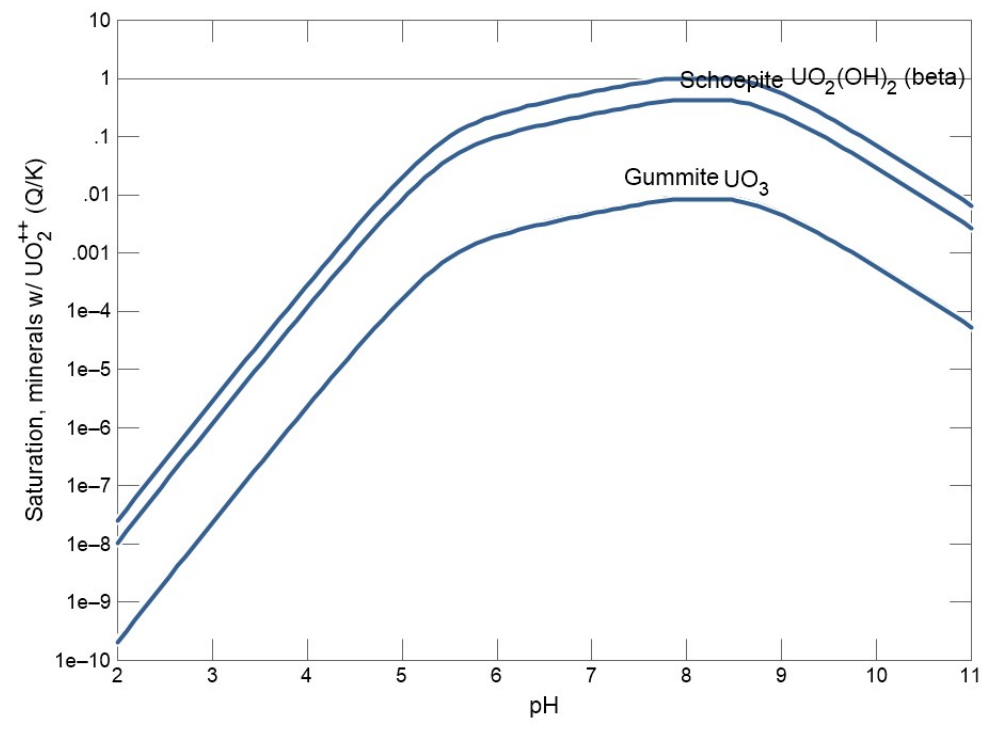

b

Figure 3S-1 Diagram for U(VI) mineral saturation in the (a) presence and (b) absence of $\mathrm{CO}_{2}\left(\mathrm{P}_{\mathrm{CO} 2}=10^{-3.5} \mathrm{~atm}\right)$ was created in Geochemist's Workbench. 


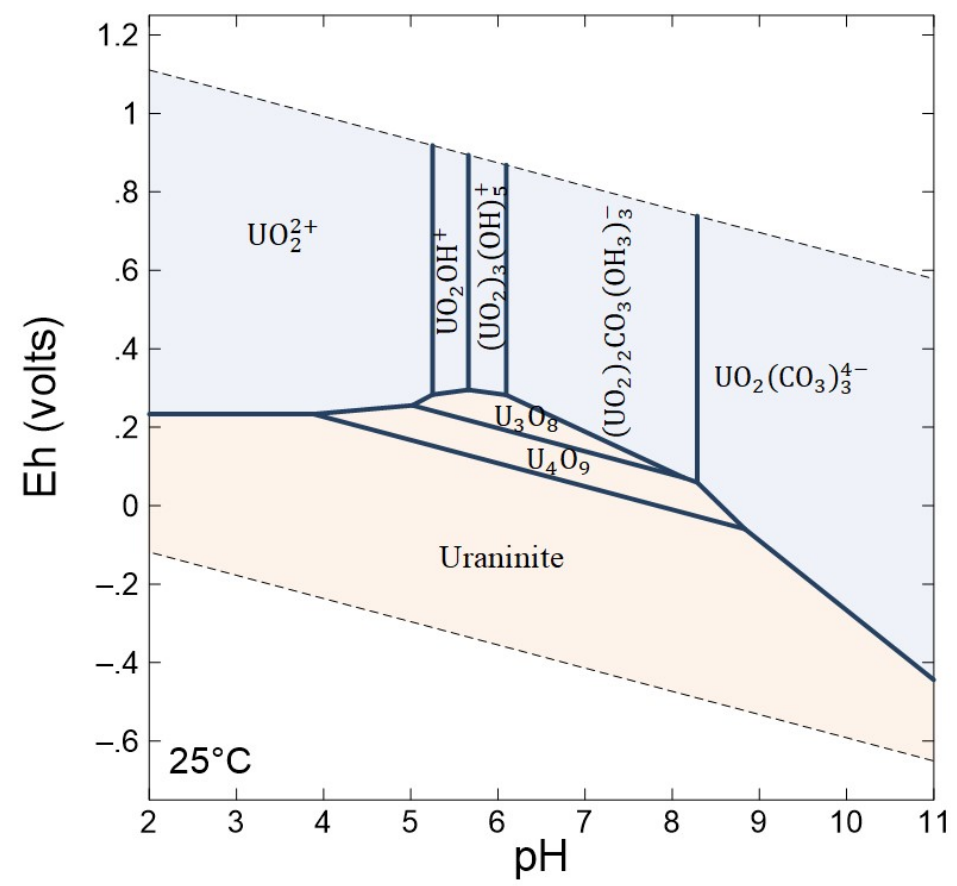

Figure 3S-2 Eh-pH diagram for aqueous U(VI) species was created in Geochemist's Workbench using the following conditions: $\mathrm{U}(\mathrm{VI})=0.5 \mathrm{mg} \mathrm{L}^{-1} ; \mathrm{P}_{\mathrm{CO} 2}=10^{-3.5} \mathrm{~atm}$. 
Chapter 4. Summary and future work 


\subsection{Summary}

Past nuclear processing activities have contaminated aquifers at many U.S. Department of Energy sites such as the Savannah River Site. Several remediation actions have been employed, but groundwater remains acidic with U(VI) concentrations at levels higher than drinking water standards. In the present study, the potential use of a low-cost unrefined humic substance as an in situ amendment for the sequestration of U(VI) in acidic conditions was explored. The first step was to characterize Huma-K and SRS sediment. From the FTIR and potentiometric titrations, the presence of functional groups such as carboxyl and phenol groups was identified. XRD and XRF results showed that SRS sediment is composed of quartz (93.2\%), kaolinite (5.1\%), and goethite (1.1\%). A variety of conditions ( $\mathrm{pH}$, kinetics, and initial Huma-K concentration) were investigated to determine the sorption-desorption behavior of Huma-K onto SRS sediment. The interactions between Huma-K and SRS sediment were favored at low $\mathrm{pH}$ where there is less electrostatic repulsion. An increase in $\mathrm{pH}$ caused a decrease in Huma-K removal because of electrostatic repulsion between negatively charged functional groups in Huma-K and negative charges at the sediment surface. The kinetic studies of Huma-K sorption onto SRS sediment were also investigated. None of the kinetic and diffusion models employed were able to precisely describe the experimental data, reflecting the heterogeneity of the system where the sorbent is a mixture of minerals and the sorbing material is a mixture of compounds. The equilibrium studies showed that the sorption of Huma-K onto SRS sediment in acidic conditions reaches an initial pseudo plateau. The pseudo plateau was attributed to 
the saturation of the binding sites present at the sediment surface. Desorption studies showed that an increase of $\mathrm{pH}$ promotes desorption of Huma-K from SRS sediment.

The sorption behavior of U(VI) was evaluated using SRS sediment with and without Huma-K amendment. The kinetic studies showed that U(VI) uptake for SRS sediment amended with Huma-K was slower compared to plain sediment. The fast U(VI) uptake for plain sediment indicates that most of the binding sites at the sediment surface are readily available. The slow U(VI) uptake by SRS sediment amended with Huma-K could be attributed to steric hindrance of the humic molecules restricting the access of U(VI) to the binding sites. Equilibrium studies showed a higher sorption capacity for SRS sediment amended with Huma-K. Huma-K enhanced U(VI) uptake because of the presence of carboxyl and phenol groups in Huma-K that can provide additional binding sites for U(VI). The $\mathrm{pH}$ had an influence in the sorption behavior of U(VI). For SRS sediment, U(VI) sorption was low in the acidic pH range (3-5). Above pH 6, U(VI) sorption significantly increased. For SRS sediment amended with Huma-K, $\mathrm{U}(\mathrm{VI})$ sorption was enhanced in the acidic $\mathrm{pH}$ range. Above $\mathrm{pH}$ 6, the sorption of U(VI) was decreased as a result of the formation of uranyl-humic complexes. Desorption studies showed at $\mathrm{pH}$ range 4-6 showed that desorption was small, but at neutral or very acidic conditions, desorption was enhanced.

Overall, the enhanced sorption of Huma-K in acidic conditions suggests that it may be useful in creating a subsurface treatment zone in acidic aquifers. The amendment of SRS sediment with Huma-K significantly enhances the sequestration of $\mathrm{U}(\mathrm{VI})$ in the acidic $\mathrm{pH}$ range. The treatment zone will persist as long as the $\mathrm{pH}$ does not 
increase sufficiently to cause sediment-bound Huma-K to be released, remobilizing $\mathrm{U}(\mathrm{VI})$.

\subsection{Future work}

The present study explored the use of unrefined humic substances (Huma-K) and its sorption properties on sediments; so, they could act as a coating treatment for the sequestration of uranium. However, in the environment, there are other co-ions present in the groundwater that could interfere or compete for the binding sites present in Huma-K and SRS sediment. Future studies should focus on studying a multi-component system to fully understand the interactions between U(VI) and SRS sediment with and without Huma-K amendment in the presence of other co-ions.

Humic substances are characterized by their heterogeneous structure and different molecular size. The fraction of humic molecules having a higher affinity for mineral surfaces will be sorbed while others will remain in solution, causing a fractionation. However, it remains unclear which fraction of humic substances is preferentially sorbed to the sediments. It has been demonstrated that humic acid molecules of large size are more aliphatic in nature while smaller sized molecules are more aromatic and have a higher content of carboxyl groups (Shin et al., 1999). The efficiency in the sequestration of uranium will depend on the fraction of humic molecules that are sorbed to the sediment. In recent years, there have been advances in the analysis of dissolved organic matter (DOM) at the molecular level by using electrospray ionization coupled with Fourier-transform ion cyclotron resonance mass spectrometry (ESI-FT-ICR-MS) (Minor et al., 2014; Reemtsma, 2009). By using ESI-FT-ICR-MS, Lv et al. (2016) 
demonstrated that molecular fractionation of DOM occurs during the sorption process into three different oxyhydroxides (ferrihydrite, goethite, and lepidocrocite). Further research should focus on the fractionation of humic molecules after sorption onto sediments by using ESI-FT-ICR-MS to investigate how the molecular fractionation of humic molecules affects its sorption to sediments and its interaction with uranium in the environment.

Most studies of uranium sorption onto mineral systems have been performed by using batch experiments. They use different models such as kinetic, isotherm, and surface complexation models to describe the sorption of uranium at the mineral-water interface. Batch experiments only observe the macroscopic aspects of the interactions of uranium with minerals surfaces such as adsorbing capacity. However, it gives very little information or evidence on the structure and local chemical environment of the sorbed species. Therefore, information at the molecular level is still needed in order to correlate with the results obtained from batch experiments. Among the techniques that can be used, time resolved laser fluorescence spectroscopy (TRLFS) and extended X-ray absorption fine structure spectroscopy (EXAFS) are useful in the determination of surface complexes. They are capable of distinguishing sorption mechanisms such as inner-sphere vs outer-sphere, co-precipitation/structural incorporation, and reductionoxidation reactions (Tan et al., 2010). The combination of batch techniques at the macroscopic level and spectroscopic analysis at the microscopic level would provide a more complete understanding of the interactions between uranium and SRS sediment with and without Huma-K amendment. 
Appendix 


\section{A.1 Preliminary study for the remediation of heavy metals using Huma-K as a low- cost amendment}

The use of a low-cost humic substance for remediation of heavy metal groundwater contamination is an attractive concept because of the natural origin of humic substances and their low pollution potential. Often, uranium mining generates mill tailings, which contain elevated concentrations of highly toxic heavy metals (Abdelouas, 2006). Mill tailings contain sulfide minerals such as pyrite $\left(\mathrm{FeS}_{2}\right)$ that, when exposed to air, acidify the mine drainage. As a result, the water originating from the tailings is highly acidic $(\mathrm{pH}<3)$ (Hogsden and Harding, 2012). If the acidic mine drainage is not intercepted, it can reach the groundwater, creating a plume. From groundwater, heavy metals can enter the food chain and be bioaccumulated and biomagnified, posing a threat to human health. Conventional treatment technologies are usually inadequate and too expensive in places where the mining occurs. Biological treatment methods have been proposed but include disadvantages such as fluctuations in their performance caused by environmental conditions and microorganism metabolic activity (Janyasuthiwong et al., 2017). Among the most promising cost-effective technologies for heavy metal sequestration is humic substances. Humic substances are nontoxic, biological recalcitrant, have a low-cost, and can sequester metals, reducing their bioavailability in the environment. The presence of a wide variety of functional groups such as carboxyl and phenol groups enables humic substances to form complexes with various metal ions in solution (Pehlivan and Arslan, 2006). However, information regarding the ability of humic substances to remove a mixture of metals is limited compared to the information available for single metals (Holland et al., 2016). 
Since contaminated groundwater includes a mixture of radionuclides and heavy metals, contaminant uptake may be complicated by competition between the various soil constituents. The objective of the preliminary study was to determine if Huma-K is useful for remediating various heavy metals $\left(\mathrm{Ag}^{+}, \mathrm{Zn}^{2+}\right.$, and $\left.\mathrm{Ce}^{3+}\right)$ at $\mathrm{pH} \geq 4$.5. Results from the present study should give an insight into the expansion of the applicability of using unrefined humic substances to other environmental conditions.

\section{A.1.1 Materials}

Huma-K (Land and Sea Organics) was extracted from Leonardite. Clean SRS sediment used in the sorption experiments (field borehole sampling FAW-1, depth interval 21.3-27.4 m) was collected from the aquifer near the F-Area seepage basins. The collected background sediment was selected because of similarities in mineral composition with the uranium contaminated aquifer sediment. The SRS sediment was sieved (U.S. Standard Testing Sieves, Fisher Scientific), and the sediment fraction with a particle diameter $\leq 2 \mathrm{~mm}$ was retained and used throughout the experiments.

\section{A.1.2 Sorption of $\mathrm{Ag}^{+}, \mathrm{Zn}^{2+}$, and $\mathrm{Ce}^{3+}$ onto SRS sediment with and without Huma- K amendment}

For the sorption experiments, a Huma-K stock solution of $1000 \mathrm{mg} \mathrm{L}^{-1}$ was prepared by dissolving $1000 \mathrm{mg}$ of Huma-K in $1 \mathrm{~L}$ of deionized (DI) water (Barnstead Nanopure Diamond Water Purification System, resistivity $\geq 18 \mathrm{M} \Omega \cdot \mathrm{cm}$ ). Stock solutions of $\mathrm{Ag}^{+}, \mathrm{Zn}^{2+}$, and $\mathrm{Ce}^{3+}$ were prepared by dissolving appropriate amounts of each to obtain a concentration of $1000 \mathrm{mg} \mathrm{L}^{-1}$. All batch experiments were conducted in triplicate under normal atmospheric conditions $\left(\mathrm{P}_{\mathrm{CO} 2}=10^{-3.5} \mathrm{~atm}\right.$ and $\left.25^{\circ} \mathrm{C}\right)$. 
In the first step, SRS sediment amended with Huma-K was prepared by bringing the sediment into contact with a Huma-K solution. The batch sorption experiments were conducted with $20 \mathrm{~mL}$ of aqueous suspension in DI water using $50 \mathrm{~mL}$ polypropylene centrifuge tubes, containing $1 \mathrm{~g}$ of SRS sediment $\left(49 \mathrm{~g} \mathrm{~L}^{-1}\right)$ spiked with a fixed concentration of Huma-K $\left(200 \mathrm{mg} \mathrm{L}^{-1}\right)$ at constant ionic strength $\left(\mathrm{I}=0.01 \mathrm{M} \mathrm{NaNO}_{3}\right)$ at $\mathrm{pH} 4.5$ and 6.5. The samples were mixed with a vortex mixer (Maxi Mix Plus, Barnstead Thermolyne) for $30 \mathrm{sec}$ and then rotated for 3 days on a platform shaker at $100 \mathrm{rpm}$ (New Brunswick Scientific Innova 2000) to ensure thorough fluid-mineral contact throughout the sorption period. All samples were centrifuged for $30 \mathrm{~min}$ at 2700 rpm (Thermo Scientific Sorvall ST 16R centrifuge), and the supernatant was withdrawn.

In the second step, the samples containing $1 \mathrm{~g}$ of sediment (with and without Huma-K amendment) were placed into contact with a $20 \mathrm{~mL}$ solution of DI water (I = $\left.0.01 \mathrm{M} \mathrm{NaNO}_{3}\right)$ spiked with an initial $\mathrm{Ag}^{+}, \mathrm{Zn}^{2+}$, and $\mathrm{Ce}^{3+}$ concentration ranging from 0.25-4 $\mathrm{mg} \mathrm{L}^{-1}$ at $\mathrm{pH} 4.5$ and 6.5. The samples were then vortex mixed, placed on a platform shaker, and centrifuged in a similar procedure as described above. Aqueous $\mathrm{Ag}^{+}, \mathrm{Zn}^{2+}$, and $\mathrm{Ce}^{3+}$ concentrations were measured by inductively coupled plasma emission spectroscopy (ICP-ES).

\section{A.2 Results and discussions}

\section{A.2.1 Sorption of $\mathrm{Ag}^{+}, \mathrm{Zn}^{2+}$, and $\mathrm{Ce}^{3+}$ onto SRS sediment with and without Huma- K amendment}

Equilibrium studies for the sorption of $\mathrm{Ag}^{+}, \mathrm{Zn}^{2+}$, and $\mathrm{Ce}^{3+}$ showed a higher metal uptake at $\mathrm{pH} 6.5$ compared to $\mathrm{pH} 4.5$ for SRS sediment (Fig. A.1). The increase in 
metal uptake with an increase in $\mathrm{pH}$ is attributed to the negative charges that develop at the sediment surface, electrostatically attracting metal cations. On the other hand, the low metal uptake at $\mathrm{pH} 4.5$ is attributed to the low degree of deprotonation of reactive surface functional groups associated with $\mathrm{Si}, \mathrm{Al}$, and $\mathrm{Fe}$ in the minerals that compose SRS sediment. For SRS sediment amended with Huma-K, there was an enhancement in the metal uptake at $\mathrm{pH} 4.5$ and 6.5 for $\mathrm{Zn}^{2+}$ and $\mathrm{Ce}^{3+}$ but not for $\mathrm{Ag}^{+}$(Fig. A.1). It was noted that for $\mathrm{Ag}^{+}$, there was no enhancement in the sorption by sediments amended by Huma-K because of the weak hydrolysis behavior of $\mathrm{Ag}^{+}$and the low stability bond with oxygen electron donors (Davis and Leckie, 1978). Therefore, sediments amended with Huma-K did not improve the removal of $\mathrm{Ag}^{+}$. The sorption of $\mathrm{Ag}^{+}$onto sediments probably only occurs through sorption onto iron hydroxides (Dyck, 1968).

Huma-K can enhance the complexation properties of sediments for the removal of metals in groundwater by providing additional complexation sites compared to the existing ones at the sediment surface. The degree of enhancement provided by the humic-rich layer of the sediments depends on $\mathrm{pH}$ and stability constants between humic molecules and metals. As the $\mathrm{pH}$ is increased, humic molecules become negatively charged, which is caused by the deprotonation of carboxyl groups. Carboxyl groups provide more complexation sites for the sorption of metals, enhancing the removal of $\mathrm{Zn}^{2+}$ and $\mathrm{Ce}^{3+}$. Since carboxyl groups have low $\mathrm{p} K$ values $(\sim 4)$, at $\mathrm{pH}<4$, only a portion of the total number of carboxyl groups react with metal ions, but at $\mathrm{pH}>4$, both carboxyl and phenolic groups contribute to the metal uptake. In addition, the deprotonation of the functional groups in humic molecules causes a molecular structure expansion, allowing the binding sites to be more accessible to the metal uptake. 

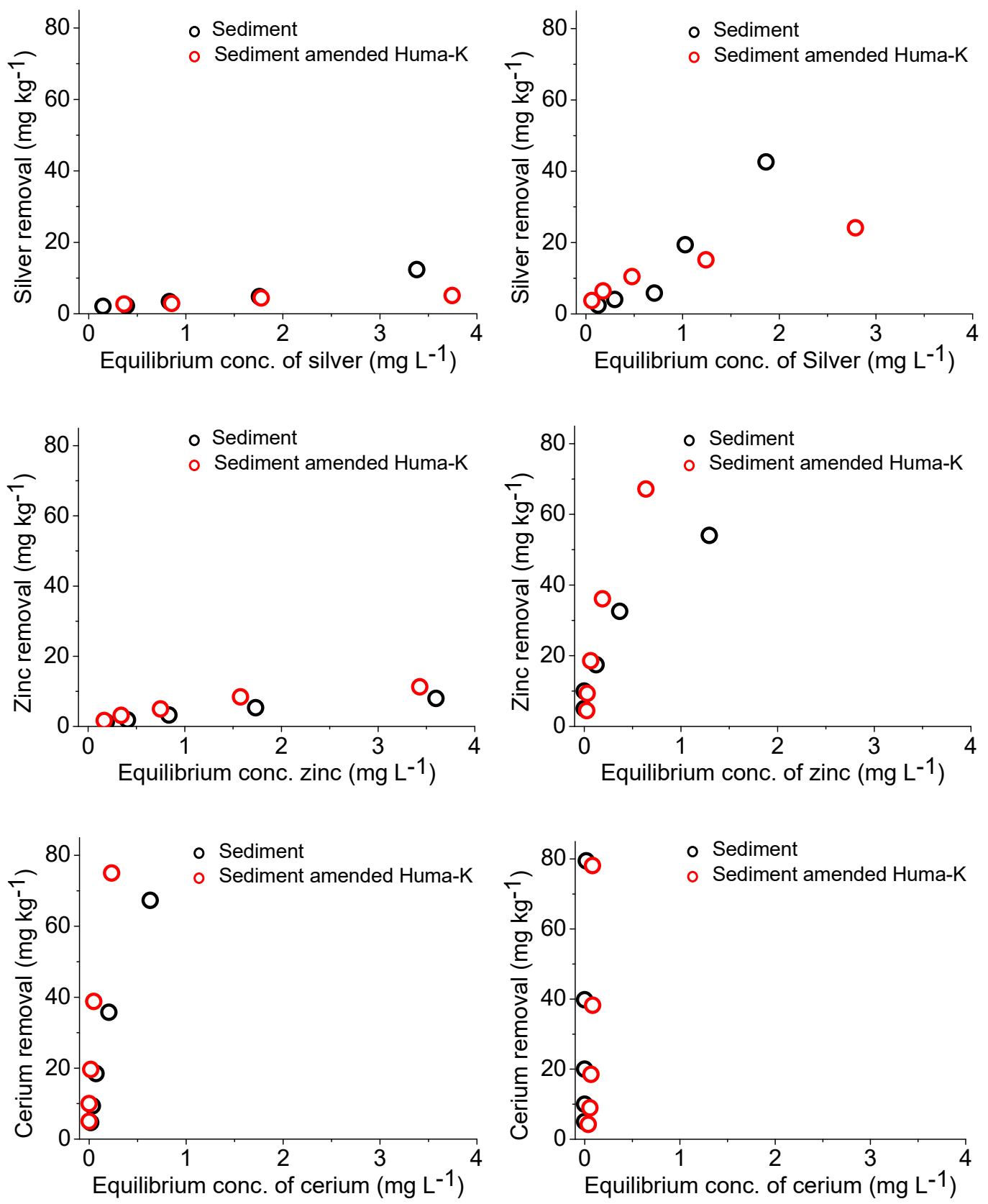

Figure A.1 Sorption isotherm of $\mathrm{Ag}^{+}, \mathrm{Zn}^{2+}$, and $\mathrm{Ce}^{3+}$ on SRS sediment amended with and without Huma-K for 3 days at 4.5 (left column) and 6.5 (right column). ( $49 \mathrm{~g} \mathrm{~L}^{-1}$ of sediment, $\mathrm{I}=\mathrm{NaNO}_{3}$, and $\mathrm{T}=25^{\circ} \mathrm{C}$ ). 


\section{A.2.2 Competitive binding of $\mathrm{Ag}^{+}, \mathrm{Zn}^{2+}$, and $\mathrm{Ce}^{3+}$ onto SRS sediment amended with Huma-K}

The experimental data for the sorption competition between $\mathrm{Ag}^{+}, \mathrm{Zn}^{2+}$, and $\mathrm{Ce}^{3+}$ (spiked as a mixture) onto SRS with Huma-K amendment are shown in Fig. A.2. It was found that the metal uptake increased with $\mathrm{pH}$ from 4.5 to 6.5 . Also, $\mathrm{Ce}^{3+}$ had a higher uptake compared to $\mathrm{Ag}^{+}$and $\mathrm{Zn}^{2+}$ at both $\mathrm{pH}$ values. When the results of the sorption competition of $\mathrm{Ag}^{+}, \mathrm{Zn}^{2+}$, and $\mathrm{Ce}^{3+}$ spiked as a mixture were compared with the sorption of $\mathrm{Ag}^{+}, \mathrm{Zn}^{2+}$, and $\mathrm{Ce}^{3+}$ spiked individually in separate samples (Fig. A.3), the comparison showed that the experimental data points for the three metals almost overlap, indicating that $\mathrm{Ag}^{+}, \mathrm{Zn}^{2+}$, and $\mathrm{Ce}^{3+}$ do not compete for the same binding sites.

Pearson classified metal ions on the basis of their complexation behavior with ligands. For example, hard metal ions such as $\mathrm{Na}^{+}, \mathrm{K}^{+}, \mathrm{Ca}^{2+}$, and $\mathrm{Mg}^{2+}$ bind preferentially to hard oxygen-containing ligands such as carboxylates and phenolates. Soft metal ions such as $\mathrm{Hg}^{2+}, \mathrm{Cd}^{2+}$, and $\mathrm{Pb}^{2+}$ bind preferentially to nitrogen- or sulfurcontaining ligands such as thiolates (Avery and Tobin, 1993).

Silver is a type-B metal cation, so it tends to coordinate and form complexes with soft bases, having a high affinity for sulfur. The complexation constant $(\log \beta)$ of $\mathrm{Ag}^{+}$ with carboxylate complexes $(\log \beta=2-4)$ is lower than the stability constant with organosulfur complexes $(\log \beta=13)$ (Bell and Kramer, 1999). Some studies have shown that organic matter present in soil increases the sorption of $\mathrm{Ag}^{+}$, probably because of the presence of sulfur groups (B. Kleja et al., 2016; Jacobson et al., 2005; Settimio et al., 2014). In the present study, the presence of Huma-K did not show a significant increase in $\mathrm{Ag}^{+}$sorption. During the humification (decomposition of organic 
matter), humic molecules tend to lose functional groups. The least abundant functional groups in humic molecules are the ones containing sulfur, which favor the interaction with soft metal cations. The low abundance of sulfur groups has an implication for the binding sites and competition among metals, resulting in fewer binding sites for the complexation of $\mathrm{Ag}^{+}$(Tipping, 2002). Therefore, it is expected that $\mathrm{Ag}^{+}$will not compete for the binding sites with $\mathrm{Zn}^{2+}$ or $\mathrm{Ce}^{3+}$ because of its affinity towards functional groups that contain sulfur donor ligands.

Zinc is on the borderline between soft acids and hard bases according to the Pearson's hard soft acid base classification system. Therefore, $\mathrm{Zn}^{2+}$ has intermediate properties of both hard and soft acids, having no strong preference for hard over soft bases. In the present study, $\mathrm{Zn}^{2+}$ had a higher sorption compared to $\mathrm{Ag}^{+}$at $\mathrm{pH}$ 6.5. Complexation studies between $\mathrm{Zn}^{2+}$ and humic acid have shown that zinc forms weak complexes compared to other divalent metal cations (Abate and Masini, 2001); therefore, it will not displace $\mathrm{Ce}^{3+}$ which forms stronger complexes with humic molecules.

Cerium is classified as a hard acid, so it tends to interact with hard bases such as carboxyl groups. Since humic molecules possess carboxyl groups, the interactions between humic molecules and $\mathrm{Ce}^{3+}$ is favored. It has been reported that the complexation constant of $\mathrm{Ce}^{3+}$ with humic acid $(\log \beta=5-6)$ is strong (An-chao et al., 1998). In the present study, $\mathrm{Ce}^{3+}$ showed the highest sorption at both $\mathrm{pH}$ values for SRS sediment with and without Huma-K amendment. In addition, it was observed that neither $\mathrm{Ag}^{+}$nor $\mathrm{Zn}^{2+}$ was able to displace $\mathrm{Ce}^{3+}$. 

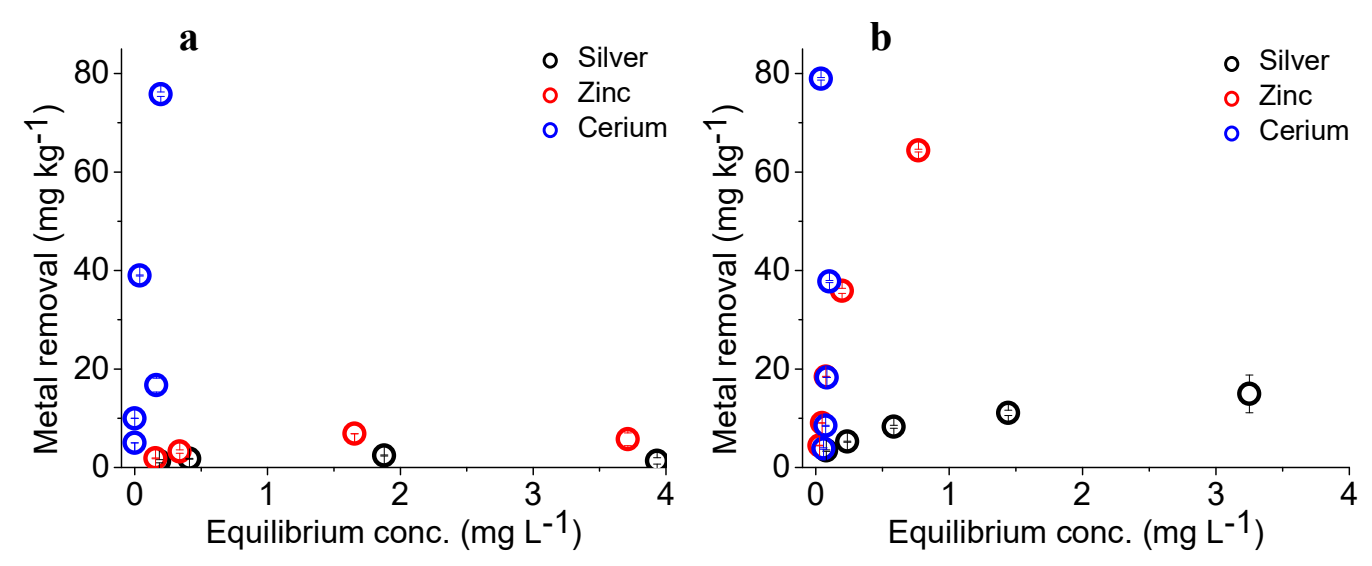

Figure A.2 Competitive binding between $\mathrm{Ag}^{+}, \mathrm{Zn}^{2+}$, and $\mathrm{Ce}^{3+}$ (spiked as a mixture) onto SRS sediment amended with Huma-K at pH 4.5 (a) and 6.5 (b).
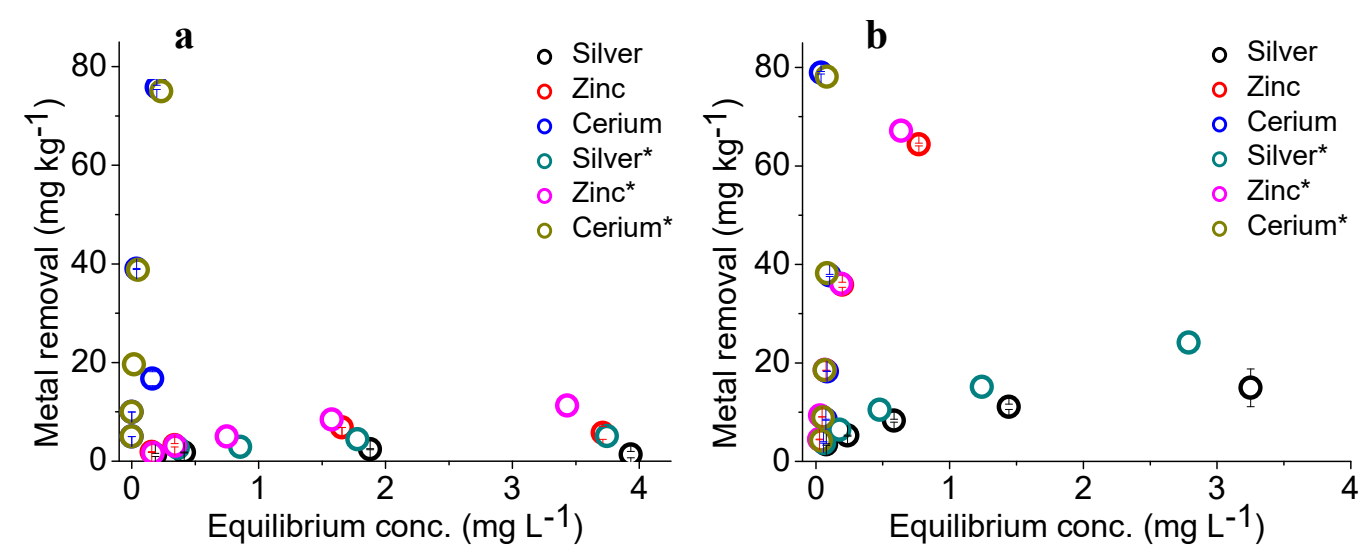

Figure A.3 Comparison of sorption competition $\left(\mathrm{Ag}^{+}, \mathrm{Zn}^{2+}\right.$, and $\mathrm{Ce}^{3+}$ spiked as a mixture at the same time) with individual sorption of $\mathrm{Ag}^{*}, \mathrm{Zn}^{*}$, and $\mathrm{Ce}^{*}$ on sediments amended with Huma-K at pH 4.5 (a) and 6.5 (b).

\section{A.3 Conclusions}

From the preliminary study, it can be concluded that the application of Huma-K to remediate contaminated soil is a promising remediation method. It can be used to amend sediments to enhance the removal of some metals from aqueous solution at acidic and circumneutral conditions. Among the heavy metals, $\mathrm{Ce}^{3+}$ exhibited the highest affinity for SRS sediment with and without Huma-K amendment compared to $\mathrm{Zn}^{2+}$ and $\mathrm{Ag}^{+}$. Functional groups in Huma-K and the surface of the SRS sediment act as 
a hard Lewis base, having higher affinity for hard acids such as $\mathrm{Ce}^{3+}$. On the other hand, the lower affinity of $\mathrm{Ag}^{+}$and $\mathrm{Zn}^{2+}$ for sediments with and without Huma-K amendment is attributed to their softness. $\mathrm{Ag}^{+}$and $\mathrm{Zn}^{2+}$ prefer to interact with soft Lewis bases. Also, the uptake for $\mathrm{Ag}^{+}, \mathrm{Zn}^{2+}$, and $\mathrm{Ce}^{3+}$ at $\mathrm{pH} 6.5$ was higher. As for silver, sediments amended with Huma-K did not show any sorption enhancement, probably because of the lack of surface functional groups where silver tends to interact. In addition, it was found that there was no binding competition between $\mathrm{Ag}^{+}, \mathrm{Zn}^{2+}$, and $\mathrm{Ce}^{3+}$ because they may interact with different functional groups on the surface of sediments and Huma-K. 


\section{References}

Abate, G., Masini, J.C., 2001. Acid-basic and complexation properties of a sedimentary humic acid. A study on the Barra Bonita reservoir of Tietê river, São Paulo State, Brazil. J. Braz. Chem. Soc. 12, 109-116.

Abdelouas, A., 2006. Uranium mill tailings: Geochemistry, mineralogy, and environmental impact. Elements. 2, 335-341.

Ahearne, J.F., 1997. Radioactive waste: The size of the problem. Phys. Today. 50, 24-29.

Allen, P.G., Bucher, J.J., Shuh, D.K., Edelstein, N.M., Reich, T., 1997. Investigation of aquo and chloro complexes of $\mathrm{UO}_{2}{ }^{2+}, \mathrm{NpO}_{2}{ }^{+}, \mathrm{Np}^{4+}$, and $\mathrm{Pu}^{3+}$ by X-ray absorption fine structure spectroscopy. Inorg. Chem. 36, 4676-4683.

Alvarez-Puebla, R.A., Garrido, J.J., 2005. Effect of $\mathrm{pH}$ on the aggregation of a gray humic acid in colloidal and solid states. Chemosphere. 59, 659 - 667.

An-chao, G., Shen, Z., Hailand, H., 1998. Complex behaviour of trivalent rare earth elements by humic acids. J Environ. Sci. 10, 302-308.

Anagnostopoulos, V.A., Koutsoukos, P.G., Symeopoulos, B.D., 2015. Removal of U(VI) from aquatic systems, using winery by-products as biosorbents: Equilibrium, kinetic, and speciation studies. Water, Air, Soil Pollut. 226, 107.

Avena, M., Koopal, L.K., 1998. Desorption of humic acids from an iron oxide surface. Environ. Sci. Technol. 32, 2572-2577.

Avery, S.V., Tobin, J.M., 1993. Mechanism of adsorption of hard and soft metal ions to Saccharomyces cerevisiae and influence of hard and soft anions. Appl. Environ. Microbiol. 59, 2851-2856.

B. Kleja, D., Nakata, S., Persson, I., Gustafsson, J.P., 2016. Silver(I) binding properties of organic soil materials are different from those of isolated humic substances. Environ. Sci. Technol. 50, 7453-7460.

Balnois, E., Wilkinson, K.J., Lead, J.R., Buffle, J., 1999. Atomic force microscopy of humic substances: Effects of $\mathrm{pH}$ and ionic strength. Environ. Sci. Technol. 33, 3911-3917.

Banday, A.A., Priyamvada, S., Farooq, N., Yusufi, A.N.K., Khan, F., 2008. Effect of uranyl nitrate on enzymes of carbohydrate metabolism and brush border membrane in different kidney tissues. Food Chem. Toxicol. 46, 2080-2088.

Bea, S.A., Wainwright, H., Spycher, N., Faybishenko, B., Hubbard, S.S., Denham, M.E., 2013. Identifying key controls on the behavior of an acidic-U(VI) plume in the Savannah River Site using reactive transport modeling. J. Contam. Hydrol. 151, 34-54.

Bell, R.A., Kramer, J.R., 1999. Structural chemistry and geochemistry of silver-sulfur compounds: Critical review. Environ. Toxicol. Chem. 18, 9-22. 
Beller, H.R., 2005. Anaerobic, nitrate-dependent oxidation of U(IV) oxide minerals by the chemolithoautotrophic bacterium Thiobacillus denitrificans. Appl. Environ. Microbiol. 71, 2170-2174.

Bleise, A., Danesi, P.R., Burkart, W., 2003. Properties, use and health effects of depleted uranium (DU): A general overview. J. Environ. Radioact. 64, 93-112.

Bourikas, K., Kordulis, C., Lycourghiotis, A., 2006a. How metal (hydr)oxides are protonated in aqueous media: The $(\mathrm{n}+1)$ rule and the role of the interfacial potential. J. Colloid Interface Sci. 296, 389-395.

Bourikas, K., Kordulis, C., Lycourghiotis, A., 2006b. The mechanism of the protonation of metal (hydr)oxides in aqueous solutions studied for various interfacial/surface ionization models and physicochemical parameters: A critical review and a novel approach. Adv. Colloid Interface Sci. 121, 111-130.

Boyd, G.E., Adamson, A.W., Myers, L.S., 1947. The exchange adsorption of ions from aqueous solutions by organic zeolites. II. Kinetics1. J. Am. Chem. Soc. 69, 28362848.

Brady, P.V., Cygan, R.T., Nagy, K.L., 1996. Molecular controls on kaolinite surface charge. J. Colloid Interface Sci. 183, 356-364.

Bruemmer, G.W., Gerth, J., Tiller, K.G., 1988. Reaction kinetics of the adsorption and desorption of nickel, zinc and cadmium by goethite. I. Adsorption and diffusion of metals. J. Soil Sci. 39, 37-52.

Cheung, W.H., Szeto, Y.S., McKay, G., 2007. Intraparticle diffusion processes during acid dye adsorption onto chitosan. Bioresour. Technol. 98, 2897-2904.

Ching-kuo Daniel, H., Langmuir, D., 1985. Adsorption of uranyl onto ferric oxyhydroxides: Application of the surface complexation site-binding model. Geochim. Cosmochim. Acta. 49, 1931-1941.

Chisholm-Brause, C.J., Berg, J.M., Matzner, R.A., Morris, D.E., 2001. Uranium(VI) sorption complexes on montmorillonite as a function of solution chemistry. J. Colloid Interface Sci. 233, 38-49.

Chotzen, R.A., Polubesova, T., Chefetz, B., Mishael, Y.G., 2016. Adsorption of soilderived humic acid by seven clay minerals: A systematic study. Clays Clay Miner. 64, 628-638.

Clark, D.L., Hobart, D.E., Neu, M.P., 1995. Actinide carbonate complexes and their importance in actinide environmental chemistry. Chem. Rev. 95, 25-48.

Cornell, R.M., Schwertmann, U., 2003. The iron oxides: Structure, properties, reactions, occurrences and uses. Wiley, Weinheim, Germany.

Cumberland, S.A., Douglas, G., Grice, K., Moreau, J.W., 2016. Uranium mobility in organic matter-rich sediments: A review of geological and geochemical processes. Earth-Sci. Rev. 159, 160-185. 
Davis, J.A., Leckie, J.O., 1978. Effect of adsorbed complexing ligands on trace metal uptake by hydrous oxides. Environ. Sci. Technol. 12, 1309-1315.

Denecke, M.A., Pompe, S., Reich, T., Moll, H., Bubner, M., Heise K, H., Nicolai, R., Nitsche, H., 1997. Measurements of the structural parameters for the interaction of uranium(VI) with natural and synthetic humic acids using EXAFS. Radiochim. Acta. 79, 151-159.

Denham, M., Millings, M., Amidon, M., Looney, B., Hyde, W., Walker, R., GonzalezRaymat, H., 2015. Evaluation of a low cost humate solution as an in situ amendment to enhance attenuation of uranium in an acidic plume. Waste Management, Phoenix, Arizona, USA, p. 14.

Denham, M., Vangelas, K.M., 2008. Biogeochemical gradients as a framework for understanding waste-site evolution. Remediation. 19, 5-17.

DiSpirito, A.A., Tuovinen, O.H., 1982. Uranous ion oxidation and carbon dioxide fixation byThiobacillus ferrooxidans. Arch. Microbiol. 133, 28-32.

Dong, W., Wan, J., 2014. Additive surface complexation modeling of uranium(VI) adsorption onto quartz-sand dominated sediments. Environ. Sci. Technol. 48, 6569-6577.

Doulia, D., Leodopoulos, C., Gimouhopoulos, K., Rigas, F., 2009. Adsorption of humic acid on acid-activated Greek bentonite. J. Colloid Interface Sci. 340, 131-141.

Duval, Y., Mielczarski, J.A., Pokrovsky, O.S., Mielczarski, E., Ehrhardt, J.J., 2002. Evidence of the existence of three types of species at the quartz-aqueous solution interface at $\mathrm{pH} 0-10$ : XPS surface group quantification and surface complexation modeling. J. Phys. Chem. B. 106, 2937-2945.

Dyck, W., 1968. Adsorption and coprecipitation of silver on hydrous ferric oxide. Can. J. Chem. 46, 1441-1444.

Efstathiou, M., Pashalidis, I., 2017. A comparative study on the sorption of tri- and hexavalent actinides on sea sediments. J. Radioanal. Nucl. Chem. 312, 181-185.

EIA, 2015. International energy statistics.

El-Khaiary, M.I., Malash, G.F., 2011. Common data analysis errors in batch adsorption studies. Hydrometallurgy. 105, 314-320.

Elfarissi, F., Pefferkorn, E., 2000. Kaolinite/humic acid interaction in the presence of aluminium ion. Colloids Surf., A. 168, 1-12.

Enev, V., Pospisilova, L., Klucakova, M., Liptaj, T., Doskocil, L., 2014. Spectral characterization of selected humic substances. Soil Water Res. 9, 9-17.

EPA, U.S., 2001. Radionuclides rule: A quick reference guide. U.S. Environmental Protection Agency.

Erdogan, S., Baysal, A., Akba, O., Hamamci, C., 2007. Interaction of metals with humic acid isolated from oxidized coal. Pol. J. Environ. Stud. 16, 671-675. 
Esmaeili, H., Ebrahimi, A., Hajian, M., Pourzamani, H., 2012. Kinetic and isotherm studies of humic acid adsorption onto iron oxide magnetic nanoparticles in aqueous solutions. Int. J. Environ. Health Eng. 1, 1-9.

Evans, A.G., Bauer, L.R., Haselow, J.S., Hayes, D.W., Martin, H.L., McDowell, W.L., Pickett, J.B., 1992. Uranium in the Savannah River Site environment. Westinghouse Savannah River Co., Aiken, SC (United States), p. 95.

Fairhurst, A.J., Warwick, P., Richardson, S., 1995. The influence of humic acid on the adsorption of europium onto inorganic colloids as a function of $\mathrm{pH}$. Colloids Surf., A. 99, 187-199.

Feng, X., Simpson, A.J., Simpson, M.J., 2005. Chemical and mineralogical controls on humic acid sorption to clay mineral surfaces. Org. Geochem. 36, 1553-1566.

Finch, R.J., Ewing, R.C., 1992. The corrosion of uraninite under oxidizing conditions. J. Nucl. Mater. 190, 133-156.

Finneran, K.T., Housewright, M.E., Lovley, D.R., 2002. Multiple influences of nitrate on uranium solubility during bioremediation of uranium-contaminated subsurface sediments. Environ. Microbiol. 4, 510-516.

Flaig, W., Beutelspacher, H., Rietz, E., 1975. Chemical composition and physical properties of humic substances, in: Soil components volume 1: organic components. Springer Berlin Heidelberg, Berlin, Heidelberg, pp. 1-211.

Fong, S.S., Seng, L., Chong, W.N., Asing, J., Nor, M.F.b.M., Pauzan, A.S.b.M., 2006. Characterization of the coal derived humic acids from Mukah, Sarawak as soil conditioner. J. Braz. Chem. Soc. 17, 582-587.

Francis, A., J., Gillow, J.B., Dodge, C., J., Harris, R., Beveridge, T.J., Papenguth, H.W., 2004. Uranium association with halophilic and non-halophilic bacteria and archaea. Radiochim. Acta. 92, 481-488.

Francis, A.J., Dodge, C.J., Lu, F., Halada, G.P., Clayton, C.R., 1994. XPS and XANES studies of uranium reduction by Clostridium sp. Environ. Sci. Technol. 28, 636639.

Freundlich, H.M.F., 1906. Over the adsorption in solution. J. Phys. Chem. 57, 385-471.

Gabriel, U., Charlet, L., Schläpfer, C.W., Vial, J.C., Brachmann, A., Geipel, G., 2001. Uranyl surface speciation on silica particles studied by time-resolved laserinduced fluorescence spectroscopy. J. Colloid Interface Sci. 239, 358-368.

Ganesh, R., Robinson, K.G., Reed, G.D., Sayler, G.S., 1997. Reduction of hexavalent uranium from organic complexes by sulfate- and iron-reducing bacteria. Appl. Environ. Microbiol. 63, 4385-4391.

García, D., Cegarra, J., Abad, M., 1996. A comparison between alkaline and decomplexing reagents to extract humic acids from low rank coals. Fuel Process. Technol. 48, 51-60. 
Ginder-Vogel, M., Criddle, C.S., Fendorf, S., 2006. Thermodynamic constraints on the oxidation of biogenic UO2 by Fe(III) (hydr)oxides. Environ. Sci. Technol. 40, 3544-3550.

Ginder-Vogel, M., Fendorf, S., 2007. Biogeochemical uranium redox transformations: Potential oxidants of uraninite, in: Adsorption of metals by geomedia II variables, mechanisms, and model applications. Elsevier, pp. 293-319.

Giovanela, M., Crespo, J.S., Antunes, M., Adamatti, D.S., Fernandes, A.N., Barison, A., da Silva, C.W.P., Guégan, R., Motelica-Heino, M., Sierra, M.M.D., 2010. Chemical and spectroscopic characterization of humic acids extracted from the bottom sediments of a Brazilian subtropical microbasin. J. Mol. Struct. 981, 111119 .

Gondar, D., Lopez, R., Fiol, S., Antelo, J.M., Arce, F., 2005. Characterization and acidbase properties of fulvic and humic acids isolated from two horizons of an ombrotrophic peat bog. Geoderma. 126, 367-374.

Gonzalez-Raymat, H., Anagnostopoulos, V., Denham, M., Cai, Y., Katsenovich, Y.P., 2018. Unrefined humic substances as a potential low-cost amendment for the management of acidic groundwater contamination. J. Environ. Manage. 212, 210218.

González A, Z.I., Krachler, M., Cheburkin, A.K., Shotyk, W., 2006. Spatial distribution of natural enrichments of arsenic, selenium, and uranium in a minerotrophic peatland, Gola di Lago, Canton Ticino, Switzerland. Environ. Sci. Technol. 40, 6568-6574.

Gorman-Lewis, D., Burns, P.C., Fein, J.B., 2008. Review of uranyl mineral solubility measurements. J. Chem. Thermodyn. 40, 335-352.

Greathouse, J.A., O'Brien, R.J., Bemis, G., Pabalan, R.T., 2002. Molecular dynamics study of aqueous uranyl interactions with quartz (010). J. Phys. Chem. B. 106, 1646-1655.

$\mathrm{Gu}$, B., Chen, J., 2003. Enhanced microbial reduction of $\mathrm{Cr}(\mathrm{VI})$ and $\mathrm{U}(\mathrm{VI})$ by different natural organic matter fractions. Geochim. Cosmochim. Acta. 67, 3575-3582.

Gu, B., Yan, H., Zhou, P., Watson, D.B., Park, M., Istok, J., 2005. Natural humics impact uranium bioreduction and oxidation. Environ. Sci. Technol. 39, 5268-5275.

Guillaumont, R., Fanghänel, T., Fuger, J., Grenthe, I., Neck, V., Palmer, D.A., Rand, M., 2003. Update on the chemical thermodynamics of uranium, neptunium, plutonium, americium and technetium. Elsevier, Amsterdam.

Haas, J.R., Dichristina, T.J., Wade, R., 2001. Thermodynamics of U(VI) sorption onto Shewanella putrefaciens. Chem. Geol. 180, 33-54.

Hessen, D.O., Tranvik, L.J., 1998. Aquatic humic substances : Ecology and biogeochemistry. Springer, Berlin; New York.

Hiemstra, T., Barnett, M.O., van Riemsdijk, W.H., 2007. Interaction of silicic acid with goethite. J. Colloid Interface Sci. 310, 8-17. 
Hiemstra, T., Van Riemsdijk, W.H., 1996. A surface structural approach to ion adsorption: The charge distribution (CD) model. J. Colloid Interface Sci. 179, 488-508.

Ho, Y.S., McKay, G., 1999. Pseudo-second order model for sorption processes. Process Biochem. 34, 451-465.

Hogsden, K.L., Harding, J.S., 2012. Consequences of acid mine drainage for the structure and function of benthic stream communities: A review. Freshwater Science. 31, 108-120.

Holland, A., Duivenvoorden, L.J., Kinnear, S.H.W., 2016. Humic substances: remediation option for anthropogenically acidified waterways. Rev. Environ. Sci. Bio/Technol. 15, 665-676.

Hu, Q.-H., Weng, J.-Q., Wang, J.-S., 2010. Sources of anthropogenic radionuclides in the environment: A review. J. Environ. Radioact. 101, 426-437.

Huertas, F.J., Chou, L., Wollast, R., 1998. Mechanism of kaolinite dissolution at room temperature and pressure: Part 1. Surface speciation. Geochim. Cosmochim. Acta. $62,417-431$.

Jacobson, A.R., McBride, M.B., Baveye, P., Steenhuis, T.S., 2005. Environmental factors determining the trace-level sorption of silver and thallium to soils. Sci. Total Environ. 345, 191-205.

Jada, A., Ait Akbour, R., Douch, J., 2006. Surface charge and adsorption from water onto quartz sand of humic acid. Chemosphere. 64, 1287-1295.

Janyasuthiwong, S., Rene, E.R., Esposito, G., Lens, P.N.L., 2017. Techniques for metal removal and recovery from waste stream, in: Sustainable heavy metal remediation: Volume 1: Principles and processes. Springer International Publishing, Cham, pp. 1-23.

Kabata-Pendias, A., Mukherjee, A.B., 2007. Trace elements of Group 3 (previously Group IIIb), in: Trace elements from soil to human. Springer, Berlin, pp. 127-150.

Kalaitzidis, S., Papazisimou, S., Giannouli, A., Bouzinos, A., Christanis, K., 2003. Preliminary comparative analyses of two Greek leonardites. Fuel. 82, 859-861.

Karpas, Z., 2015. Analytical chemistry of uranium : Environmental, forensic, nuclear, and toxicological applications. CRC Press, Boca Raton, FL.

Kathren, R.L., Burklin, R.K., 2008. Acute chemical toxicity of uranium. Health Phys. 94, 170-179.

Katsenovich, Y.P., Cardona, C., Szecsody, J., Lagos, L.E., Tang, W., 2018. Assessment of calcium addition on the removal of $\mathrm{U}(\mathrm{VI})$ in the alkaline conditions created by NH3 gas. Appl. Geochem. 92, 94-103.

Keith, S., Faroon, O., Roney, N., Scinicariello, F., Wilbur, S., Ingerman, L., Llados, F., Plewak, D., Wholers, D., Diamond, G., 2013. Toxicological profile for uranium. Agency for Toxic Substances and Disease Registry, Atlanta, Georgia. 
Kerisit, S., Liu, C., 2014. Molecular dynamics simulations of uranyl and uranyl carbonate adsorption at aluminosilicate surfaces. Environ. Sci. Technol. 48, 3899-3907.

Kevin, L., Louise, J.C., 2012. Predicting the acidity constant of a goethite hydroxyl group from first principles. J. Phys.: Condens. Matter. 24, 124105.

Khan, S., Yaoguo, W., Xiaoyan, Z., Youming, X., Zhang, J., Shihai, H., 2014. Relationship for the concentration of dissolved organic matter from corn straw with absorbance by using uv-visible spectrophotometer. Int. J. Environ. Pollut. Rem. 2, 18-23.

Killops, S., Killops, V., Killops, S., Killops, V., 2004. Long-term fate of organic matter in the geosphere, in: Introduction to organic geochemistry. Blackwell Publishing Ltd., pp. 117-165.

Ko, I., Kim, J.-Y., Kim, K.-W., 2005. Adsorption properties of soil humic and fulvic acids by hematite. Chem. Speciation Bioavailability. 17, 41-48.

Koch-Steindl, H., Pröhl, G., 2001. Considerations on the behaviour of long-lived radionuclides in the soil. Radiat. Environ. Biophys. 40, 93-104.

Komlos, J., Peacock, A., Kukkadapu, R.K., Jaffé, P.R., 2008. Long-term dynamics of uranium reduction/reoxidation under low sulfate conditions. Geochim. Cosmochim. Acta. 72, 3603-3615.

Kremleva, A., Krüger, S., Rösch, N., 2008. Density functional model studies of uranyl adsorption on (001) surfaces of kaolinite. Langmuir. 24, 9515-9524.

Kremleva, A., Krüger, S., Rösch, N., 2009. Role of aliphatic and phenolic hydroxyl groups in uranyl complexation by humic substances. Inorg. Chim. Acta. 362, 2542-2550.

Kremleva, A., Zhang, Y., Shor, A.M., Krüger, S., Joseph, C., Raditzky, B., Schmeide, K., Sachs, S., Bernhard, G., Rösch, N., 2012. Uranyl(VI) complexation by sulfonate ligands: A relativistic density functional and time-resolved laser-induced fluorescence spectroscopy study. Eur. J. Inorg. Chem. 2012, 3636-3644.

Křepelová, A., Brendler, V., Sachs, S., Baumann, N., Bernhard, G., 2007. U(VI)kaolinite surface complexation in absence and presence of humic acid studied by TRLFS. Environ. Sci. Technol. 41, 6142-6147.

Křepelová, A., Sachs, S., Berhard, G., 2006. Uranium(VI) sorption onto kaolinite in the presence and absence of humic acid. Radiochim. Acta. 94, 825-833.

Lagergren, S., 1898. Zur Theorie der Sogenannten Adsorption Gelöster Stoffe, Kungliga Svenska Vetenskapsakademiens. Finska läkaresällskapets handlingar (Helsinki, Finland : 1948). 24, 1-39.

Langmuir, D., 1997. Aqueous environmental geochemistry. Prentice Hall, Upper Saddle River, N.J.

Langmuir, I., 1918. The adsorption of gases on plane surfaces of glass, mica and platinum. J. Am. Chem. Soc. 40, 1361-1403. 
Largitte, L., Pasquier, R., 2016. A review of the kinetics adsorption models and their application to the adsorption of lead by an activated carbon. Chem. Eng. Res. Des. 109, 495-504.

Leung, K., Nielsen, I.M.B., Criscenti, L.J., 2009. Elucidating the bimodal acid-base behavior of the water-silica interface from first principles. J. Am. Chem. Soc. 131, 18358-18365.

Li, I., Bandara, J., Shultz, M.J., 2004. Time evolution studies of the $\mathrm{H}_{2} \mathrm{O}$ /quartz interface using sum frequency generation, atomic force microscopy, and molecular dynamics. Langmuir. 20, 10474-10480.

Li, L., Liu, X., Lu, X., 2015. A molecular dynamics study of uranyl-carbonate complexes adsorbed on basal surfaces of clay minerals. Chinese Journal of Geochemistry. 34, 143-155.

Liu, X., Cheng, J., Lu, X., Wang, R., 2014. Surface acidity of quartz: Understanding the crystallographic control. Phys. Chem. Chem. Phys. 16, 26909-26916.

Liu, X., Lu, X., Sprik, M., Cheng, J., Meijer, E.J., Wang, R., 2013. Acidity of edge surface sites of montmorillonite and kaolinite. Geochim. Cosmochim. Acta. 117, 180-190.

Lloyd, J.R., Chesnes, J., Glasauer, S., Bunker, D.J., Livens, F.R., Lovley, D.R., 2002. Reduction of actinides and fission products by Fe(III)-reducing bacteria. Geomicrobiol. J. 19, 103-120.

Looney, B.B., Grant, M.W., King, C.M., 1987. Estimation of geochemical parameters for assessing subsurface transport at the Savannah River Plant: Environmental information document, United States, p. 74.

Lorenc-Grabowska, E., Gryglewicz, G., 2005. Adsorption of lignite-derived humic acids on coal-based mesoporous activated carbons. J. Colloid Interface Sci. 284, 416423.

Lövgren, L., Sjöberg, S., Schindler, P.W., 1990. Acid/base reactions and Al(III) complexation at the surface of goethite. Geochim. Cosmochim. Acta. 54, 13011306.

Lovley, D.R., Phillips, E.J., 1992. Reduction of uranium by Desulfovibrio desulfuricans. Appl. Environ. Microbiol. 58, 850-856.

Lovley, D.R., Phillips, E.J.P., Gorby, Y.A., Landa, E.R., 1991. Microbial reduction of uranium. Nature. 350, 413-416.

Lovley, D.R., Widman, P.K., Woodward, J.C., Phillips, E.J., 1993. Reduction of uranium by cytochrome c3 of Desulfovibrio vulgaris. Appl. Environ. Microbiol. 59, 35723576.

Lubal, P., Fetsch, D., Široký, D., Lubalová, M., Šenkýr, J., Havel, J., 2000. Potentiometric and spectroscopic study of uranyl complexation with humic acids. Talanta. 51, 977-991. 
Lv, J., Zhang, S., Wang, S., Luo, L., Cao, D., Christie, P., 2016. Molecular-scale investigation with ESI-FT-ICR-MS on fractionation of dissolved organic matter induced by adsorption on iron oxyhydroxides. Environ. Sci. Technol. 50, 23282336.

Macaskie, L.E., Bonthrone, K.M., Rouch, D.A., 1994. Phosphatase-mediated heavy metal accumulation by a Citrobacter sp. and related enterobacteria. FEMS Microbiol. Lett. 121, 141-146.

Madejová, J., 2003. FTIR techniques in clay mineral studies. Vib. Spectrosc. 31, 1-10.

Martinez, R.J., Beazley, M.J., Taillefert, M., Arakaki, A.K., Skolnick, J., Sobecky, P.A., 2007. Aerobic uranium (VI) bioprecipitation by metal-resistant bacteria isolated from radionuclide- and metal-contaminated subsurface soils. Environ. Microbiol. 9, 3122-3133.

Martorell, B., Kremleva, A., Krüger, S., Rösch, N., 2010. Density functional model study of uranyl adsorption on the solvated (001) surface of kaolinite. J. Phys. Chem. C. $114,13287-13294$.

Merroun, M.L., Selenska-Pobell, S., 2008. Bacterial interactions with uranium: An environmental perspective. J. Contam. Hydrol. 102, 285-295.

Minor, E.C., Swenson, M.M., Mattson, B.M., Oyler, A.R., 2014. Structural characterization of dissolved organic matter: A review of current techniques for isolation and analysis. Environ. Sci.: Processes Impacts. 16, 2064-2079.

Müller, K., Brendler, V., Foerstendorf, H., 2008. Aqueous uranium(VI) hydrolysis species characterized by attenuated total reflection Fourier-transform infrared spectroscopy. Inorg. Chem. 47, 10127-10134.

Murphy, E.M., Zachara, J.M., Smith, S.C., Phillips, J.L., Wietsma, T.W., 1994. Interaction of hydrophobic organic compounds with mineral-bound humic substances. Environ. Sci. Technol. 28, 1291-1299.

Newsome, L., Morris, K., Lloyd, J.R., 2014. The biogeochemistry and bioremediation of uranium and other priority radionuclides. Chem. Geol. 363, 164-184.

Ngah, W.S.W., Fatinathan, S., Yosop, N.A., 2011. Isotherm and kinetic studies on the adsorption of humic acid onto chitosan- $\mathrm{H}_{2} \mathrm{SO}_{4}$ beads. Desalination. 272, 293-300.

Nguyen-Trung, C., Palmer, D.A., Begun, G.M., Peiffert, C., Mesmer, R.E., 2000. Aqueous uranyl complexes 1 . Raman spectroscopic study of the hydrolysis of uranyl(VI) in solutions of trifluoromethanesulfonic acid and/or tetramethylammonium hydroxide at $25^{\circ} \mathrm{C}$ and $0.1 \mathrm{MPa}$. J. Solution Chem. 29, 101-129.

Nilgiriwala, K.S., Alahari, A., Rao, A.S., Apte, S.K., 2008. Cloning and overexpression of alkaline phosphatase PhoK from Sphingomonas sp. strain BSAR-1 for bioprecipitation of uranium from alkaline solutions. Appl. Environ. Microbiol. 74, 5516-5523. 
Oeste, F.D., Kempfert, J., 1996. Barrier to prevent spread of soil contamination, United States.

Ong, S., Zhao, X., Eisenthal, K.B., 1992. Polarization of water molecules at a charged interface: Second harmonic studies of the silica/water interface. Chem. Phys. Lett. 191, 327-335.

Osmari, T.A., Gallon, R., Schwaab, M., Barbosa-Coutinho, E., Severo, J.B., Pinto, J.C., 2013. Statistical analysis of linear and non-linear regression for the estimation of adsorption isotherm parameters. Adsorpt. Sci. Technol. 31, 433-458.

Pacheco, M.L., Havel, J., 2001. Capillary zone electrophoretic (CZE) study of uranium(VI) complexation with humic acids. J. Radioanal. Nucl. Chem. 248, 565570 .

Pashalidis, I., Buckau, G., 2007. U(VI) mono-hydroxo humate complexation. J. Radioanal. Nucl. Chem. 273, 315-322.

Payne, R.B., Gentry, D.M., Rapp-Giles, B.J., Casalot, L., Wall, J.D., 2002. Uranium reduction by Desulfovibrio desulfuricans strain G20 and a cytochrome c3 mutant. Appl. Environ. Microbiol. 68, 3129-3132.

Pehlivan, E., Arslan, G., 2006. Uptake of metal ions on humic acids. Energy Sources, Part A. 28, 1099-1112.

Perminova, I.V., Hatfield, K., Hertkorn, N., 2005. Use of humic substances to remediate polluted environments: From theory to practice. Springer, Dordrecht, Netherlands.

Perminova, I.V., Karpiouk, L.A., Ponomarenko, S.A., Hatfield, K., Konstantinov, A.I., Hertkorn, N., Muzafarov, A.M., 2012. Controlling aqueous sorption of humic substances on silica gel by directed alkoxysilyl-derivatization of their functionalities. Colloids Surf., A. 396, 224-232.

Petrović, M., Kaštelan-Macan, M., Horvat, A.J.M., 1999. Interactive sorption of metal ions and humic acids onto mineral particles. Water, Air, Soil Pollut. 111, 41-56.

Petteys, M.P., Schimpf, M.E., 1998. Characterization of hematite and its interaction with humic material using flow field-flow fractionation. J. Chromatogr. A. 816, 145158.

Philippe, A., Schaumann, G.E., 2014. Interactions of dissolved organic matter with natural and engineered inorganic colloids: A review. Environ. Sci. Technol. 48, 8946-8962.

Piccolo, A., Conte, P., Cozzolino, A., Spaccini, R., 2001. Molecular sizes and association forces of humic substances in solution, in: Humic substances and chemical contaminants. Soil Science Society of America, Madison, WI, pp. 89-118.

Pitois, A., Abrahamsen, L.G., Ivanov, P.I., Bryan, N.D., 2008. Humic acid sorption onto a quartz sand surface: A kinetic study and insight into fractionation. J. Colloid Interface Sci. 325, 93-100. 
Pompe, S., Schmeide, K., Bubner, M., Geipel, G., Heise, K.H., Bernhard, G., Nitsche, H., 2000. Investigation of humic acid complexation behavior with uranyl ions using modified synthetic and natural humic acids. Radiochim. Acta. 88, 553.

Prikryl, J.D., Jain, A., Turner, D.R., Pabalan, R.T., 2001. UraniumVI sorption behavior on silicate mineral mixtures. J. Contam. Hydrol. 47, 241-253.

Qiu, H., Lv, L., Pan, B.-c., Zhang, Q.-j., Zhang, W.-m., Zhang, Q.-X., 2009. Critical review in adsorption kinetic models. J. Zhejiang Univ., Sci., A. 10, 716-724.

Quilès, F., Burneau, A., 2000. Infrared and Raman spectra of uranyl(VI) oxo-hydroxo complexes in acid aqueous solutions: A chemometric study. Vib. Spectrosc. 23, 231-241.

Raditzky, B., Schmeide, K., Sachs, S., Geipel, G., Bernhard, G., 2010. Interaction of uranium(VI) with nitrogen containing model ligands studied by laser-induced fluorescence spectroscopy. Polyhedron. 29, 620-626.

Reemtsma, T., 2009. Determination of molecular formulas of natural organic matter molecules by (ultra-) high-resolution mass spectrometry: Status and needs. J. Chromatogr. A. 1216, 3687-3701.

Regenspurg, S., Margot-Roquier, C., Harfouche, M., Froidevaux, P., Steinmann, P., Junier, P., Bernier-Latmani, R., 2010. Speciation of naturally-accumulated uranium in an organic-rich soil of an alpine region (Switzerland). Geochim. Cosmochim. Acta. 74, 2082-2098.

Saab, S.d.C., Carvalho, E.R., Bernardes Filho, R., Moura, M.R.d., Martin-Neto, L., Mattoso, L.H.C., 2010. $\mathrm{pH}$ effect in aquatic fulvic acid from a Brazilian river. J. Braz. Chem. Soc. 21, 1490-1496.

Sachs, S., Bernhard, G., 2011. Influence of humic acids on the actinide migration in the environment: Suitable humic acid model substances and their application in studies with uranium - a review. J. Radioanal. Nucl. Chem. 290, 17-29.

Sachs, S., Reich, T., Bernhard, G., 2010. Study of the role of sulfur functionalities in humic acids for uranium(VI) complexation. Radiochim. Acta. 98, 467-477.

Scheinost, A.C., Abend, S., Pandya, K.I., Sparks, D.L., 2001. Kinetic controls on Cu and $\mathrm{Pb}$ sorption by ferrihydrite. Environ. Sci. Technol. 35, 1090-1096.

Schmeide, K., Sachs, S., Bubner, M., Reich, T., Heise, K.H., Bernhard, G., 2003. Interaction of uranium(VI) with various modified and unmodified natural and synthetic humic substances studied by EXAFS and FTIR spectroscopy. Inorg. Chim. Acta. 351, 133-140.

Schroth, B.K., Sposito, G., 1997. Surface charge properties of kaolinite. Clays Clay Miner. 45, 85-91.

Schulten, H.R., Schnitzer, M., 1993. A state of the art structural concept for humic substances. Naturwissenschaften. 80, 29-30. 
Schwaab, M., Steffani, E., Barbosa-Coutinho, E., Severo Júnior, J.B., 2017. Critical analysis of adsorption/diffusion modelling as a function of time square root. Chem. Eng. Sci. 173, 179-186.

Seko, N., Katakai, A., Hasegawa, S., Tamada, M., Kasai, N., Takeda, H., Sugo, T., Saito, K., 2003. Aquaculture of uranium in seawater by a fabric-adsorbent submerged system. Nucl. Technol. 144, 274-278.

Senko, J.M., Istok, J.D., Suflita, J.M., Krumholz, L.R., 2002. In-situ evidence for uranium immobilization and remobilization. Environ. Sci. Technol. 36, 14911496.

Settimio, L., McLaughlin, M.J., Kirby, J.K., Langdon, K.A., Lombi, E., Donner, E., Scheckel, K.G., 2014. Fate and lability of silver in soils: Effect of ageing. Environ. Pollut. 191, 151-157.

Shaker, A.M., Komy, Z.R., Heggy, S.E., El-Sayed, M.E.A., 2012. Kinetic study for adsorption humic acid on soil minerals. J. Phys. Chem. A. 116, 10889-10896.

Shelobolina, E.S., Sullivan, S.A., O'Neill, K.R., Nevin, K.P., Lovley, D.R., 2004. Isolation, characterization, and U(VI)-reducing potential of a facultatively anaerobic, acid-resistant bacterium from low-pH, nitrate- and U(VI)-contaminated subsurface sediment and description of Salmonella subterranea sp. nov. Appl. Environ. Microbiol. 70, 2959-2965.

Sherman, D.M., Peacock, C.L., Hubbard, C.G., 2008. Surface complexation of U(VI) on goethite $(\alpha-\mathrm{FeOOH})$. Geochim. Cosmochim. Acta. 72, 298-310.

Shin, H.-S., Monsallier, J.M., Choppin, G.R., 1999. Spectroscopic and chemical characterizations of molecular size fractionated humic acid. Talanta. 50, 641-647.

Simonin, J.-P., 2016. On the comparison of pseudo-first order and pseudo-second order rate laws in the modeling of adsorption kinetics. Chem. Eng. J. 300, 254-263.

Simpson, A.J., 2002. Determining the molecular weight, aggregation, structures and interactions of natural organic matter using diffusion ordered spectroscopy. Magn. Reson. Chem. 40, S72-S82.

Skipperud, L., Strømman, G., Yunusov, M., Stegnar, P., Uralbekov, B., Tilloboev, H., Zjazjev, G., Heier, L.S., Rosseland, B.O., Salbu, B., 2013. Environmental impact assessment of radionuclide and metal contamination at the former $U$ sites Taboshar and Digmai, Tajikistan. J. Environ. Radioact. 123, 50-62.

Steudtner, R., Müller, K., Schmeide, K., Sachs, S., Bernhard, G., 2011 a. Binary and ternary uranium(VI) humate complexes studied by attenuated total reflection Fourier-transform infrared spectroscopy. Dalton Trans. 40, 11920-11925.

Steudtner, R., Sachs, S., Schmeide, K., Brendler, V., Bernhard, G., 2011b. Ternary uranium(VI) carbonato humate complex studied by cryo-TRLFS. Radiochim. Acta. 99, 687-692.

Stevenson, F.J., 1982. Humus chemistry : Genesis, composition, reactions. John Wiley \& Sons, New York. 
Strandberg, G.W., Shumate, S.E., Parrott, J.R., 1981. Microbial cells as biosorbents for heavy metals: Accumulation of uranium by Saccharomyces cerevisiae and Pseudomonas aeruginosa. Appl. Environ. Microbiol. 41, 237-245.

Stumm, W., Morgan, J.J., 1996. Aquatic chemistry chemical equilibria and rates in natural waters, 3rd ed. Wiley, New York.

Sundararajan, M., Rajaraman, G., Ghosh, S.K., 2011. Speciation of uranyl ions in fulvic acid and humic acid: A DFT exploration. Phys. Chem. Chem. Phys. 13, 1803818046.

Sutton, R., Sposito, G., 2005. Molecular structure in soil humic substances: The new view. Environ. Sci. Technol. 39, 9009-9015.

Swift, R.S., 1999. Macromolecular properties of soil humic substances: Fact, fiction, and opinion. Soil Science. 164, 790-802.

Sylwester, E.R., Hudson, E.A., Allen, P.G., 2000. The structure of uranium (VI) sorption complexes on silica, alumina, and montmorillonite. Geochim. Cosmochim. Acta. 64, 2431-2438.

Tan, K.H., 2003. Humic matter in soil and the environment : Principles and controversies. Marcel Dekker, New York.

Tan, K.H., 2011a. Humic acid nanotube membranes as revealed by scanning electron microscopy.

Tan, K.H., 2011b. The new look and nanotube concept of humic acids.

Tan, K.H., 2014. Humic matter in soil and the environment. CRC Press, Boca Raton.

Tan, X., Fang, M., Wang, X., 2010. Sorption speciation of lanthanides/actinides on minerals by TRLFS, EXAFS and DFT studies: A review. Molecules. 15, 8431.

Thurman, E.M., 1985. Organic geochemistry of natural waters. Springer Netherlands, Dordrecht.

Tipping, E., 2002. Cation binding by humic substances, 1st ed. Cambridge University Press, New York, USA.

Tokunaga, T.K., Kim, Y., Wan, J., 2009. Potential remediation approach for uraniumcontaminated groundwaters through potassium uranyl vanadate precipitation. Environ. Sci. Technol. 43, 5467-5471.

Tokunaga, T.K., Kim, Y., Wan, J., Yang, L., 2012. Aqueous uranium(VI) concentrations controlled by calcium uranyl vanadate precipitates. Environ. Sci. Technol. 46, 7471-7477.

Tokunaga, T.K., Wan, J., Kim, Y., Daly, R.A., Brodie, E.L., Hazen, T.C., Herman, D., Firestone, M.K., 2008. Influences of organic carbon supply rate on uranium bioreduction in initially oxidizing, contaminated sediment. Environ. Sci. Technol. 42, 8901-8907. 
Tutu, H., Cukrowska, E.M., Dohnal, V., Havel, J., 2005. Application of artificial neural networks for classification of uranium distribution in the Central Rand goldfield, South Africa. Environ. Model. Assess. 10, 143-152.

Vicente-Vicente, L., Quiros, Y., Pérez-Barriocanal, F., López-Novoa, J.M., LópezHernández, F.J., Morales, A.I., 2010. Nephrotoxicity of uranium:

Pathophysiological, diagnostic and therapeutic perspectives. Toxicol. Sci. 118, 324-347.

Villalobos, M., Pérez-Gallegos, A., 2008. Goethite surface reactivity: A macroscopic investigation unifying proton, chromate, carbonate, and lead(II) adsorption. J. Colloid Interface Sci. 326, 307-323.

von Wandruszka, R., 2000. Humic acids: Their detergent qualities and potential uses in pollution remediation. Geochem. Trans. 1, 10.

Wahlgren, U., Moll, H., Grenthe, I., Schimmelpfennig, B., Maron, L., Vallet, V., Gropen, O., 1999. Structure of uranium(VI) in strong alkaline solutions. A combined theoretical and experimental investigation. J. Phys. Chem. A. 103, 8257-8264.

Wan, J., Dong, W., Tokunaga, T.K., 2011. Method to attenuate U(VI) mobility in acidic waste plumes using humic acids. Environ. Sci. Technol. 45, 2331-2337.

Wan, J., Kim, Y., Tokunaga, T.K., Wang, Z., Dixit, S., Steefel, C.I., Saiz, E., Kunz, M., Tamura, N., 2009. Spatially resolved U(VI) partitioning and speciation: Implications for plume scale behavior of contaminant $U$ in the Hanford vadose zone. Environ. Sci. Technol. 43, 2247-2253.

Wan, J., Tokunaga, T., Brodie, E., Wan, Z., Zheng, Z., Herman, D., Hazen, T.C., Firestone, M.K., Sutton, S.R., 2005. Reoxidation of bioreduced uranium under reducing conditions. Environ. Sci. Technol. 39, 6162-6169.

Wan, J., Tokunaga, T.K., Dong, W., Denham, M.E., Hubbard, S.S., 2012. Persistent source influences on the trailing edge of a groundwater plume, and natural attenuation timeframes: The F-Area Savannah River Site. Environ. Sci. Technol. 46, 4490-4497.

Wan, J., Tokunaga, T.K., Kim, Y., Brodie, E., Daly, R., Hazen, T.C., Firestone, M.K., 2008. Effects of organic carbon supply rates on uranium mobility in a previously bioreduced contaminated sediment. Environ. Sci. Technol. 42, 7573-7579.

Wang, Y.H., Siu, W.K., 2006. Structure characteristics and mechanical properties of kaolinite soils. I. Surface charges and structural characterizations. Canadian Geotechnical Journal. 43, 587-600.

Weber, W.J., Morris, J.C., 1963. Intraparticle diffusion during the sorption of surfactants onto activated carbon J. Sanit. Eng. Div., Am. Soc. Civ. Eng. 89, 53-61.

Weir, E., 2004. Uranium in drinking water, naturally. Can. Med. Assoc. J. 170, 951-952.

Wershaw, R.L., 1986. A new model for humic materials and their interactions with hydrophobic organic chemicals in soil-water or sediment-water systems. J. Contam. Hydrol. 1, 29-45. 
Wershaw, R.L., 1999. Molecular aggregation of humic substances. Soil Science. 164, 803-813.

WHO, 2012. Guidelines for drinking-water quality. World Health Organization, Geneva, Switzerland.

Wu, W.-M., Carley, J., Fienen, M., Mehlhorn, T., Lowe, K., Nyman, J., Luo, J., Gentile, M.E., Rajan, R., Wagner, D., Hickey, R.F., Gu, B., Watson, D., Cirpka, O.A., Kitanidis, P.K., Jardine, P.M., Criddle, C.S., 2006. Pilot-scale in situ bioremediation of uranium in a highly contaminated aquifer. 1. Conditioning of a treatment zone. Environ. Sci. Technol. 40, 3978-3985.

Zhou, J.L., Rowland, S., Fauzi, R., Mantoura, C., Braven, J., 1994. The formation of humic coatings on mineral particles under simulated estuarine conditions-a mechanistic study. Water Res. 28, 571-579.

Zhu, C., Anderson, G.M., Burden, D.S., 2002. Natural attenuation reactions at a uranium mill tailings site, western U.S.A. Ground Water. 40, 5-13. 


\section{HANSELL GONZALEZ RAYMAT}

Born: Havana, Cuba

2008-2010

A.A., Chemistry

Miami Dade College

Miami, Florida

2010-2012

B.S., Chemistry

Florida International University

Miami, Florida

2016

M.S., Chemistry

Florida International University

Miami, Florida

$2014-2018$

Doctoral Candidate

Florida International University

Miami, Florida

Graduate Research Assistant

Applied Research Center

Florida International University

Miami, Florida

Department of Energy Fellowship

Florida International University

Miami, Florida

$2014-2015$

DOE Fellow of the Year

2015

$2^{\text {nd }}$ Place DOE Fellows Student Poster Competition Florida International University

Miami, Florida

2018

Winner of the Student Poster Competition

Waste Management Symposia

Phoenix, Arizona 


\section{PUBLICATIONS AND PRESENTATIONS}

Gonzalez-Raymat, H., Anagnostopoulos, V., Denham, M., Cai, Y., and Katsenovich, Y.P., (2018). Unrefined humic substances as a potential low-cost amendment for the management of acidic groundwater contamination. Journal of Environmental Management, 212: 210-218.

Gonzalez-Raymat, H., Liu, G., Liriano, C., Li, Y., Yin, Y., Shi, J., Jiang, G., Cai, Y., (2017). Elemental mercury: Its unique properties affect its behavior and fate in the environment. Environmental Pollution, 229: 69-86.

Gonzalez-Raymat, H., Yin, Y., Cai, Y., (2018). Environmental behavior of iodine released by anthropogenic activities. (To be submitted)

Gonzalez-Raymat, H., Gudavalli, R., Denham, M., Cai, Y., and Katsenovich, Y.P., (2018). In situ uranium plume attenuation by using a low-cost humate amendment. (To be submitted)

Gonzalez-Raymat, H., Katsenovich, Y., Denham, M., (2015-2018). Study of an unrefined humate solution as a possible remediation method for groundwater contamination. Poster presented at the Waste Management Symposia, Phoenix, Arizona.

Gonzalez-Raymat, H., Katsenovich, Y., Denham, M., Gudavalli, R., Lagos, L., (March, 2015). The influence of humic acid and colloidal silica on the sorption of U(VI) onto SRS sediments collected from the $\mathrm{F} / \mathrm{H}$ area (oral presentation). Full paper in the Waste Management Symposia proceedings, Phoenix, Arizona.

Denham, M., Millings, M., Amidon, M., Looney, B., Hyde, W., Walker, R., GonzalezRaymat, H., (March, 2015). Evaluation of a low cost humate solution as an in situ amendment to enhance attenuation of uranium in an acidic plume (oral presentation). Full paper in the Waste Management Symposia proceedings, Phoenix, Arizona. 